\title{
Efeitos da inibição crônica das óxido nítrico sintases na mecânica de tecido periférico, no recrutamento eosinofílico e no remodelamento da matriz extracelular induzida por inflamação crônica pulmonar
}

Dissertação apresentada à Faculdade de Medicina da Universidade de São Paulo para obtenção do título de Mestre em Ciências

Área de concentração: Fisiopatologia Experimental Orientadora: Profa. Dra. Iolanda de F. L. Calvo Tibério

São Paulo 


\section{Dedicatória}

À Dra Iolanda de Fátima Lopes Calvo Tibério, professora, doutora, médica, mãe e acima de tudo mußher. Sua inteligência é inquestionável, sua dedicação e contribuição ao ensino, impecáveis. Não tenho palavras para agradecer o sonho que ela me ajudou a realizar. Obrigada Mestra!

À Dra Carla Máximo Prado, que foi a primeira pessoa a me acolher no laboratório. Com ela aprendi que não há fronteiras àqueles que se esforçam em busca de conhecimento. Admiro-a por sua inteligência e dedicação ao trabalho experimental, sendo motivo de orgulho e modelo para os profissionais da nossa área de atuação, mostrando que podemos ir muito além do que muitas vezes nos foi proposto.

Ao meu companheiro, José Roberto Pigati, que me conquista a cada dia, por ter tantos sonhos parecidos com os meus, por ter me escolfido para dividir o presente e o futuro e por comemorar comigo minhas conquistas mais imperceptiveis aos olhos de outras pessoas. Sensivel de alma e forte de caráter. Amo-te.

Ao meu primo-irmão, Thiago, que carreguei no colo tantas vezes, $e$ que hoje é meu motivo de orgulho em vê-lo formado e com futuro tão promissor. Obrigada por sempre me incentivar e acreditar em mim e, acima de tudo, por ser meu amigo.

À minha avó e madrinha Lina Angeli, pessoa de personalidade forte, matriarca italiana, cuidadosa e amiga. Muito mais do que uma avó pode ser para uma neta. A ela devo respeito e admiração por ter cuidado de mim de modo tão especial.

Ao meu avô João Francisco, que muitas vezes se sacrificou acordando cedo para levar-me ao colégio. Sempre pronto a ajudar, com seu jeito calmo, prestativo e carinhoso de ser. Maravilhosa pessoa e exemplo que sempre guardarei em minha lembrança. 
Aos meus pais José e Lúcia, meu eterno reconhecimento e agradecimento, pelo esforço a que se submeteram inúmeras vezes, dia após dia, com o objetivo de proporcionar-me condições de realizar meu sonho acadêmico e profissional. Muito obrigada, de coração. 


\section{Agradecimentos}

Ao Professor Milton de Arruda Martins, primeiramente, por sua respeitável posição frente ao Ensino e Pesquisa dentro da Faculdade de Medicina da Universidade de São Paulo. Meus agradecimentos sinceros por estar ao meu lado em momentos importantes durante a realização deste trabalho. Obrigada, "Professor" pelo incentivo e força.

À Professora Thais Mauad por sua contribuição na melhoria deste trabalho nos ensinamentos da leitura do isoprostano.

À Professora Marisa Dolhnikoff pelos comentários e questionamentos relevantes que contribuíram para o aperfeiçoamento desta dissertação.

Ao Professor Paulo Saldiva pela sua inteligência e constante incentivo, em nosso dia a dia de pesquisa e trabalhos acadêmicos.

À querida Edna Leick-Maldonado, por sua amizade e companherismo em várias etapas desta tese. Agradeço a dedicação e paciência em repassar minhas aulas de Qualificação e do Congresso Europeu madrugada afora...

À Flavia Tayar Fernandes, primeiro ex-aluna, depois amiga $e$ companheira de trabalho, admiro-a por sua inteligência e consideração pela nossa amizade. Pessoa responsável pelo meu primeiro contato com a USP.

À Claudia Miranda Starling, amiga e companheira de residência e cuja amizade pude resgatar após tantos anos, mostrando que sempre há uma chance quando um sentimento é sincero e verdadeiro: "Obrigada, amiga". 
À Rosana, pela amizade que cresceu naturalmente durante minha presença no laboratório. Obrigada por torcer por mim tanto no aspecto profissional quanto no pessoal.

As professoras Adenir Perini, Maria Lúcia Bueno Garcia e Claudia Marina Fló, pela presença na minha banca de qualificação, rica contribuição durante argüição e comentários para a melhoria do trabalho.

À Tatiana Lanças que com extrema didática e paciência orientoume durante as minhas primeiras leituras de colágeno.

À Mariana Guerato Pires, pessoa de humor ímpar, que sempre teve uma palavra de estímulo em momentos dificeis. Ser sua amiga é um privilégio.

Agradeço os ensinamentos e apoio recebido do casal Chow, Sra. Helena D'Almeida e Sra. Alzira Mesquita.

A todos os meus alunos, que me deram e continuam dando a oportunidade de fazer o que mais gosto, ou seja, ensinar, e que sempre, todos os dias me fazem aprender.

Agradeço o apoio da chefia e coordenação do serviço de Fisioterapia do Hospital Sírio Libanês, Claudia Kondo e Edy Floriano, respectivamente.

Ao diretor do curso de Fisioterapia da UNGG, Prof. Dr. Fábio Cardoso e Coordenadora de Estágio Prof (a). Roseli Cordeiro, os meus agradecimentos pelo incentivo recebido durante o desenvolvimento desta dissertação.

Aos meus colegas de trabalho, professores da UNG, em especial a Luciana Aristóteles que se tornou meu braço direito durante a realização deste trabalho.

Aos colegas e amigos fisioterapeutas do Hospital Sírio Libanês: Renata Salerno Mariano, Daniella Fontenelle Corrêa dos Reis, Flávia Cristina Almeida Leite Figueiredo, Geraldo Gomes Filho, Adriane Sayuri Nakashima, Welligton Yamaguti, Gabriela Caliccho e Carolina Fuentes. 
Aos meus companheiros de plantão, que de alguma forma contribuíram muitas vezes sem perceber na confecção desta tese, desde palavras de incentivo até na paciência em aturar-me nos dias de extremo cansaço. Com vocês comemorei algumas vitórias da minha vida: Patricia Rosa, Kátia Silveira, Joice Souza, Marcelo Souza Ferreira, Anderson Garcia, Fabiana Guilherme e Alessandra Marin.

À bibliotecária Rita Ortega do Hospital Sírio Libanês, pelo apoio e dicas durante o processo de levantamento de artigos.

As técnicas de laboratório Esmeralda e Sandra, pela extrema gentileza, atenção e carinho no atendimento e confeç̧ão das lâminas e colorações.

Aos meus colegas de Pós-Graduação da Universidade de São Paulo: Ricardo, Fabiana e Rafael.

Aos encarregados do biotério Carlos e David.

Ao Hugo Nakazato, companheiro fundamental na realização do protocolo de sensibilização, obrigada.

À Simone Sato, professora e amiga, pessoa fundamental na minha formação e crescimento profissional, além de ser exemplo de extrema competência e admiração por todos aqueles que tiveram a oportunidade de trabalhar ao seu lado.

Á Professora Dra. Patricia Rocco, pela parceria na idealização e realização deste trabalho, meus sinceros agradecimentos pela oportunidade de usarmos e conhecermos seu trabalho no laboratório de Fisiologia Respiratória da UFRJ. Aos colaboradores Pedro Leme, Carolina Pássaro e Débora Xisto que nos receberam tão gentilmente e trabalharam arduamente na realização dos "strips" e obtenção dos dados de mecânica pulmonar.

Às minhas queridas sobrinhas, Letícia Angeli de Andrade, Giovanna Angeli Farina e afilhada Bruna Dalomo. A vocês meninas, peço desculpas por minha ausência em aniversários, Gatizados e outras datas comemorativas devido aos compromissos profissionais. 
À Amanda Serio pela ajuda na confecção das figuras desta tese, meus sinceros agradecimentos.

A minhas irmãs Viviane e Daniela Angeli laços de sangue, mulheres batalhadoras, agradeço pelo apoio e torcida.

E por fim as cobaias, seres fundamentais na realização do protocolo experimental e conseqüentemente nos resultados da minha dissertação, o meu respeito pelo sacrifício a que são submetidas contribuindo com a humanidade na descoberta, tratamento e cura das doenças. 
Agradeço à Fundação de Amparo à Pesquisa do Estado de São Paulo (FAPESP) pelo apoio financeiro. 
"Sem sonhos, as perdas se tornam insuportáveis, as pedras do caminho se tornam montanhas, os fracassos se transformam em golpes fatais. Mas, se você tiver grandes sonhos... seus erros produzirão crescimento, seus desafios produzirão oportunidades, seus medos produzirão coragem". 
Esta dissertação está de acordo com as seguintes normas, em vigor no momento desta publicação:

Referências: adaptado de International Commitee of Medical Journals Editors (Vancouver)

Universidade de São Paulo. Faculdade de Medicina. Serviço de Biblioteca e Documentação. Guia de apresentação de dissertações, teses e monografias. Elaborado por Anneliese Carneiro da Cunha, Maria Julia de A. L. Freddi, Maria F. Crestana, Marinalva de Souza Aragão, Suely Campos Cardoso, Valéria Vilhena. $2^{\mathrm{a}}$ ed. São Paulo: Serviço de Biblioteca e Documentação; 2005.

Abreviaturas dos títulos e periódicos de acordo com List of Journals Indexed in Index Médicus. 


\section{SUMÁRIO}

Lista de abreviaturas

Lista de figuras

Lista de tabelas

Resumo

Summary

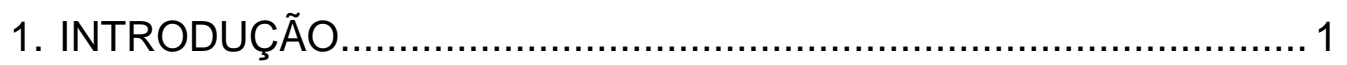

1.1 Asma brônquica ........................................................... 2

1.2 Definição e aspectos fisiopatológicos .................................... 4

1.3 Importância da avaliação de mecânica oscilatória de tecido pulmonar

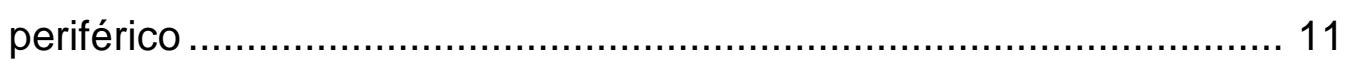

1.4 Óxido nítrico e asma................................................. 15

1.5 Óxido nítrico e o estresse oxidativo ................................... 21

1.6 Justificativa do estudo............................................. 28

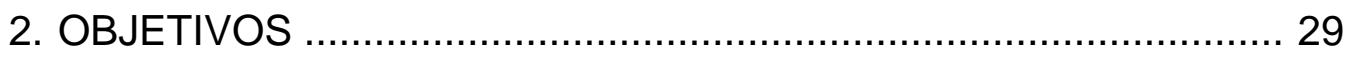

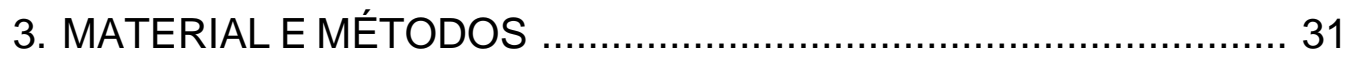

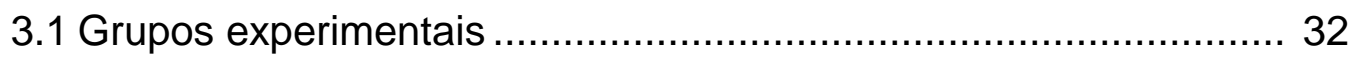

3.2 Protocolo de sensibilização............................................ 33

3.3 Tratamento crônico com L-NAME .................................... 34

3.4 Avaliação da mecânica oscilatória de tecido pulmonar periférico .. 36

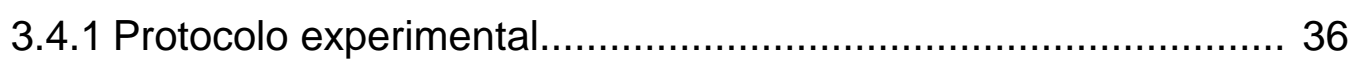

3.4.2 Preparação do tecido ................................................ 36

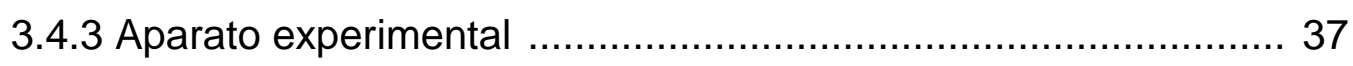




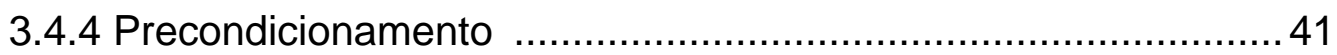

3.4.5 Medidas dos parâmetros mecânicos teciduais ...................... 42

3.5 Estudo morfométrico ....................................................... 43

3.5.1 Coloração de LUNA ...................................................... 44

3.5.2 Imunohistoquímica para detecção de células nNOS positivas no

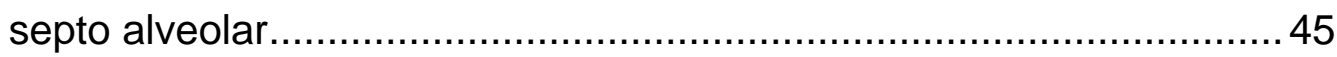

3.5.3 Imunohistoquímica para detecção de células iNOS positivas no

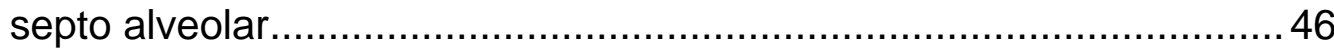

3.5.4 Coloração de Picro-Sírius .............................................. 47

3.5.5 Coloração de Resorcina-Fucsina ........................................ 48

3.5.6 Imunohistoquímica para Actina ................................... 48

3.5.7 Imunohistoquímica para detecção de 8-iso-PGF2 $\alpha$ no septo

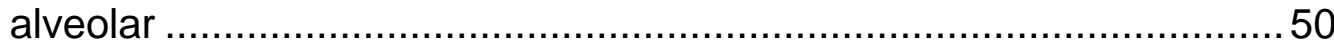

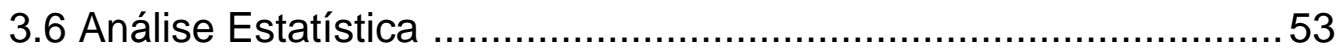

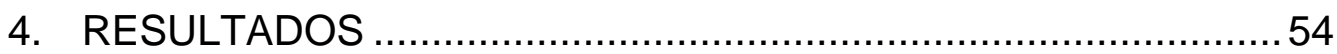

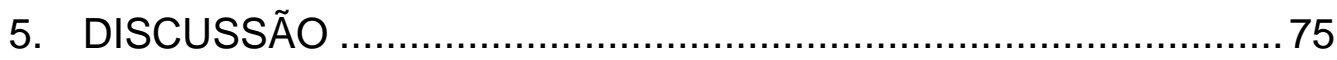

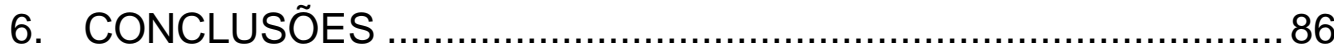

7. REFERÊNCIAS BIBLIOGRÁFICAS. .................................. 89

Apêndices 


\section{LISTA DE ABREVIATURAS}

eNOS óxido nítrico sintase endotelial

e-NANC componente excitatório do sistema não adrenérgico não colinérgico

Et elastância do sistema respiratório

GRUPO SAL+L-NAME animais que receberam inalações com soro fisiológico e tratamento com L-NAME

GRUPO SAL + VE animais que receberam inalações com soro fisiológico e tratamento com veículo

GRUPO OVA+L-NAME animais que receberam inalações com ovoalbumina e tratamento com L-NAME

GRUPO OVA + VE animais que receberam inalações com ovoalbumina e tratamento com veículo

iNOS óxido nítrico sintase induzida

i.p. intra peritoneal

i-NANC componente inibitório do sistema não adrenérgico não colinérgico

L-NAME L-NG-nitroarginina metil Ester

NANC sistema não adrenérgico não colinérgico

nNOS óxido nítrico sintase neuronal

NO óxido nítrico

NOS óxido nítrico sintases

OVA ovoalbumina

Rt resistência do sistema respiratório

SF soro fisiológico

VE veículo 


\section{LISTA DE FIGURAS}

Figura 1 - Relação entre mecanismos fisiopatológicos e conseqüências clínicas na asma 9

Figura 2 - Conseqüências clínicas do remodelamento de vias aéreas na asma 10

Figura 3 - Mecanismo de peroxidação lipídica na asma 26

Figura 4 - Esquema do protocolo de sensibilização e administração do tratamento utilizado. 35

Figuras 5 - Medida da fatia de parênquima pulmonar com a utilização de paquímetro 39

Figura 6 - Aparato experimental para medida da mecânica tecidual de tecido pulmonar periférico 40

Figura 7 - Esquema da avaliação morfométrica e histopatológica. 52

Figura 8 - Valores de tempo de inalação 56

Figura 9 - Valores de resistência basal e pós-desafio antigênico 59

Figura 10 - Valores de elastância basal e pós-desafio antigênico 60

Figura 11 - Densidade de eosinófilos no parênquima pulmonar 64

Figura 12 - Células nNOS e iNOS positivas no parênquima pulmonar 65

Figura 13 - Proporção de volume de fibras colágenas no parênquima pulmonar 68 
Figura 14 - Proporção de volume de fibras elásticas no parênquima

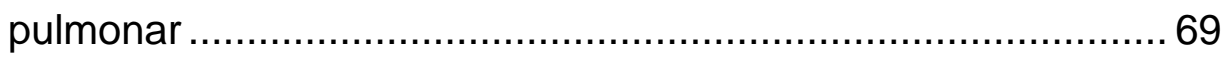

Figura 15 - Proporção de volume do 8-iso-PGF2 $\alpha$ no septo alveolar · ......... 71

Figura 16 - Fotomicrografias representativas do parênquima pulmonar distal 


\section{LISTA DE TABELAS}

Tabela 1 - Proporção de estruturas de alvéolos, vasos e vias aéreas no fragmento de tecido pulmonar periférico ...............................61 
RESUMO

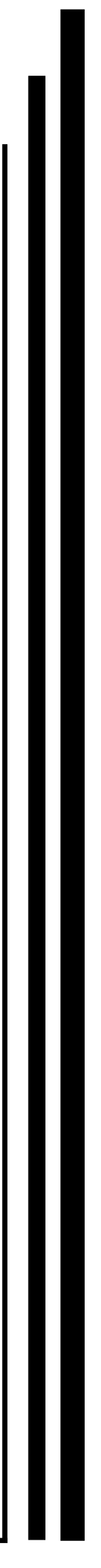


Angeli P. Efeitos da inibição crônica das óxido nítrico sintases na mecânica de tecido periférico, no recrutamento eosinofílico e no remodelamento da matriz extracelular induzida por inflamação crônica pulmonar. [dissertação]. São Paulo: Faculdade de Medicina, Universidade de São Paulo; 2008. 105p.

INTRODUÇÃO: A importância da resposta mecânica do parênquima pulmonar na fisiopatologia da asma tem sido recentemente reconhecida. O óxido nítrico é um mediador que controla o tônus muscular liso das vias aéreas, porém este efeito no parênquima pulmonar periférico ainda não foi previamente investigado. Nossa hipótese é que a inibição crônica das óxido nítrico sintases por meio do tratamento com L-NAME (falso substrato para todas as óxido nítrico sintases) pode modular a mecânica do parênquima pulmonar, o recrutamento eosinofílico e o remodelamento da matriz extracelular em modelo de inflamação alérgica crônica pulmonar em cobaias. MÉTODOS: Os animais foram expostos a sete inalações com soro fisiológico ou com ovoalbumina em doses crescentes (1 5mg/ml - 4 semanas) e tratadas ou não com L-NAME (60 mg/kg/ por dia /por animal) na água de beber. Setenta e duas horas após a sétima inalação os animais foram anestesiados, exsanguinados e a mecânica oscilatória do parênquima pulmonar foi medida na condição pré e após desafio (0.1\%). Utilizando a técnica de morfometria foram avaliadas a densidade de eosinófilos, o número de células nNOS e iNOS positivas, a densidade de actina, das fibras colágenas e das fibras elásticas bem como a proporção de volume de 8-iso-PGF2 $\alpha$ no septo alveolar. RESULTADOS: Os animais que foram expostos à ovoalbumina apresentaram um aumento da resistência e da elastância tecidual (resposta basal e após desafio antigênico), na densidade de eosinófilos, no número de células nNOS e iNOS positivas, na densidade de fibras colágenas e de fibras elásticas bem como na expressão de 8-isoPGF2 $\alpha$ no septo alveolar comparativamente aos grupos controles $(p<0,05)$. O tratamento com L-NAME em animais expostos à 
ovoalbumina atenuou todas as respostas de mecânica do tecido pulmonar periférico $(p<0,01)$, reduziu o número de células nNOS e iNOS positivas $(p<0.01)$, o conteúdo de fibras elásticas $(p<0,001)$ e de 8 -iso-PGF2 $\alpha$ no septo alveolar $(p<0,001)$. No entanto, este tratamento não afetou o número total de eosinófilos e o conteúdo de fibras colágenas. Este trabalho sugere que o óxido nítrico contribui para a constrição do parênquima pulmonar e para a deposição de fibras elásticas neste modelo. Estes efeitos foram associados à ativação de iNOS e nNOS em células do parênquima distal e aumento na via do estresse oxidativo. 
Angeli P. Effects of chronic nitric oxide inhibition on lung tissue mechanics, eosinophilic and extracellular matrix responses induced by chronic pulmonary inflammation. [dissertation]. São Paulo: "Faculdade de Medicina, Universidade de São Paulo"; 2008. 105p.

The importance of lung tissue mechanical responses in asthma pathophysiology has been recently recognized. Although nitric oxide (NO) is a mediator that controls smooth muscle tonus control in the airways, its effects on lung tissue responsiveness has not been previously investigated. We hypothesized that chronic nitric oxide synthase inhibition by L-NAME (false substrate for all nitric oxide synthases) treatment may modulate lung tissue mechanics, eosinophilic recruitment and extracellular matrix remodeling in a model of chronic pulmonary allergic inflammation. Guinea pigs were submitted to seven normal saline or ovalbumin exposures with increasing doses (1 5mg/mL-4weeks) and treated or not with L-NAME in drinking water. Seventy-two hours after the seventh inhalation the animals were anesthetized, exsanguinated, and oscillatory mechanics of lung tissue strips was performed in baseline condition and after ovalbumin challenge $(0.1 \%)$. Using morphometry, we assessed the density of eosinophils, the number of iNOS and nNOS-positive cells, the density of actin, the collagen and elastic fibers content and the volume proportion of 8-iso-PGF2 $\alpha$ in the alveolar septa. Ovalbumin-exposed animals presented an increase in baseline and maximal tissue resistance and elastance responses, eosinophil density, in the number of iNOS and nNOS positive cells, in the amount of collagen and elastic fibers and in the volume proportion of 8-iso-PGF2 $\alpha$ in the alveolar septa compared to controls $(p<0.05)$. L-NAME treatment in ovalbumin-exposed animals attenuated all lung tissue mechanical responses $(p<0.01)$, reduced the number of iNOS and nNOS positive cells $(p<0.01)$, elastic fiber content $(p<0.001)$ and 8 -isoPGF2 $\alpha$ in the alveolar septa $(p<0.001)$. However, this treatment did not affect the total number of eosinophils and collagen deposition. These data suggest that NO contributes to 
distal lung parenchyma constriction and to elastic fibers deposition in this model. These effects were associated to iNOS and nNOS activation in pulmonary parenchyma and with an increase in oxidative stress pathway activation. 


\subsection{Asma Brônquica}

A asma representa um sério problema de saúde mundial, já que em vários países há um percentual significativo de pacientes asmáticos, com manifestações variadas, desde um quadro clínico leve a grave, sendo que o cuidado a estes pacientes, particularmente os graves, se associa a significativas repercussões pessoais, sociais e econômicas (GINA, 2007). Considerando o impacto econômico cabe ressaltar os altos gastos com a utilização de medicamentos e hospitalizações (Weiss e Sullivan, 2001). No ano de 2007, foi registrado no Brasil um gasto de $\mathrm{R} \$ 98.542 .045,79 \mathrm{com}$ internações e medicações para a doença (DATASUS).

Quanto ao impacto social cabe ressaltar as das perdas por prejuízo de produtividade, antecipação da aposentadoria, absenteísmo na escola e no trabalho e, o mais grave de todos, o falecimento prematuro por insuficiência respiratória (Marion et al., 1985; GINA, 2007; Mahapatra et al., 1993; Neffen et al., 2005).

Sua prevalência mundial já foi estudada por meio da aplicação de um questionário denominado ISAAC (Internacional Study of Asthma and Allergies in Children). Participaram do estudo ISSAC centros colaboradores da Europa, Ásia, África, Américas do Norte e do Sul e Oceania. Na faixa etária de 13 a 14 anos, foram entrevistados 366.106 estudantes de 119 centros de 45 países. Na faixa etária de 6 a 7 anos, foram 208.723 
estudantes oriundos de 74 centros de 34 paises. O Brasil é o oitavo país o mundo no que diz respeito à quantidade de pessoas que apresentam sinais e sintomas de asma (ISSAC, 1998). No Brasil, foram sete os centros que utilizaram o protocolo para o estudo, sendo que as maiores taxas observadas foram encontradas em Recife e em Porto Alegre (Solé et al., 2001).

Solé et al. (2007) observaram que há uma tendência maior de sintomas relatados de asma em adolescentes que vivem em áreas urbanas como Caruaru e Santa Maria. Seus resultados confirmam que morar na área rural está associado a uma diminuição na prevalência dos sintomas em crianças.

Toyoshima et al. (2005) realizaram um estudo no município de São Paulo e demonstraram que a taxa de internação por asma manteve-se constante no período de 1995 a 2000 . Neste período, a asma representou a segunda causa de internação por doenças respiratórias no município de São Paulo, acometendo indivíduos de ambos os sexos e todas as faixas etárias.

Os últimos dados epidemiológicos, com fonte DATASUS, apontaram que no período de janeiro a dezembro de 2007 houve 280.000 casos de internação por asma no Brasil e ocorreram 779 óbitos neste período. 


\subsection{Definição e Aspectos Fisiopatológicos}

A definição da asma inclui características clínicas, fisiológicas e fisiopatológicas, sendo que a atualização mais recente foi realizada em 2007 pela "Global Initiative National of Asthma" (GINA), onde se definiu que:

"A asma é uma doença inflamatória crônica das vias aéreas onde muitas células e elementos celulares são recrutados. A inflamação crônica é associada com hiperresponsividade das vias aéreas com recorrentes episódios de sibilos, dispnéia, tiragem intercostal e tosse, particularmente à noite e pela manhã. Esses episódios são associados com obstrução ao fluxo aéreo pulmonar, que é freqüentemente reversível com o tratamento ou espontaneamente".

A asma pode acometer crianças, adultos e idosos que, além da predisposição genética, possuem alergia a uma série de fatores como poeira, alimentos, pólen, fungos, insetos, inseticidas e outros agentes alérgenos (GINA, 2007).

Os indivíduos atópicos são capazes de produzir anticorpos do tipo $\lg \mathrm{E}$ e a asma representa a doença alérgica mais comum em crianças e adultos jovens. O contato com o antígeno externo ocorre freqüentemente nas vias aéreas, mas o sistema respiratório apresenta uma série de mecanismos de defesa que limitam o acesso dos antígenos ao sistema imunológico (Holgate, 1997; Platts-Mills e Wheatley, 1996).

As exacerbações asmáticas podem ser causadas por uma série de fatores conhecidos que, geralmente, são tolerados por indivíduos normais 
(GINA, 2007) como, por exemplo, a exposição a alérgenos, vírus, poluentes, emoções, lipossácarides, sendo que qualquer um desses agentes poderá desencadear a resposta inflamatória aguda.

Após o primeiro contato com alérgeno, há produção de $\lg E$ que se liga à superfície de mastócitos. Em um novo contato com o alérgeno, a ligação deste antígeno ao $\lg E$ de superfície de mastócitos ocasiona a desgranulação destas células, ocorrendo a liberação de histamina e cisteinil-leucotrienos e, em um período de 2 a 4 horas, há contração da musculatura lisa peribrônquica podendo se associar ao quadro clínico de chiado, tosse e falta de ar (fase imediata).

As células apresentadoras de antígenos têm como função induzir a tolerância a estes antígenos. Os macrófagos podem suprimir as respostas imunológicas pulmonares por modularem a atividade das células dendríticas, processo conhecido como tolerização. Quando não ocorre a tolerização, as células T CD4+ desviam para um perfil Th2. Por outro lado, a ativação da resposta TH1 leva a um aumento no índice de apoptose celular (GINA, 2007; Van Parijs et al., 1998).

Se ocorrer ativação contínua, pela perda da barreira epitelial, ocorre aumento da produção dos percussores T CD4+, proliferação dos T CD4+ de memória e redução da apoptose destas células (Böckmann et al., 2001; Santoni et al., 2004) .

A partir desse momento, se inicia o recrutamento de linfócitos e eosinófilos, responsáveis pela liberação de outros mediadores que ocasionam contração da musculatura lisa, aumentam a permeabilidade 
vascular, potencializam a hiperresponsividade e aumentam a produção de muco, o que caracteriza a resposta tardia. Esta ocorre de 6 a 9 horas após o contato com o antígeno (Bousquet et al., 2000). Nesta fase a obstrução brônquica é mais intensa e duradoura, caracterizada por contração da musculatura lisa peribrônquica, infiltrado inflamatório e edema (de Monchy et al., 1985; Robinson et al., 1993; Guo et al., 1994; Montefort et al., 1994; Calhoun et al., 1993).

Sabe-se que a ação de alérgenos e poluentes podem causar o dano epitelial. O epitélio pode produzir fatores de crescimento pró-fibróticos que estimulam a proliferação e diferenciação dos fibroblastos em miofibroblastos. Uma vez que estes estejam ativados, ocorre a produção de fatores de crescimento e citocinas que promovem a proliferação das células do músculo liso, aumento da permeabilidade microvascular com extravasamento de plasma que pode comprometer a integridade epitelial e sua presença pode diminuir a eliminação do muco. As proteínas plasmáticas podem promover a formação de rolhas de exsudato viscoso, decorrentes da produção aumentada de muco, presença de células inflamatórias e epiteliais descamadas, contribuindo mais ainda para a obstrução ao fluxo aéreo (Chung e Barnes, 1999).

Alguns pacientes asmáticos apresentam perda parcial e irreversível da função respiratória ao longo do tempo. Postula-se que o processo inflamatório crônico provoca alterações estruturais irreversíveis causadas tanto pela ativação de células inflamatórias quanto pela falta de reparo adequado à injúria crônica. A este processo dá-se o nome remodelamento 
brônquico (Mauad et al., 2000; Bousquet et al., 1992). Episódios repetidos de inflamação podem levar ao remodelamento de vias aéreas, contribuindo para a não reversibilidade na obstrução ao fluxo de ar (Cohen et al., 2004).

O processo de remodelamento das vias aéreas é caracterizado por: aumento de células caliciformes, de glândulas submucosas, do número de vasos e do número de células do músculo liso. Além disso, ocorre espessamento da membrana basal com deposição de fibras colágenas e elásticas e alterações subepiteliais da matriz extracelular (Bousquet et al., 2000). Uma série de evidências atuais sugere que a inflamação e o remodelamento não ocorrem somente em vias aéreas centrais, mas também no pulmão distal e parênquima pulmonar. A contração de vias aéreas distais é reconhecida como importante determinante na obstrução ao fluxo aéreo. A inflamação distal tem papel crucial na hiperresponsividade, na asma noturna e na fisiopatogenia das exacerbações (Kraft et al., 2007).

Cada compartimento da via aérea pode estar estruturalmente alterado desde o epitélio (Rennard et al., 1995) até a vascularização (Cutz et al., 1978). O evento inicial desencadeante do remodelamento parece ser a agressão repetida do epitélio decorrente do recrutamento de células inflamatórias e da indução de apoptose (Mauad et al., 2000).

Acredita-se que os eosinófilos possam ter um papel fundamental por causar lesão epitelial e estimular a fibrogênese através da produção de TGF- $\beta$, citocina que regula a produção de colágeno (NHL, 1997). Além deles, os mastócitos podem produzir citocinas como TNF-a, IL-4, FGF (fator de crescimento fibroblástico), que influenciam a proliferação fibroblástica e 
atuam na digestão da matriz extracelular. Os linfócitos possuem efeito regulatório na fibrose e na inflamação. Os macrófagos produzem citocinas, elastase, e metaloproteinases (principalmente 9 e 12), que podem degradar componentes da matriz extracelular, além das próprias células epiteliais, que liberam vários mediadores inflamatórios, potencializando a agressão tecidual e a formação do tecido cicatricial (Boulet ,1997, Mauad et al., 2000).

As vias aéreas distais e o parênquima pulmonar podem produzir muitas citocinas de perfil Th2, quimiocinas e mediadores que estão envolvidos na iniciação e na perpetuação do processo inflamatório. A inflamação distal assim como o remodelamento da matriz extracelular, em vias aéreas menores que $2 \mathrm{~mm}$ e no parênquima pulmonar, tem sido descrita como mais intenso do que a observado em vias aéreas maiores (Tulic et al., 2006).

As Figuras 1 e 2 esquematizam anormalidades funcionais que estão presentes em asmáticos assintomáticos, ou seja, quando os pacientes estão controlados com tratamento, por exemplo, com corticosteróides inalatórios. 


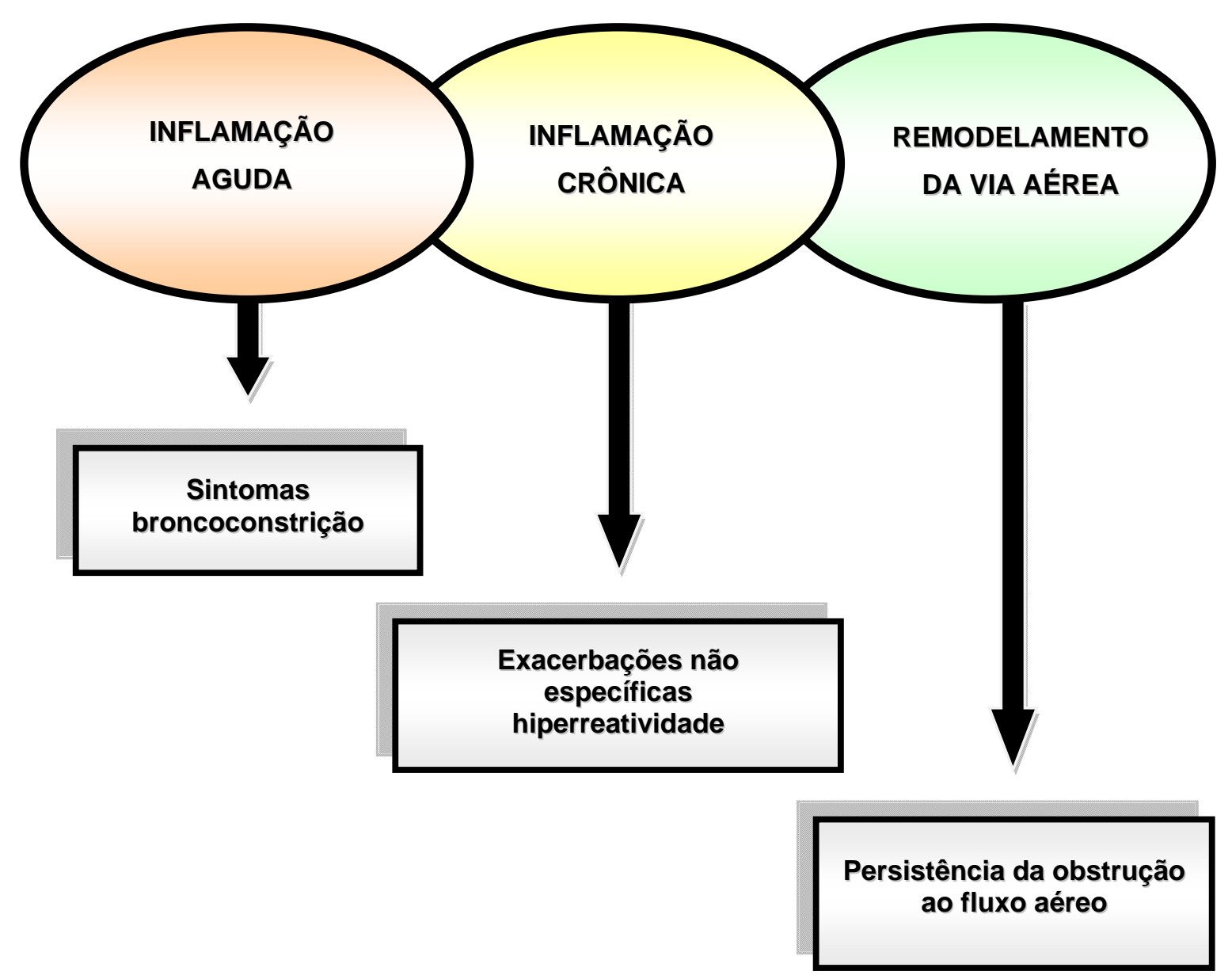

Figura 1. O esquema representativo demonstra a relação entre mecanismos fisiopatológicos e as conseqüências clínicas destas alterações em pacientes asmáticos, desde a fase imediata até episódios repetidos de inflamação responsáveis pelo remodelamento de vias aéreas, contribuindo para a não reversibilidade ao fluxo de ar.

Modificado da Fonte: "Asthma from bronchoconstriction to airways inflammation and remodeling". Am J Resp Crit Care Med, 2000. 


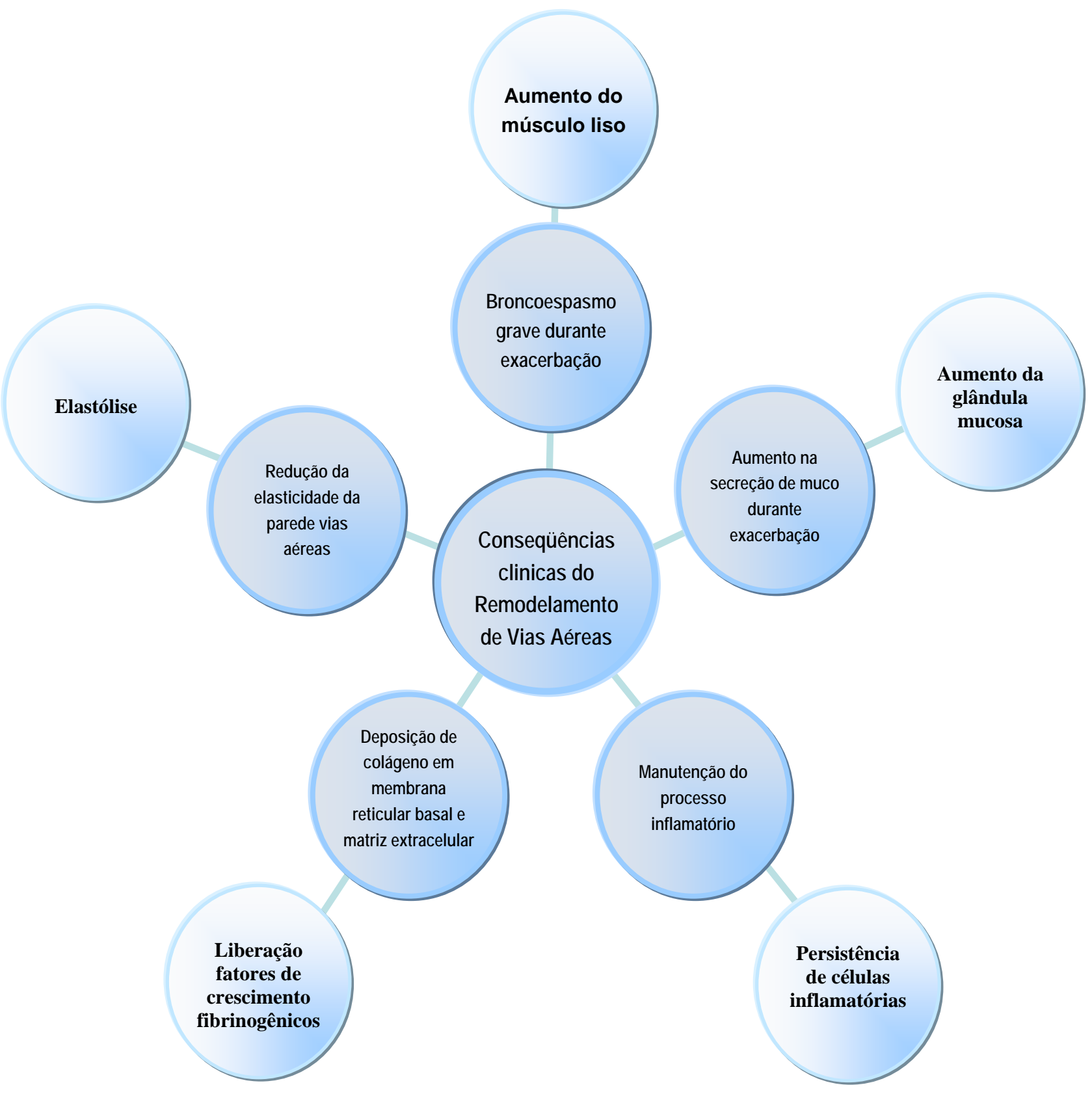

Figura 2. Conseqüências Clinicas do Remodelamento de Vias Aéreas na Asma.

Modificado da Fonte: "Asthma from bronchoconstriction to airways inflammation and remodeling". Am J Resp Crit Care Med, 2000. 


\subsection{Importância da Avaliação de Mecânica Oscilatória de Tecido Pulmonar Periférico}

As propriedades mecânicas do parênquima pulmonar têm sido bem consideradas como um dos determinantes da alteração funcional na asma (Romero et al., 2001; Lanças et al., 2006, Nakashima et al., 2008). Apesar de que grande parte do aumento da resistência de vias aéreas possa ser atribuída à obstrução de vias aéreas, alguns estudos têm sugerido que a resposta inflamatória e funcional que ocorre na asma não está restrita apenas às vias aéreas, mas também ao parênquima pulmonar isto é, ao tecido pulmonar periférico (Bachofen, 1968). A resistência do tecido pulmonar (Rti) tem um importante papel na resistência pulmonar total $(R L)$ e aumenta significativamente em resposta a estímulos primariamente broncoconstritores (Cortijo et al., 1984).

Ainda não está totalmente estabelecido o local da resposta contrátil do parênquima pulmonar alveolado. Os mecanismos que podem estar potencialmente envolvidos nesta resposta são: a resposta contrátil de miofibroblastos ou de outras células intersticiais, alterações na interface arlíquido alveolar, alterações da matriz extracelular, contração de células musculares lisas ao nível de ductos alveolares, pequenas vias aéreas ou vasos presentes no tecido pulmonar periférico (Lai et al., 1994). 
Uma revisão realizada por Kraft et al. (1999), em animais e humanos, demonstrou a importância da participação das vias aéreas distais (diâmetro<2 mm) e parênquima pulmonar na fisiopatologia da asma. Os pesquisadores mostraram que pacientes que morreram de asma apresentam importantes alterações no parênquima pulmonar. Mauad et al. (2004) estudaram 15 pacientes que foram a óbito por crises asmáticas. No estudo de autópsia observou-se a diminuição da quantidade de fibras elásticas em pequenas vias aéreas, que são essenciais para a manutenção do recolhimento elástico pulmonar e que este fator poderia contribuir para o desfecho fatal observado nestes pacientes (Foreman et al., 1985).

Para a avaliação das propriedades mecânicas e da resposta farmacológica da periferia do pulmão têm se estudado os fragmentos do parênquima pulmonar (Ludwig et al., 1987). Estudos realizados com fragmentos de parênquima pulmonar periférico de cobaias e ratos apontam para uma característica de contração e relaxamento do tecido periférico dependendo da droga utilizada, o que sugere a participação do parênquima na resistência pulmonar total.

Romero et al. (2001) demonstraram que a broncoconstrição induzia mudanças estruturais na matriz do tecido conectivo em fragmentos pulmonares. Tanaka e Ludwig (1999) comparando as propriedades mecânicas de fragmentos pulmonares periféricos de cobaias com diferentes idades demonstraram que o parênquima pulmonar de cobaias jovens apresentava baixa histerese e maior plasticidade que o observado em animais adultos. 
Dolhnikoff et al. (1998) verificaram que o parênquima pulmonar humano responde a estimulação contrátil por acetilcolina através do aumento da resistência e da elastância do tecido pulmonar periférico. Os autores notaram que não houve diferença na resposta contrátil entre os fragmentos pulmonares com e sem vias aéreas (detectadas por análise morfométrica). Estes dados sugerem que a resposta contrátil encontrada decorra de alterações do parênquima pulmonar. Salerno et al. (1995) demonstraram que quanto mais proximais forem os fragmentos, maior seria a influência da parede brônquica na determinação da resposta mecânica.

Além disso, vários trabalhos avaliaram em modelos animais de inflamação alérgica crônica a importância do parênquima pulmonar. Lanças et al. (2006) estudaram a resposta tardia e imediata em modelo de asma em cobaias utilizando a avaliação por mecânica oscilatória de fragmentos de tecido pulmonar periférico. Os autores demonstraram que neste compartimento pulmonar é possível detectar-se resposta imediata e duas respostas tardias e que estes achados se correlacionaram à intensidade da resposta inflamatória eosinofílica e houve aumento na deposição de colágeno.

Xisto et al. (2005) avaliaram a mecânica e o remodelamento de vias aéreas e de parênquima pulmonar em modelo de inflamação alérgica pulmonar em camundongos. Os autores mostraram que a inflamação eosinofilica não está somente presente em vias aéreas, mas também em parênquima pulmonar, concluindo que a exposição prolongada a alérgenos 
induz o remodelamento não só de vias aéreas, mas também de parênquima pulmonar.

Nakashima et al. (2008) mostraram que, em cobaias com inflamação alérgica crônica, a indução de tolerância oral atenuou as respostas de mecânica oscilatória de tecido pulmonar periférico, bem como a resposta inflamatória eosinofílica.

É importante considerar que muitos dos dispositivos utilizados para administração de corticóides inalatórios geram partículas que não chegam efetivamente às vias aéreas distais e ao parênquima pulmonar (Kraft et al., 2007). As formulações mais novas de corticosteróides inalados, que usam o hidroflurorano, têm maior deposição distal, sendo que a taxa de deposição pulmonar pode chegar a $60 \%$, enquanto $30 \%$ se depositam na orofaringe, podendo contribuir em longo prazo para a maior efetividade do tratamento destes pacientes (Ibiapina et al, 2004).

Burburan et al. (2007) destacam a importância do conhecimento da indução anestésica geral em pacientes asmáticos e do envolvimento do parênquima distal na fisiopatologia da doença. Os autores estudaram anestésicos que podem beneficiar pacientes asmáticos e que possuem efeitos em vias aéreas distais. Quando viável a anestesia periférica ou regional seria sempre preferível porque reduz a irritação das vias aéreas e as complicações pós-operatórias. Se a anestesia geral for necessária, a máscara laríngea e mais segura do que a intubação endotraqueal. A inalação com lidocaína, sozinha ou combinada com albuterol, miniminiza a 
broncoconstrição induzida pela histamina. O propofol e a cetamina inibem a broncoconstrição, diminuindo o risco de broncoespasmo durante indução anestésica. O propofol contribui para a dilatação de vias aereas centrais e é mais efetivo do que o etomidato ou tiopental. $O$ halotano, o enflurano e o isoflurano são potentes broncodilatadores e podem ajudar pacientes asmáticos. O sevoflurano mostrou resultados controversos em pacientes asmáticos. O vecurônio, rocurônio, cisatracúrio e pancurônio não induzem broncoespasmo, enquanto atracúrio e mivacúrio podem, dependendo da dose, liberar histamina e devem ser administrados cautelosamente.

\section{4. Óxido Nítrico e Asma}

A molécula de óxido nítrico (NO) durante muitos anos foi conhecida como um nocivo poluente ambiental proveniente da fumaça de cigarros, (Norman et al., 1965) bem como é gerado pela exaustão de combustíveis de veículos automotores, destruindo a camada de ozônio e causando chuva ácida (Cullota e Koshland, 1992). No entanto, a partir dos anos 80, pesquisadores demonstraram que o NO é uma molécula essencial na fisiologia do corpo humano (Bell, 2004). O NO tornou-se biologicamente conhecido em 1998, quando três americanos: Louis J. Ignarro da 
Universidade da Califórnia em Los Angeles, Robert Furchgott, da Universidade do Estado da Califórnia e Ferid Murad, da Escola de Medicina da Universidade do Texas em Houston, foram honrados com o Prêmio Nobel, devido à publicação de vários trabalhos com o intuito de esclarecer sua função, via de formação no organismo e sua atuação nas doenças. Hoje o papel do óxido nítrico já é bem mais estabelecido no sistema respiratório. Os primeiros estudos em asma demonstraram que havia altas concentrações de óxido nítrico no ar exalado de asmáticos em comparação com indivíduos normais (Alving et al., 1993; Gaston et al., 1993; Kharitonov et al., 1994).

O NO tem sido bem descrito como um neurotransmissor não adrenérgico não colinérgico (NANC) sendo responsável e também pela modulação do tônus brônquico (Alving et al., 1992, Barnes e Belvisi,1993; Högman et al.,1993) e exudação plasmática (Kuo et al.,1992; Erjefält et al.,1994), tanto em modelos animais quanto em humanos.

Há três componentes principais que compõem o sistema nervoso autônomo pulmonar: o adrenérgico, o colinérgico e o sistema nãoadrenérgico não-colinérgico (NANC) (Kaliner et al., 1991). O sistema NANC é composto por um conjunto de fibras sensitivas não-mielinizadas, cujos processos terminais atingem as células epiteliais, vasos, musculatura lisa peribrônquica e glândulas mucosas. O sistema NANC apresenta dois grandes grupos: um componente inibitório (i-NANC) que causa broncodilatação e outro excitatório (e-NANC) cuja estimulação resulta em broncoconstrição. 
Quando um grupo molecular guanidino de aminoácido L-arginina é quebrado, através de oxidação enzimática (Moncada et al., 1989; Tayeh e Marletta, 1989), ocorre a geração de NO e L-citrulina e não D-arginina (Culotta e Koshland, 1992; Moncada e Higgs, 1993). Essa reação é estereoespecífica, ou seja, somente a L-arginina é metabolizada e é catalisada por um grupo de enzimas chamadas de óxido nítrico sintases (NOS).

A partir do substrato L-arginina ocorre síntese do óxido nítrico (Palmer et al., 1998) por intermédio da ação das isoformas das óxido nítrico sintases (NOS) constitutivas (Bredt et al., 1991; Lamas et al., 1992, Janssens et al., 1992) ou induzida (Xie et al, , 1992).

As enzimas constitutivas podem estar expressas nas células endoteliais (Lamas et al., 1992) ou nos neurônios (Bredt e Snyder, 1989; Bredt et al., 1990), sendo denominadas eNOS e nNOS, respectivamente. A forma induzida (iNOS) pode estar expressa em uma variedade de tecidos e órgãos e também no endotélio vascular. Sua produção é estimulada pelo lipopolissacarídeo bacteriano ou por algumas citocinas como o TNF- $\alpha$, IL-1 e IFN- $\gamma$ (Moncada e Higgs, 1993; Moncada et al., 1991). É responsável pela produção de quantidades nanomolares de NO e parece estar presente principalmente em condições patológicas.

O NO parece atuar em vários mecanismos fisiopatológicos que desencadeiam as alterações funcionais e histopatológicas encontradas em pacientes asmáticos, sendo que a sua contribuição depende principalmente 
da enzima pela qual foi produzido. Barnes (1996) sugere que o NO derivado da enzima nNOS apresenta efeito benéfico na asma por causar relaxamento na musculatura lisa brônquica, estando presente nos nervos do sistema NANC. No entanto, o NO derivado da enzima eNOS pode levar a vasodilatação nas arteríolas, com conseqüente extravasamento de plasma e edema. A grande quantidade de NO oriundo da enzima iNOS pode resultar em vasodilatação, extravasamento de plasma, aumento da secreção do muco e ativação indireta de células Th2 contribuindo para a fisiopatologia da asma.

A produção de NO pode ser inibida pelo bloqueio das enzimas NOS, sendo, portanto estes inibidores de enzima de importância fundamental na avaliação do papel do NO na fisiopatogenia de diversas doenças (Moncada e Higgs, 1993). A L-NG-nitro-arginina, um inibidor da produção de NO, tem um efeito inibitório nas respostas nervosas de i-NANC na traquéia de cobaias (Li e Rand, 1991).

No mercado encontramos um grande número de inibidores que são utilizados em laboratórios para bloquear a ação destas enzimas. Alguns deles incluem a L-NG-monometil-arginina (L-NMMA), a L-NG-nitroarginina metil ester (L-NAME), NG-nitro-L-arginina (L-NOARG), NG-iminoetil-Lornitina (L-NIO), L-NG-nitroarginina-p-nitroanilida (L-NAPNA), L-canavanina, hidroxicobalamina e aminoguanidina (Rees et al., 1990). A hidroxicobalamina aparece como o mais seletivo inibidor eNOS, o L-NAPNA como o da enzima nNOS e a aminoguanidina e o 1400W da enzima iNOS (Baddedge et al., 1993). 
Resultados de nosso grupo de pesquisa demonstraram uma importante participação do óxido nítrico neste modelo de asma experimental em cobaias. Prado et al. (2005a) demonstraram que existe um aumento da expressão de iNOS em células linfomononucleares e eosinófilos presente nas vias aéreas distais de animais sensibilizados. Além disso, ainda observaram que a isoforma nNOS, embora constitutiva, encontra-se presente em células inflamatórias (linfomononucleares e eosinófilos) e o número de células que expressam esta isoforma é maior nos animais sensibilizados com ovoalbumina ( Prado et al., 2008).

Prado et al. (2005b) estudaram os efeitos do tratamento agudo e crônico com L-NAME em animais sensibilizados e observaram que o NO tem uma importante função broncodilatadora, vasodilatadora e pró-inflamatória neste modelo. Considerando a mecânica do sistema respiratório, notaram que a inibição crônica de produção de NO alterou, particularmente, os valores de resistência basal e após desafio antigênico. Por outro lado, a inibição aguda da produção de NO alterou principalmente os valores de elastância do sistema respiratório nos animais sensibilizados, sugerindo efeito broncodilatador do NO em vias aéreas distais.

Julgamos que parte destes resultados possa ser decorrente de alterações do tecido alveolado, que ocorreu nos animais sensibilizados que receberam tratamento agudo com L-NAME. Os animais deste grupo apresentaram uma broncoconstrição muito intensa e evoluíram com parada cardíaca (55\% de perda). Ao examinar o coração e o pulmão destes animais observou-se uma extrema dilatação de câmaras cardíacas, particularmente 
de ventrículo direito e hiperinsuflação pulmonar associada a áreas de hemorragias, o que corrobora os dados de mecânica, sugerindo um papel broncodilatador e controlador do tônus da circulação pulmonar.

Para estudar o extravasamento sanguíneo no parênquima pulmonar, os autores avaliaram o índice de hemorragia e observaram que, embora tenha sido maior nos animais sensibilizados que receberam tratamento agudo com L-NAME, houve aumento do índice de hemorragia nos dois grupos sensibilizados e que receberam inibidores de $\mathrm{NO}$ em relação àqueles que receberam apenas veículo de L-NAME. Cabe ressaltar que não existem evidências na literatura que tenham avaliado o papel do NO nas propriedades viscoelásticas do parênquima distal do pulmão.

Por fim, nosso grupo ainda demonstrou que o tratamento crônico com L-NAME nos animais sensibilizados induziu um aumento na deposição de fibras colágenas na parede das vias aéreas distais (Prado et al., 2006), sugerindo um importante papel protetor do óxido nítrico no remodelamento de vias aéreas em modelo experimental de asma. 


\section{5. Óxido Nítrico e o Estresse Oxidativo}

As espécies reativas de oxigênio incluem uma série de radicais livres de oxigênio como o ânion superóxido e os radicais hidroxil, mas também derivados do oxigênio que não tem um elétron não pareado, como por exemplo, o peróxido de hidrogênio, ácido hipocloroso, peroxinitrito e ozônio. São produzidas continuamente por vários sistemas enzimáticos e estão presentes nas mitocôndrias ou microssomos, podendo ser diretamente inaladas. O NO pode reagir com estes radicais livres formando compostos reativos nitrogenados, que exercem funções fisiológicas e são importantes na destruição de microorganismos.

No entanto, quando as vias aéreas são expostas a este estresse oxidativo desencadeado pelo contato com poluentes, infecções, resposta inflamatória exarcebada ou mesmo em situações nas quais os sistemas antioxidantes do organismo estão diminuídos, podem ocorrer várias alterações. Dentre elas, cabe ressaltar a lesão de DNA, estímulo à degradação de lipídeos, proteínas e carboidratos, as quais podem alterar as funções celulares e potencializar as respostas inflamatórias. Estes mecanismos podem ser de importância na fisiopatogenia da asma, da doença pulmonar obstrutiva crônica (DPOC), da síndrome do desconforto respiratório do adulto (SDRA), de doenças intersticiais entre outras (Vallyathan e Shi, 1997; Ricciardollo et al., 2004). 
O óxido nítrico e o superóxido podem reagir formando peroxinitrito, que pode ser degradado ao ligar-se com o dióxido de carbono. O NO pode se decompor em nitrato e nitrito, os quais podem ser medidos no plasma. É possível detectar os resíduos de nitrotirosina em vários tecidos, utilizando técnicas imunohistoquímicas. É importante ressaltar que podem ocorrer artefatos nestes estudos porque a 3-nitrotirosina pode ser formada por uma via independente do NO, mediada pela mieloperoxidase. Nesta via alternativa, o substrato é o peróxido de hidrogênio e os nitritos. Além disto, a ativação peroxidase eosinófilica também pode produzir 3-nitrotirosina (Wu et al., 1999; Reiter et al., 2000). O NO pode ser formado via nitrito, o que ocorre quando o $\mathrm{pH}$ diminui. Tal fato foi observado em asmáticos durante as crises (Hunt et al., 2000).

Os principais sistemas antioxidantes do organismo são representados por superóxidos dismutases ligadas ao manganês ou ao zinco, que convertem rapidamente ânion superóxido a peróxido de hidrogênio e água pela glutationa peroxidase. O fluido das vias aéreas contém grandes quantidades de glutationa reduzida. É importante lembrar que o NO se liga aos tióis das proteínas. A limitação da produção de superóxidos via bloqueio de NADPH (nicotinamida adenina dinuclotídeo fosfatase) oxidase pode ser uma opção interessante para reduzir a produção de radicais livres nitrogenados visto que este bloqueio não interfere com outras funções do NO. Os efeitos dos radicais livres nitrogenados ocorrem, principalmente, em proteínas com resíduos heme e tirosina e podem causar várias alterações já citadas podendo induzir a apoptose. Contudo, estes radicais são 
fundamentais na destruição de microorganismos estranhos ao organismo (Vallyathan e Shi, 1997; Eiserich et al., 1998; Ricciardolo et al., 2004).

A exposição a uma variedade de substâncias diferentes, tais como alérgenos, gases poluentes, químicos, drogas, bactérias e vírus (Levine, 1995; Wood et al., 2003) conduz ao recrutamento e ativação das células inflamatórias nas vias aéreas de pacientes asmáticos, incluindo mastócitos, eosinófilos, neutrófilos, linfócitos, macrófagos e plaquetas. Como indicado na Figura 3 às reações específicas alérgicas envolvendo o sistema imunológico adquirido são caracterizados pela produção de IL-5 e o subseqüente recrutamento e ativação dos eosinófilos. Em contraste, o estímulo que age via sistema imunológico inato conduz a produção do IL-8 e o subseqüente recrutamento e ativação de neutrófilos. Entretanto, as duas vias conduzem a produção de espécies reativas de oxigênio (ROS) primariamente devido às células inflamatórias ativadas.

As células inflamatórias ativadas respondem causando um dano respiratório com liberação de espécies reativas de oxigênio (ROS) para as células adjacentes. Durante o dano respiratório, há redução de nicotaminada-adenina dinucleótido fosfatase-superóxido dependente. O sistema gerador é ativado e libera superóxido $\left(\mathrm{O}_{2}{ }^{-}\right)$dentro da célula. Uma reação de dismutação, catalizada pela supeóxido dismutase (SOD) resulta na produção do peróxido de hidrogênio $\left(\mathrm{H}_{2} \mathrm{O}_{2}\right)$, o qual, na presença de íons de íons haleto $\left(\mathrm{I}^{-}, \mathrm{Cl}^{-}, \mathrm{Br}^{-}\right)$, reagirá para formar os ácidos como, por exemplo: $\mathrm{HOCl} / \mathrm{HOBr}$. Em eosinófilos, esta reação é catalizada pela peroxidase eosinofilica (EPO) em neutrófilos pela mieloperoxidase (MPO). O 
$\mathrm{HOCl} / \mathrm{HOBr}$ podem então reagir com $\mathrm{O}_{2}{ }^{--}$ou $\mathrm{Fe}^{2+}$ para produzir outro forte oxidante, o radical hidroxil $(. \mathrm{OH})$. Além disto, durante esta "queima respiratória" as células inflamatórias liberam altas concentrações de $\mathrm{O}_{2}{ }^{--}$, $. \mathrm{OH}, \mathrm{HOCL} / / \mathrm{HOBr}$ e $\mathrm{H}_{2} \mathrm{O}_{2}$, que podem lesar as células adjacentes resultando em aumentos na quantidade de radicais livres nas células respiratórias teciduais (Wood et al., 2003)

Cabe ressaltar que as células inflamatórias dos asmáticos possuem uma capacidade aumentada de gerarem radicais livres quando comparados com controles, os quais posteriormente contribuem para a produção de altas concentrações de ROS (Jarjour et al., 1994). A espécies reativas de nitrogênio em excesso (RNS) podem também ser produzidas pelos asmáticos. Citocinas podem estimular o aumento da produção de nitrosil (NO) (Kharitonov et al., 1994) o qual reage com o $\mathrm{O}_{2}$ para a formação do peróxido nitrito, uma espécie citotóxica que possui muitos efeitos danosos, incluindo a oxidação lipídica (Radi et al., 1991). O NO pode também ser convertido em nitrato, o qual pode oxidar proteínas. Isto pode ocorrer por meio de uma reação denominada da nitração da tirosina e catalizada pelo EPO (Wu et al., 1999). Níveis elevados de nitrotirosina foram observados em asmáticos (Hanazawa et al., 2000).

O estresse oxidativo tem papel importante na fisiopatologia da asma (Barnes, 1990; Doelman et al., 1990a) e um método para quantificar a injúria oxidativa é a mensuração da peroxidação lipídica (Milne et al., 2007). O estresse oxidativo pode levar a muitos efeitos prejudiciais na função de vias aéreas, incluindo a contração da musculatura lisa (Rhoden e Barnes, 1989), 
indução da hiperrresponsividade de vias aéreas (Katsumata et al., 1990; Weiss et al.,1986), hipersecreção brônquica (Doelman et al., 1990b), lesão epitelial e o aumento da permeabilidade vascular (del Maestro et al., 1981; Tate et al.,1982). Além disso, ROS pode induzir a produção citocinas e quimiocinas via aumento da transcrição do fator nuclear NF-KB em células epiteliais bronquiais (Biaglioli et.al.,1999).

A peroxidação da membrana lipídica leva a produção de isoprostanos, uma série recentemente descoberta de prostaglandinas bioativas (PG)F2like. Os isoprostanos são produzidos independentemente das enzimas ciclooxigenases, via a peroxidação do ácido araquidônico, catalizada por radicais livres. Esta via tem a capacidade de formar 64 estruturas isoméricas, das quais o 8-iso-PGF2a é o melhor caracterizado. Há evidências que sugerem que o 8-iso-PGF2 $\alpha$ pode atuar, em parte, por meio da ligação ao receptor vascular de tromboxane $\mathrm{A}_{2} / \mathrm{PGH}_{2}$ (TP) receptor (Takahashi et al.,1992). 

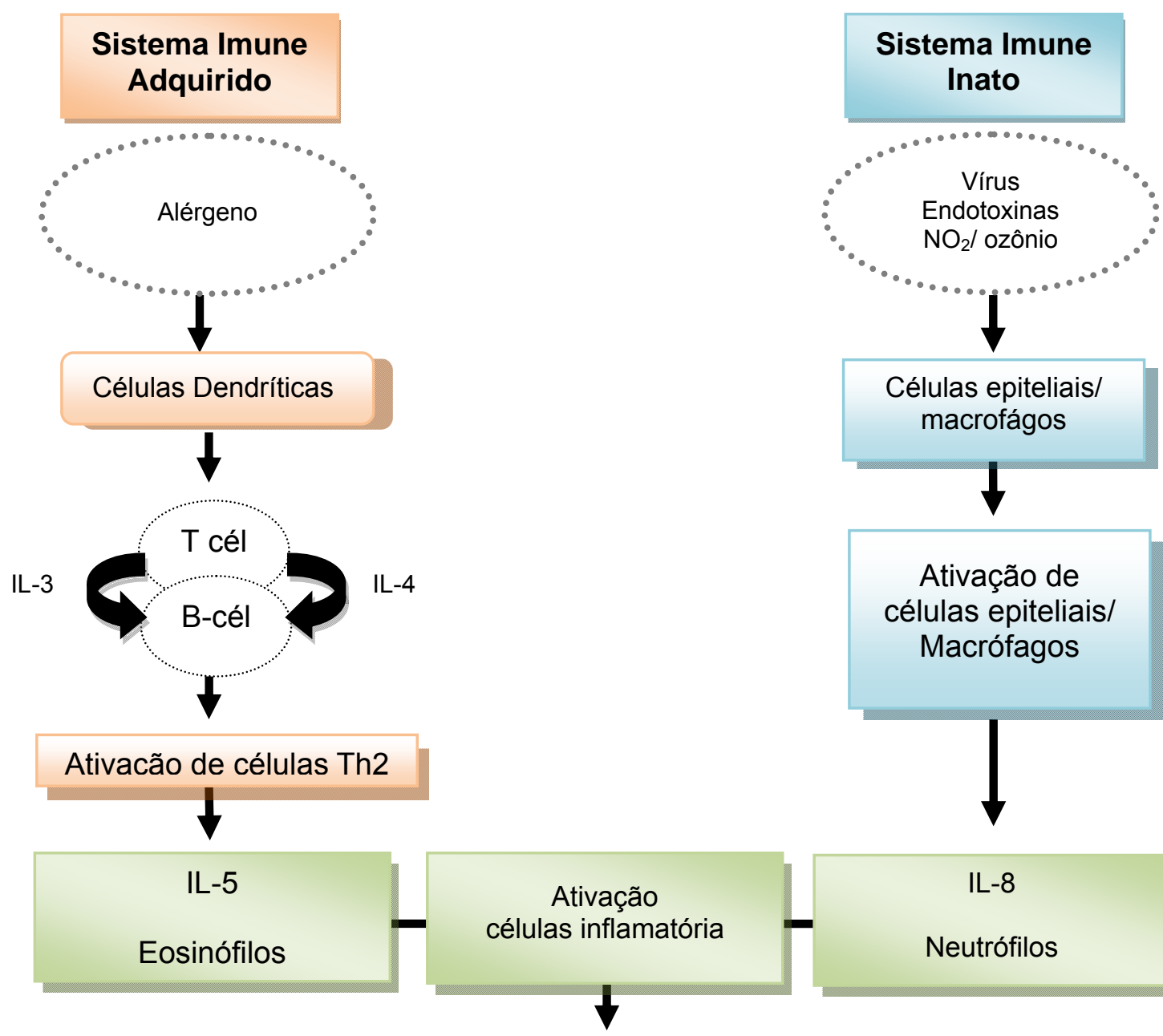

Liberação de Mediadores (leucotrienos, prostaglandinas, histamina, citocina e ROS)

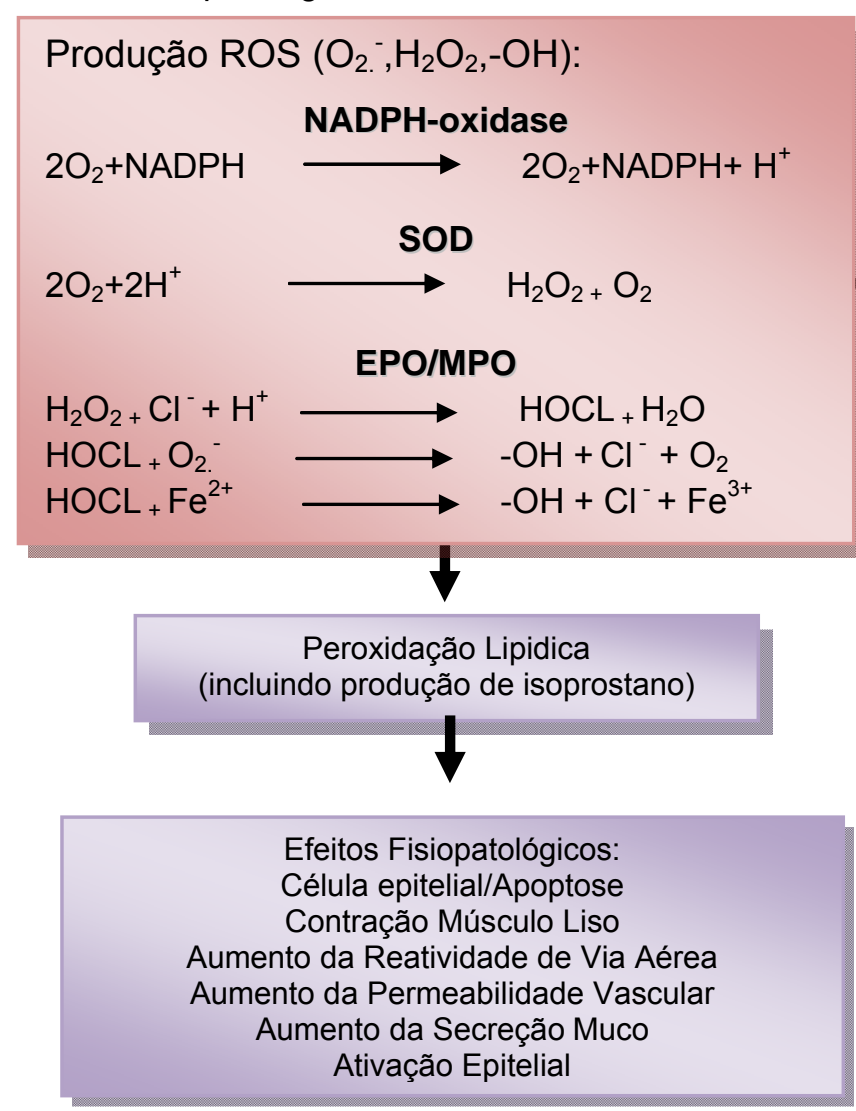


Figura 3. Representação esquemática do mecanismo da produção da peroxidação lipídica na asma. IL: interleucina; Th2: célula T-helper tipo 2 ; $\mathrm{NO}_{2}$ : dióxido de nitrogênio;ROS: espécies reativas de oxigênio; $\mathrm{O}_{2}$ superóxido; $\mathrm{H}_{2} \mathrm{O}_{2}$ : peróxido de hidrogênio; $-\mathrm{OH}$ : radical hidroxil; $\mathrm{NADPH}$ : nicotaminada adenina dinucleotídeo fosfato reduzida;NADP: nicotinamida adenina dinucleotídeo fosfato ; SOD: superóxido dismutase; EPO: peroxidase eosinofílica; MPO: mieloperoxidase; NF: fator transcrição nuclear.

Modificado da Fonte: "Biomarkers of lipid peroxidation, airway inflammation and asthma". Eur Resp J, 2003. 


\subsection{Justificativa do Estudo}

Frente aos resultados obtidos em relação ao papel do óxido nítrico na modulação das alterações de mecânica do sistema respiratório no modelo experimental de inflamação alérgica anteriormente descrito, da importância do óxido nítrico e do parênquima pulmonar distal na asma, consideramos relevante avaliar esta interação. Cabe também ressaltar que não há estudos que avaliassem estes aspectos.

Deste modo, nosso intuito neste projeto foi estudar as alterações de mecânica oscilatória de parênquima pulmonar induzidas pelo tratamento crônico com L-NAME (que atua como falso substrato para a produção do NO) em cobaias com inflamação pulmonar alérgica crônica. Além disto, procuramos caracterizar os determinantes histológicos presentes no parênquima pulmonar, que se correlacionariam às alterações de mecânica oscilatória, incluindo a avaliação da matriz extracelular, caracterizando o conteúdo de fibras colágenas e elásticas, e a resposta inflamatória eosinofílica na parede alveolar. Avaliamos também a ativação da via do estresse oxidativo por meio da identificação da expressão de isoprostano PGF2 $\alpha$. Para avaliarmos a efetividade do tratamento com L-NAME estudamos a expressão das óxido nítrico sintases neuronal e induzida nas células do parênquima pulmonar. 
Neste modelo experimental, nossos objetivos foram:

1. Avaliar os efeitos da inibição crônica da produção de óxido nítrico por meio do tratamento crônico com L-NAME (falso substrato para todas as óxido nítrico sintases) nas respostas de mecânica oscilatória do parênquima pulmonar.

2. Avaliar os efeitos do tratamento crônico com L-NAME na resposta inflamatória eosinofílica presente no parênquima pulmonar.

3. Avaliar os efeitos do tratamento crônico com L-NAME na expressão das óxido nítrico sintases neuronal e induzida nas células do parênquima pulmonar.

4. Avaliar os efeitos do tratamento crônico com L-NAME nas alterações da matriz extracelular (densidade de fibras colágenas e elásticas) do parênquima pulmonar.

5. Avaliar os efeitos do tratamento crônico com L-NAME na ativação da via do estresse oxidativo no parênquima pulmonar, por meio da detecção da expressão de 8-iso PGF2 $\alpha$. 
MATERIAIS

E MÉTODOS 
Esse estudo foi aprovado pela Comissão de Ética em Pesquisa do Hospital das Clínicas da Faculdade de Medicina da Universidade de São Paulo, em sessão de 09.11.05, protocolo de pesquisa número 808/05. Este estudo foi realizado em parceria com pesquisadores da Universidade Federal do Rio de Janeiro, no Departamento de Fisiologia Respiratória coordenado pela Profa. Dra. Patrícia Rocco.

\subsection{Grupos Experimentais}

Os animais foram divididos nos seguintes grupos (conforme o tipo de inalação e tratamento recebido):

A. Inalações com soro fisiológico (SF) e tratamento crônico com L-NAME na água de beber (SF-L, $\mathrm{n}=7$ );

B. Inalações com ovoalbumina (OVA) e tratamento crônico com L-NAME na água de beber (OVA-L, $n=11$ );

C. Inalações com soro fisiológico (SF) e tratamento com veículo (SF+ VE, n=9);

D. Inalações com ovoalbumina (OVA) e tratamento crônico com veículo (OVA+VE, n=11). 
Utilizamos para este protocolo 38 cobaias, com perda de 5 cobaias, do sexo masculino, da linhagem Hartley, com peso corporal variável entre 300 a 350g, sendo mantidas, sob alimento e água ad libitum, no biotério conjunto de manutenção dos Laboratórios de Investigação Médica (LIM) 20 e 05, da Faculdade de Medicina da Universidade de São Paulo, em condições ideais e controladas de temperatura, umidade e ruído. As cobaias eram provenientes da empresa MEDLAB Produtos Diagnósticos LTDA (São Paulo, Brasil). Todos os animais receberam cuidados de acordo com o "Guia de cuidados e uso de animais de laboratório", publicado pelo National Institutes of Health (NIH publication 85-23, revisado em 1985), sendo que todos os procedimentos cirúrgicos foram realizados sob anestesia geral.

\subsection{Protocolo de Sensibilização}

Os animais foram colocados em uma caixa de exposição de acrílico (30 x 15 x 20 cm) acoplada a um nebulizador ultrassônico (US-1000, ICEL, Brasil). Foram submetidos à inalação com aerossol de ovoalbumina diluída em $\mathrm{NaCl}$ 0,9\% (soro fisiológico) com concentrações crescentes de ovoalbumina (1 5mg/dL) por 15 minutos ou até o aparecimento de sinais de desconforto respiratório como tosse, tiragem intercostal,coriza intensa e lou cianose. O protocolo de inalação foi repetido 
duas vezes por semana durante um período de quatro semanas (Figura 4). O aumento crescente nas concentrações de ovoalbumina tinha o intuito de evitar-se a ocorrência de tolerância (Paré et al., 1979; Sedgwick e Holt, 1985). Animais controle foram submetidos à exposição de aerossol de solução de soro fisiológico seguindo o mesmo protocolo descrito acima (Tibério et al., 1997; Leick-Maldonado et al., 2004). Após 72 horas da sétima inalação, todos os animais foram anestesiados, exsanguinados, os pulmões foram removidos e submetidos à avaliação da mecânica oscilatória pulmonar.

\subsection{Tratamento Crônico com L-NAME}

Vinte e quatro horas após a quarta inalação com ovoalbumina, os animais receberam diariamente L-NAME, dissolvido em água estéril, que foi oferecido ad libitum, seguindo protocolo previamente descrito por Ribeiro et al. (1992) e já utilizado e padronizado em nosso laboratório (Prado et al., 2005a). A dose utilizada foi de 60mg/Kg/cobaia/dia. No dia da Avaliação de Mecânica Pulmonar esta solução foi oferecida aos animais até 30 min antes do início do experimento. 


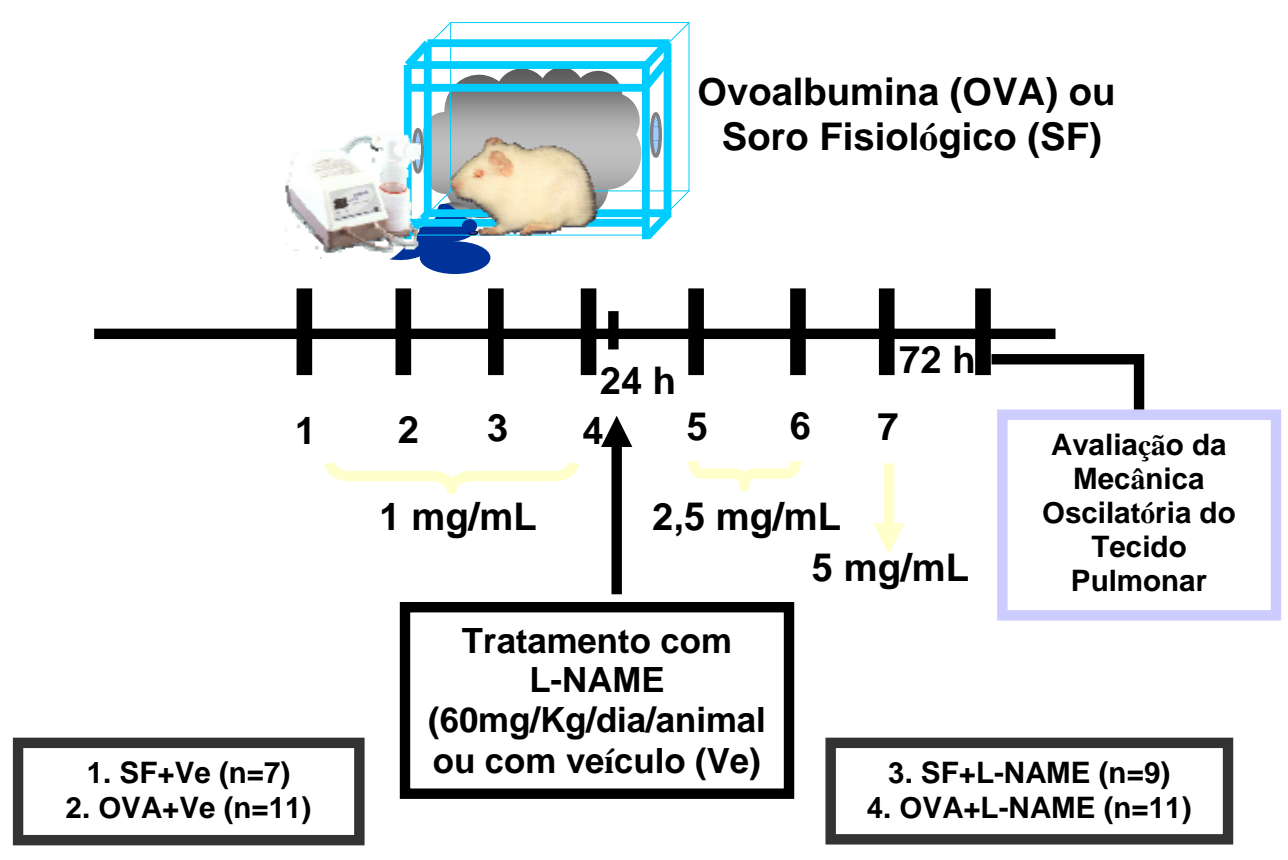

Figura 4. Esquema do protocolo de sensibilização e administração do tratamento utilizado. As cobaias foram submetidas a sete inalações (2x/semana/4 semanas) com aerossóis contendo soro fisiológico $(\mathrm{NaCl}$ 0,9\%) ou com concentrações crescentes de solução de ovoalbumina. Da $1^{\mathrm{a}}$ a $4^{\mathrm{a}}$ inalação, a dose foi de $1 \mathrm{mg} / \mathrm{ml}$ de ovoalbumina. Durante a $5^{\mathrm{a}}$ e a $6^{\mathrm{a}}$ inalações os animais receberam aerossóis com a concentração de $2,5 \mathrm{mg} / \mathrm{ml}$ de ovoalbumina e na $7^{\mathrm{a}}$ inalação a concentração foi de $5 \mathrm{mg} / \mathrm{ml}$ de ovoalbumina. O aerossol, tanto o SF quanto a OVA foi emitido durante 15 minutos ou até que se instalassem sinais de desconforto respiratório. Após 72 horas da sétima inalação todos os animais foram anestesiados, exsaguinados e seus pulmões removidos e submetidos à mecânica oscilatória de parênquima pulmonar. O tratamento com L-NAME $(60 \mathrm{mg} / \mathrm{Kg} / \mathrm{dia} / \mathrm{animal})$ diluído em água de beber teve início 24 horas após a $4^{\mathrm{a}}$ inalação e foi administrado até o dia da avaliação da mecânica oscilatória pulmonar. 


\subsection{Avaliação da Mecânica Oscilatória de Tecido Pulmonar Periférico}

\subsubsection{Protocolo Experimental}

Os animais foram sedados com diazepan (5 mg i.p.), anestesiados com pentobarbital sódico (20 mg/kg i.p.) e traqueotomizados. A mesma cânula utilizada para o estudo in vivo foi posicionada na traquéia, passando um fio de linha de algodão por baixo da mesma. Imediatamente após, o abdômen do animal foi aberto sendo exangüinado por secção da aorta e da veia cava em suas porções abdominais. Depois, o tórax foi aberto e retirou-se o monobloco coração-pulmões.

\subsubsection{Preparação do Tecido}

Em uma segunda etapa, uma tira subpleural de tecido pulmonar foi retirada do pulmão esquerdo, com dimensões de 1,0 x 0,3 x 0,3 cm, (Figura 5) a fim de se evitar a presença de vasos e brônquios (vias aéreas mais centrais). Tal tira de parênquima pulmonar foi imediatamente colocada em um recipiente contendo solução de Krebs gelada, continuamente borbulhada com uma mistura carbogênica (95\% O2 e 5\% 
CO2), devendo ser trocada a cada 20 minutos (Salerno et al., 1998; Lopez-Aguilar e Romero, 1998; Faffe et al., 2001; Rocco et al., 2001; Leite-Junior et al., 2003).

As tiras de tecido pulmonar foram pesadas e seus comprimentos iniciais (LO) medidos com um paquímetro. O volume das tiras foi determinado por densitometria simples e calculado como $\mathrm{Vol}=\Delta \mathrm{F} / \delta$, onde $\Delta \mathrm{F}$ é a alteração total na força devido à imersão da tira, e $\delta$ é a densidade de massa da solução K-H $(1,002$ g/cm³) (Scherle et al., 1970).

\subsubsection{Aparato Experimental}

As tiras de tecido pulmonar foram suspensas verticalmente num banho, contendo solução $\mathrm{K}-\mathrm{H}$ a $37^{\circ} \mathrm{C}$ e continuamente borbulhada com a mistura carbogênica (Romero et al., 2001; Faffe et al., 2001; Rocco et al., 2001), por meio de ganchos de metal fixados nas extremidades das tiras com cianocrilato e acoplados a transdutores de força (FT03, Grass Instruments Co., Quincy, MA, EUA). Um deles estava associado a uma haste de metal que, por sua vez, estava conectado a um alto-falante.

Esse sistema foi conectado a um gerador de função, o computador, que controlou a forma da onda, a freqüência e a amplitude de oscilação da tira. Portanto, 
esses sinais foram condicionados, passaram através de filtros Bessel de oito pólos (902LPF, Frequency Devices, Haverhill, MA, EUA) e foram convertidos analogicamente.

O movimento da haste conectada ao alto-falante foi transmitido para uma mola de prata, com módulo de Young conhecido, conectada a outro transdutor de força, permitindo as medidas de deslocamento da mesma (Figura 6).

A resposta de freqüência do sistema foi dinamicamente estudada, usando-se molas de prata calibradas com diferentes módulos elásticos de Young. Observou-se nenhuma dependência de amplitude ou diferença de fase com a freqüência entre 0,01 e $14 \mathrm{~Hz}$. A histeresividade do sistema independe da freqüência e possui valor< 0,003 . 


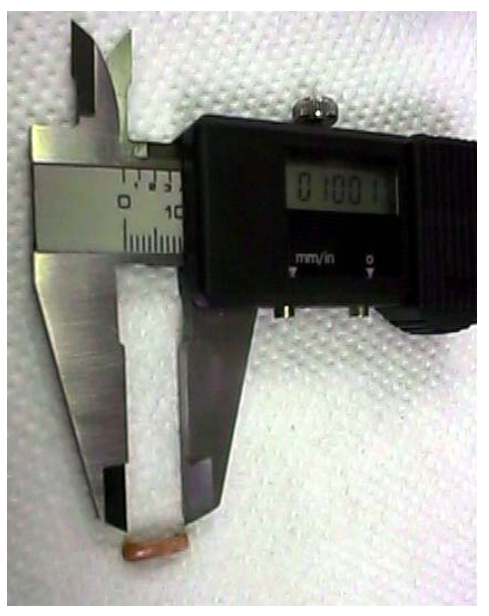

I - Medida Comprimento

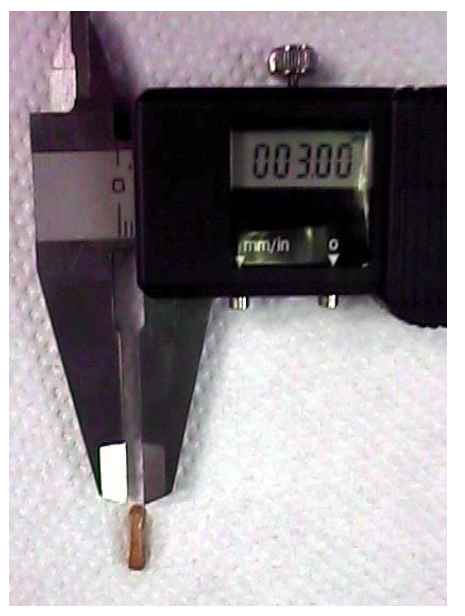

II- Medida da Espessura

Figura 5. Medida da fatia de parênquima pulmonar com a utilização de paquímetro. Após o corte, a fatia pulmonar retirada da porção distal do pulmão esquerdo foi mensurada por intermédio de um paquímetro, tanto em relação ao seu comprimento quanto a espessura e largura. 


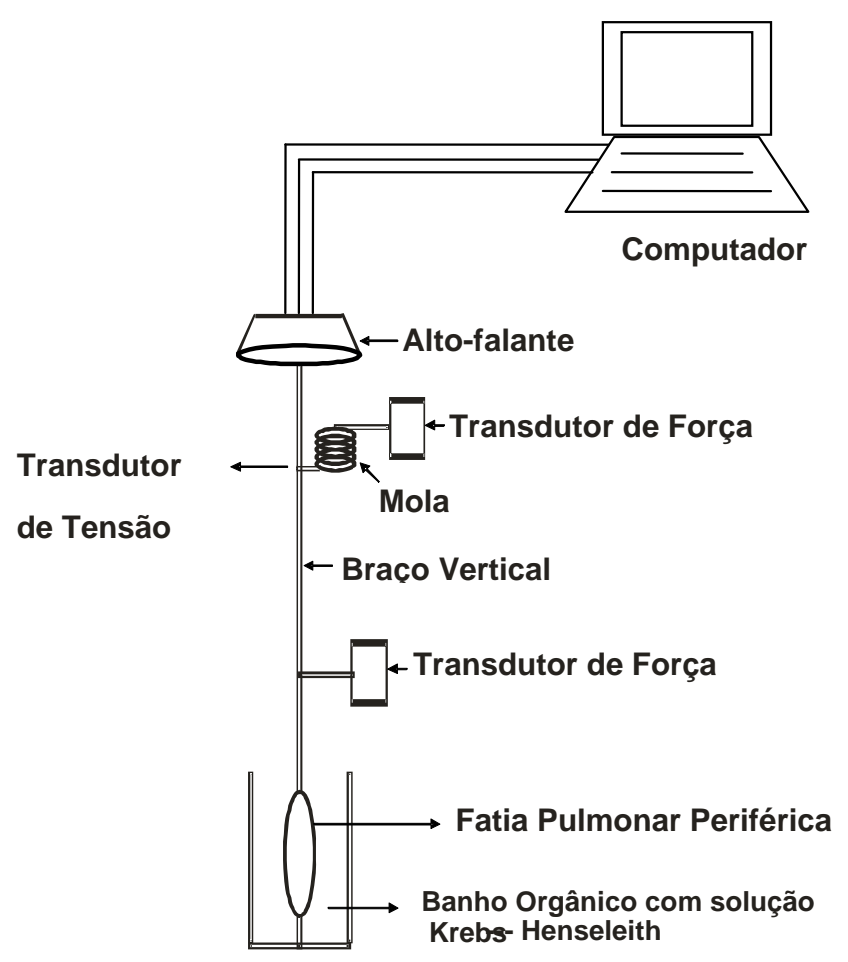

Figura 6. Esquema representativo do aparato experimental para medida da mecânica tecidual de tecido pulmonar periférico. As tiras de tecido pulmonar foram suspensas verticalmente num banho, contendo solução $\mathrm{K}-\mathrm{H}$ a $37^{\circ} \mathrm{C}$ e continuamente borbulhada com a mistura carbogênica, através de ganchos de metal fixados nas extremidades das tiras com cianocrilato e acoplados a transdutores de força. Um deles estava associado a uma haste de metal que, por sua vez, estava acoplado a um alto-falante. Esse sistema foi conectado a um computador, que controla a forma da onda, a freqüência e a amplitude de oscilação da tira. Os sinais foram condicionados e passaram através de filtros Bessel de oito pólos sendo convertidos analogicamente.O movimento da haste conectada ao altofalante foi transmitido para uma mola de prata, unida a outro transdutor de força, permitindo as medidas de deslocamento da mesma. A resposta de freqüência do sistema foi dinamicamente estudada, usando-se molas de prata calibradas com diferentes módulos elásticos de Young. 


\subsubsection{Precondicionamento}

A área de seção transversa inicial da tira (A0) foi determinada através da relação entre o volume e o comprimento iniciais da mesma, de acordo com $A 0=$ vol/LO. Para um estresse de $10 \mathrm{~g} / \mathrm{cm}^{2}$, a força basal $(F B)$ foi calculada como FB $(\mathrm{g})=$ $\mathrm{AO}\left(\mathrm{cm}^{2}\right) \times 10 \mathrm{~g} / \mathrm{cm}^{2}$ e ajustada pelo deslocamento vertical do transdutor de força.

Durante 10 minutos, cada tira de tecido foi pré-condicionada através de oscilações senoidais com freqüência de $0,5 \mathrm{~Hz}$ e amplitude ajustada até que se alcance o estresse máximo de $20 \mathrm{~g} / \mathrm{cm}^{2}=1 \times 10^{-2} \mathrm{~N}$. Após este período, uma nova FB foi calculada, sendo a amplitude ajustada para 5\% de LO e mantendo a oscilação com freqüência de $1 \mathrm{~Hz}$, por mais 30 minutos, até que uma curva estável fosse atingida.

Posteriormente, para calcular os parâmetros mecânicos, elastância (Et), resistência (Rt) e histeresividade ( $\eta$ - relação entre as energias dissipada e armazenada), curvas de força $x$ deslocamento foram coletadas, através do software LABDAT, na força, amplitude e freqüência estabelecidas anteriormente. 


\subsubsection{Medida dos Parâmetros Mecânicos Teciduais}

As tiras de tecido pulmonar foram submetidas à oscilação senoidal na amplitude de $5 \%$ de LB, freqüência de $1 \mathrm{~Hz}$ e FB calculada, imediatamente após 0 precondicionamento. A medida foi obtida após 5 minutos de oscilação senoidal. Para

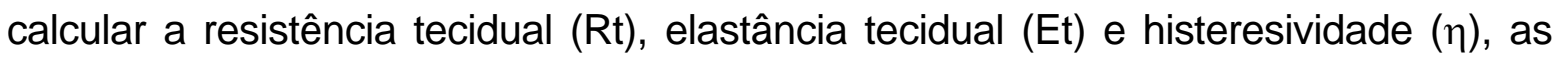
curvas de força-deslocamento foram analisadas (Lopez-Aguilar e Romero, 1998; Fredberg et al., 1989). A área de seção transversa instantânea (Ai) foi determinada como: $\mathrm{Ai}=\mathrm{Vol} / \mathrm{Li}\left(\mathrm{cm}^{2}\right)$, onde Li é o comprimento instantâneo. A força instantânea $(\sigma i)$ foi calculada dividindo força (g) por Ai. Todos os parâmetros foram medidos ciclo por ciclo. A resistência tecidual (Rt) foi determinada a partir da área contida na curva força-deslocamento:

$$
\mathrm{Rt}=(4 . \mathrm{H}) /\left[\pi \cdot \omega \cdot(\Delta \varepsilon)^{2}\right]
$$

onde, $\mathrm{H}$ é a área de histerese da curva força-deslocamento, $\omega$ é a freqüência angular ( $\omega=2 \pi \mathrm{f}, \mathrm{rad} / \mathrm{s}$ ), e $\Delta \varepsilon$ é o deslocamento normalizado ou variação de deslocamento ciclo por ciclo dividido por LB. A elastância dinâmica tecidual foi determinada por:

$$
\mathrm{Et}=(\Delta \sigma \mathrm{i} / \Delta \varepsilon) \cos \theta
$$

onde, $\Delta \sigma$ i representa a variação ciclo a ciclo na força, e $\theta$ é o ângulo de fase entre força e deslocamento $[\theta=\operatorname{sen}-1(4 \mathrm{H} / \pi . \Delta \sigma \mathrm{i} . \Delta \varepsilon)]$. 
A histeresividade, uma variável empiricamente determinada que quantifica a dependência de processos dissipativos nos processos elásticos (Fredberg et al., 1989), foi determinada como:

$$
\eta=\tan \theta
$$

Todas as avaliações acima citadas foram realizadas pré e após desafio no banho com solução de ovoalbumina na concentração de 0,1\%.

\subsection{Estudo Morfométrico}

O fragmento de tecido pulmonar periférico avaliado durante a mecânica oscilatória foi retirado do aparato experimental descrito na Figura 6 e foi fixado em solução de Carnoy, solução de etanol/clorofórmio/ácido acético (60: 30:10). Após 24 horas, os fragmentos foram transferidos para uma solução de etanol $70 \%$. Depois de terminada a fixação, o material foi submetido às técnicas histológicas habituais com parafina, para obtenção de cortes de $5 \mu \mathrm{m}$ de espessura e corados com Hematoxilina e Eosina, LUNA, Resorcina-Fucsina, Pico-Sírius, imunohistoquímica para detecção de 8-iso-PGF2 $\alpha$, iNOS e nNOS em células do parênquima pulmonar. 


\subsubsection{Coloração de LUNA}

Foi utilizada a técnica de coloração LUNA para a avaliação da densidade de eosinófilos no pedaço de tecido pulmonar periférico. O tecido foi desparafinizado e hidratado até água destilada, as lâminas foram coradas na solução HematoxilinaEscarlate por 5 minutos e lavadas em água corrente com uma passagem em água destilada. Foi diferenciado o núcleo em solução álcool-ácido a 1\% até a tonalidade nuclear desejada. As lâminas foram lavadas novamente em água corrente e reveladas em solução de carbonato de lítio, até que os eosinófilos da seção ficassem vermelhos (15 segundos aproximadamente). Ao final todo o processo, o tecido foi desidratado em álcool 95\%, 100\% e xilol com duas mudanças cada solução.

Com o método de morfometria convencional, foi avaliada a densidade de eosinófilos nos septos alveolares das fatias de tecido pulmonar periférico. Utilizando um retículo de 100 pontos acoplado à ocular do microscópio, foi quantificado o número de pontos que incidiam no tecido alveolar em cada campo e o número de eosinófilos presentes nos septos alveolares. A densidade de eosinófilos foi determinada pelo número de células positivas de cada campo dividido pela área de tecido. As medidas foram expressas por eosinófilos $/ 10^{4} \mu \mathrm{m}^{2}$. A contagem foi feita em 10 campos de fragmento de tecido pulmonar periférico em cada animal em um aumento de 1000x. 


\subsubsection{Imunohistoquímica para Detecção de Células nNOS Positivas no Septo Alveolar}

Foi retirado um fragmento pulmonar periférico e fixado por congelação. A imunohistoquímica foi realizada de acordo com o protocolo previamente descrito por Coers et al. (1998). Para tanto, os cortes foram incubados (30 min em temperatura ambiente) com uma solução bloqueadora contendo soro de camundongo normal (Dako Corp., Carpintria, CA). Anticorpo monoclonal de camundongo anti-nNOS, IgG2a (nNOS/NOS Type I - Transduction Laboratories N31020) foi utilizado como anticorpo primário (incubado durante toda a noite em temperatura ambiente, diluição 1:150 em tampão TRIS). Após três lavagens em tampão TBS por 5 minutos, os cortes foram incubados com anticorpo secundário (LSAB+AP Link Universal) por 30 minutos a $37^{\circ} \mathrm{C}$ em câmara úmida. Os cortes foram então lavados 3 vezes com tampão TBS por 5 min e cobertos com fosfatase alcalina pré-diluída ( $L S A B+A P$ - Streptavidin AP- Dako Corp., Carpintria, CA), por 30 minutos, seguido de incubação com substrato Fast Red TR (Sigma Chemical CO, St. Louis, MO), por 6 min e submetidos à contra-coloração com hematoxilina por 1 minuto.

Foi utilizado um microscópio óptico comum (CH30, Olympus, Japão) e a técnica de contagem de pontos (Weibel, 1963) com o auxílio de um retículo de 100 pontos e 50 retas, com $1 \mathrm{~mm}$ de extensão, sobreposto à ocular deste microscópio. (Figura 7). A área total do retículo é de $10^{4} \mu \mathrm{m}^{2}$. Foram contadas todas as células 
nNOS positivas presentes nas paredes alveolares no aumento de 1000X. Os resultados foram expressos como células por unidade de área $\left(10^{4} \mu \mathrm{m}^{2}\right)$.

\subsubsection{Imunohistoquímica para Detecção de Células iNOS Positivas no Septo} Alveolar

A imunohistoquímica utilizada para a pesquisa do anticorpo em tecido foi realizada pelo método Biotina-estreptavidina peroxidase para o anticorpo iNOS. Os cortes histológicos a $5 \mu \mathrm{m}$ de espessura foram colocados em lâminas silanizadas (3-Aminopropil-trietoxi-silano - Sigma). As lâminas foram desparafinadas e hidratas e, na seqüência, o bloqueio da peroxidase endógena com água oxigenada $\left(\mathrm{H}_{2} \mathrm{O}_{2}\right)$ 10V 3\% 7 vezes de 5 minutos cada. Foi então feita a lavagem com água e PBS. A recuperação antigênica foi obtida através de alta temperatura. Após este período, as lâminas foram lavadas em PBS. Finalizada a etapa dos bloqueios, a solução com o anticorpo primário iNOS título 1:400 (LabVision, NeoMarkers, Fremont CA cód. RB-9242-P) foi aplicada nos cortes histológicos dos animais em estudo assim como nos controles, tanto positivo quanto negativo (aplicado apenas BSA) e, em seguida, as lâminas foram incubadas durante todo o período da noite. As lâminas então foram lavadas em PBS e incubadas com o kit Vector ABC Elite (HRP, cód. PK-6101, Vector Laboratories, INC, Burlingame,CA). Após esta etapa, as lâminas foram lavadas em PBS e seguiu-se a revelação pelo cromógeno 3,3 Diaminobenzidine (DAB) (DakoCitomation, Carpinteria, CA, EUA, Cód. K3468). As lâminas foram lavadas abundantemente em água corrente e contra-coradas com 
Hematoxilina de Harris (Merck, Darmstadt, Alemanha). Em seguida, as mesmas foram lavadas em água corrente, desidratadas, diafanizadas e montadas com resina para microscopia Entellan (Merck, Darmstadt, Alemanha).

A contagem de células positivas para a expressão de iNOS foi realizada conforme descrito no item análise histopatológica e avaliação da densidade de eosinófilos e células nNOS positivas. As células positivas para iNOS foram analisadas sob aumento de 1000X em 10 campos por tecido e expressas como células $/ 10^{4} \mu \mathrm{m}^{2}$.

\subsubsection{Coloração de Picro-Sírius}

Esta coloração foi utilizada para a contagem da densidade fibras colágenas no septo alveolar. Os cortes foram desparafinados e levados à água. Na seqüência as lâminas foram coradas por 1 hora com Picro-Sírius à temperatura ambiente e posteriormente foram lavadas em água corrente por 5 minutos. Após esta etapa, os cortes foram corados pela Hematoxilina de Harris por 6 minutos e posteriormente as lâminas foram lavadas em água corrente por 10 minutos e por fim montadas. 


\subsubsection{Coloração de Resorcina-Fucsina}

Utilizando esta coloração foram estudadas as fibras elásticas propriamente ditas e as elaunínicas. Para Tanto, os cortes foram desparafinados e hidratados em álcool 95. Posteriormente foram corados pela Resorcina-Fucsina por 1 hora e lavados em água corrente por 5 minutos. Foram então realizadas duas trocas de álcool $70^{\circ}$ durante 10 minutos, sendo esta etapa a da diferenciação das fibras. Em seguida foram desidratados, diafanizados e posteriormente montados. A leitura foi realizada no analisador de imagens e os resultados foram expressos em porcentagem de área de fibras positivas em relação à área do septo alveolar.

\subsubsection{Imunohistoquímica para Actina}

Através de análise imunohistoquímica foi avaliada a presença de actina utilizando a pesquisa dos marcadores Anti-Human Smooth Muscle Actin (clone 1A4, marca Dako,A/S, Dinamarca). O estudo foi realizado pelo através de método LSAB ${ }^{\circledR}$ - HRP System Peroxidase. Os cortes histológicos de $3 \mu \mathrm{m}$ de espessura foram colocados em lâminas silanizadas (3-Aminopropil-trietoxi-silano- Sigma) e 
posteriormente desparafinizados. Após esta fase, as lâminas foram hidratadas em banhos de álcool absoluto, $95^{\circ} \mathrm{e} 70^{\circ}$ por 1 minuto e lavadas em água corrente abundante seguida de lavagem com água deionizada. Na seqüência foi realizado o bloqueio da peroxidase endógena por água oxigenada 10 volumes, 5 minutos por 7 vezes. Posteriormente, as lâminas foram lavadas em água corrente abundante, seguida de lavagem com água deionizada e incubadas em PBS. A recuperação antigênica foi obtida por alta temperatura para o marcador Actina Músculo Liso em solução de Citrato pH 6,0 por 30 minutos. Após este período, as lâminas imersas nesta solução foram resfriadas em temperatura ambiente por 20 minutos e lavadas em PBS, o que foi repetido por 3 vezes. Previamente a incubação do anticorpo primário, foi realizada bloqueio de proteínas pelo leite desnatado a 2\% por 10 minutos. Então as lâminas foram lavadas em PBS e incubadas pelo Kit $\angle S A B \circledR$ Plus-HRP (código K-0690 DAKO Corporation, Carpinteria, EUA) e foi feita a revelação pelo cromógeno 3,3 Diaminobenzidina (DAB) Sigma Chemical Co, St Louis, MO, EUA. Finalmente, as lâminas foram lavadas abundantemente em água corrente, contra-coradas com Hematoxilina de Harris (Merck, Darmstadt, Alemanha) e montadas com resina para microscopia (Entellan, Merck, Darmstadt, Alemanha). 


\subsubsection{Imunohistoquímica para Detecção de 8-iso-PGF2 $\alpha$ no Septo Alveolar}

A imunohistoquímica para detecção de isoprostano foi realizada utilizando o anticorpo anti-8-epi-PGF2 $\alpha$ (Oxford Biomedical Research, Rochester Hills, MI, EUA) com diluição de 1: 500. Os blocos foram desparafinados e lavados 7 vezes por 5 minutos com $\mathrm{H}_{2} \mathrm{O}_{2} \mathrm{IOV} 3 \%$ para inibir a atividade de peroxidase endógena. Após banhos em PBS e água, a recuperação do antígeno foi realizada com tripsina por 20 minutos. Após isto, 3 banhos de 3 minutos/cada em PBS foram realizados. Os cortes foram incubados com anticorpo anti-8-epi-PGF2 $\alpha$ diluídos em BSA durante toda a noite. Após lavagem em PBS, Vectastain ABC Kit foi usado como anticorpo secundário (Vector Elite PK-6105, Burlingame, CA, EUA) e 3,3 Diaminobenzidina (DAB) (Sigma Chemical Co., St. Louis, MO, EUA) foi usado como cromógeno. Os cortes foram contra-corados com hematoxilina de Harris (Merck). A análise de imagem foi feita através do programa Image Pro Plus (versão 4.5), instalado em um microcomputador de padrão IBM acoplado a um microscópio e câmera fotográfica digital. Em cada caso foram capturadas 10 imagens em aumento de 400x vezes.

Em cada imagem foi selecionada a área de interesse e aplicado um filtro prémontado, com base em um número representativo de fotos, marcando as áreas positivas. Para cada imagem foram coletados: (1) área total; (2) área positiva com base no padrão estabelecido; (3) Densidade média de cor caracterizada pela 
média da intensidade de cor do padrão RGB (0 a 255), sendo que valores maiores representam áreas mais claras; (4) Densidade óptica integrada (IOD) correspondente à densidade média de cada objeto marcado multiplicado pela área do mesmo. A divisão do valor da somas dos IODs de cada objeto pela área total de positividade fornece um valor entre 0 e 255 correspondente à media ponderada da intensidade de cor, dados que foram utilizados para a análise estatística. 


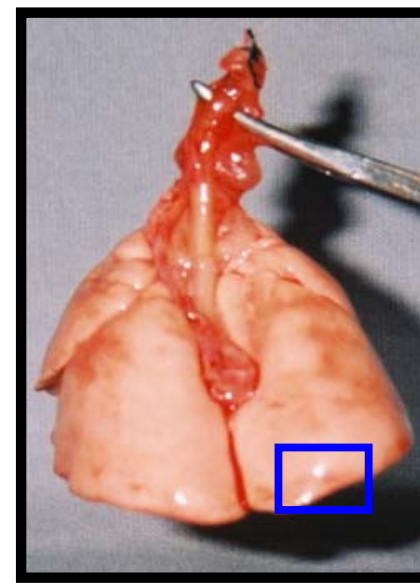

\section{I - Fatia Pulmonar Periférica}

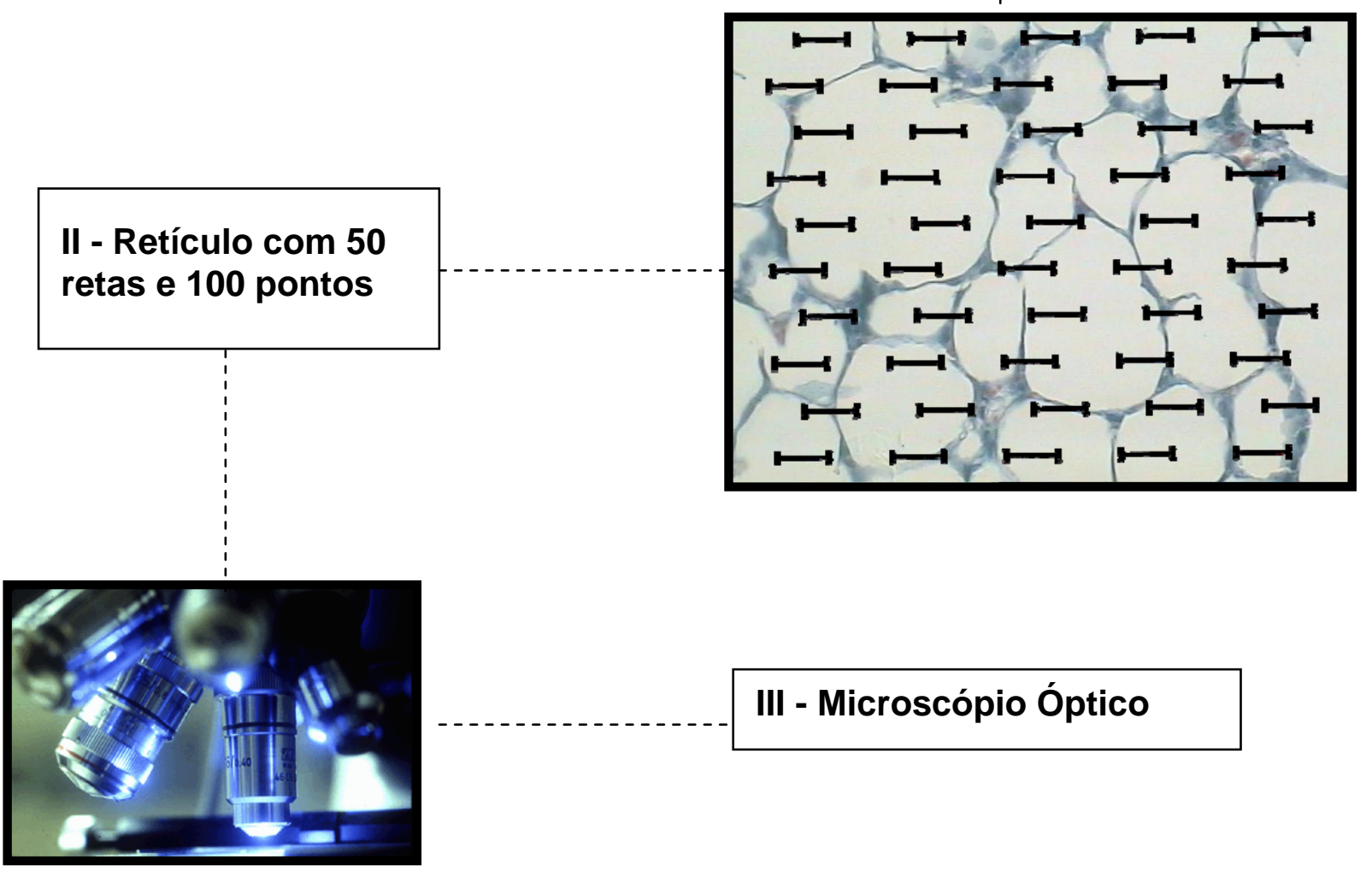

Figura 7. Esquema da avaliação morfométrica e histopatológica. I - Retirada dos pulmões em bloco e esquema da porção distal do pulmão esquerdo que foi retirado para o estudo. II - Retículo composto de 50 retas e 100 pontos foi acoplado à ocular do microscópio e foram realizadas a leituras em 400X e 1000X sobre 0 parênquima pulmonar distal. III - Microscópio óptico. 


\subsection{Análise Estatística}

A análise estatística foi realizada através do programa Sigma Stat (Jandel Corporation, San Rafhael, CA, EUA). Os resultados foram analisados pela técnica de análise de variância dois fatores (ANOVA), sendo um fator a sensibilização e o outro o tratamento (inibição crônica das óxido nítrico sintases). Os resultados obtidos foram paramétricos e, portanto, expressos em média e erro padrão e a representação gráfica foi realizada na forma de barras paralelas. Para realizar as comparações múltiplas entre os grupos utilizou-se o teste de Holm-Sidak ou Student-Newman-Keuls. Foi considerado estatisticamente significativo um $\mathrm{p}<0,05$ para todas as análises (Zar, 1984). 


\subsection{Tempo de Inalação}

Durante as quatro primeiras inalações não foram observados sinais de desconforto respiratório em nenhuma das cobaias do estudo. Na Figura 8 observa-se as médias e erros padrão dos valores do tempo de inalação (segundos) correspondentes à sétima inalação. Houve redução significativa do tempo de inalação das cobaias dos grupos que receberam inalações repetidas de ovoalbumina (OVA: média \pm erro padrão: $486,4 \pm 114,14$; OVAL: 495,62 $\pm 114,53$ ) comparativamente ao controles (SF: 900,0; SF-L: 900,0 segundos, $p<0,05)$. Não houve diferenças entre os grupos controles (SF e SF-L) bem como em relação aos grupos de cobaias sensibilizadas (OVA e OVA-L). 


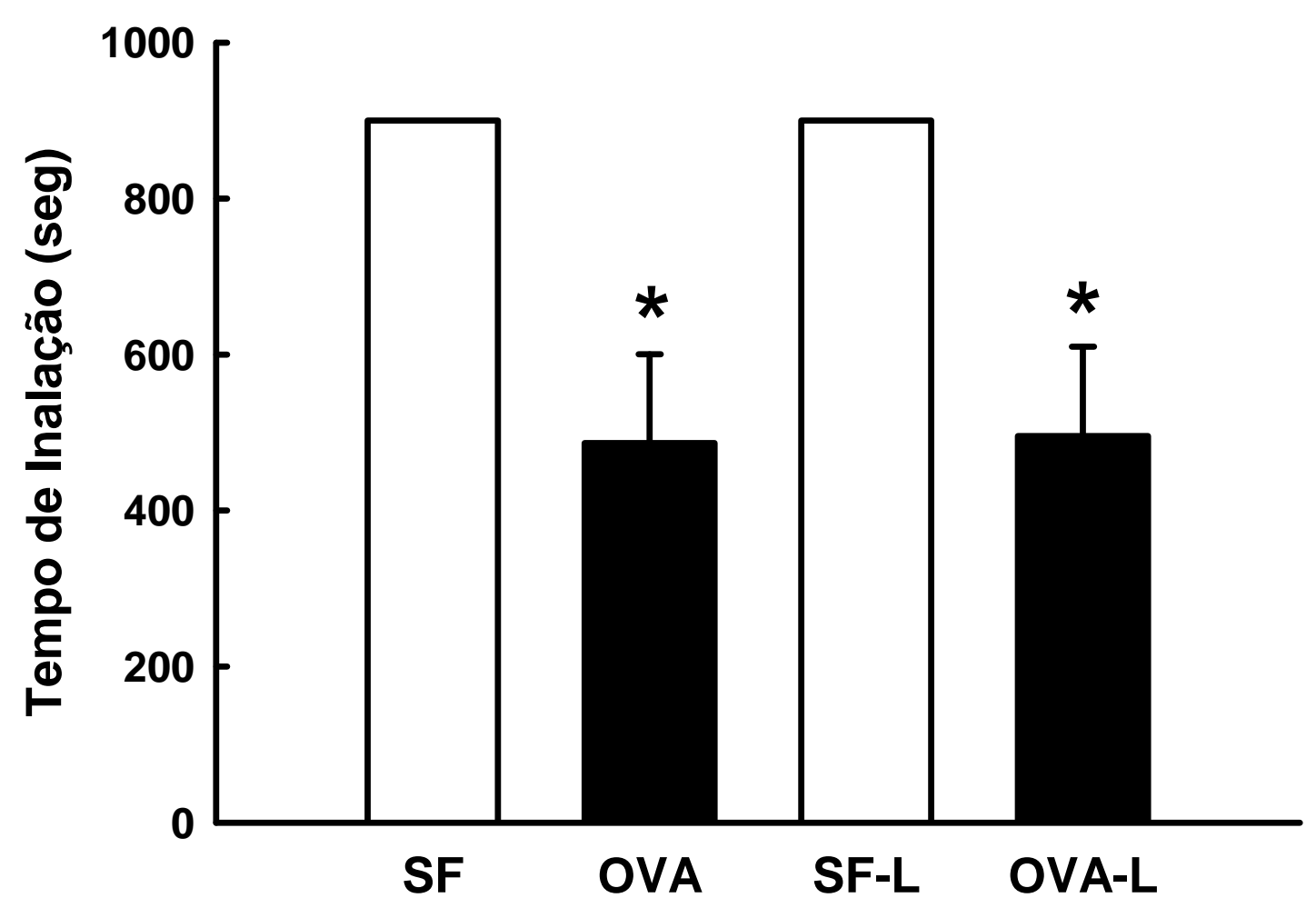

Figura 8. Valores de tempo de inalação (segundos) dos grupos que receberam inalações com ovoalbumina (grupo OVA e OVA-L) e dos demais animais dos grupos controle SF e SF-L. O gráfico está apresentado na forma de barras paralelas, no qual se demonstra média e erro padrão do tempo que as cobaias permaneceram em contato com 0 antígeno na $7^{\mathrm{a}}$ inalação. ${ }^{*} p<0,05$ comparativamente aos controles SF e SF-L. Os animais do grupo controle (SF) permaneceram 900 segundos em todas as inalações. 


\subsection{Mecânica de Tecido Pulmonar Periférico}

Com relação às medidas de mecânica oscilatória pulmonar em condições basais e pós-desafio com ovoalbumina, obtivemos os seguintes resultados com relação à resistência e elastância teciduais e a histerisividade.

A resistência tecidual basal aumentou no grupo exposto à ovoalbumina (OVA: $1,21 \pm 0,05 \times 10^{2} \mathrm{~N} . \mathrm{s} / \mathrm{m}^{2}$ ) comparativamente aos expostos a inalações com soro fisiológico (SF: 1,06 \pm 0,05, SF-L: 1,05 \pm 0,05 $x 10^{2} \mathrm{~N} . \mathrm{s} / \mathrm{m}^{2}, \mathrm{p}<0,001$ para todas as comparações). O tratamento com LNAME em animais expostos à ovoalbumina (OVA-L: $1,01 \pm 0,05 \times 10^{2} \mathrm{~N} . \mathrm{s} / \mathrm{m}^{2}$ ) reduziu a resistência tecidual basal no grupo OVA-L comparativamente aos animais do grupo OVA.

A resistência tecidual aumentou no grupo exposto à ovoalbumina (OVA: $1,56 \pm 0,05 \times 10^{2} \mathrm{~N} \cdot \mathrm{s} / \mathrm{m}^{2}$ ) comparativamente aos expostos a inalações com soro fisiológico após o desafio antigênico (SF: 1,25 \pm 0,06, SF-L: 1,12 \pm $0,06 \times 10^{2} \mathrm{~N} . \mathrm{s} / \mathrm{m}^{2} \mathrm{p}<0,001$ para todas as comparações). O tratamento com L-NAME em animais expostos à ovoalbumina. (OVA-L: 1,19 $\pm 0,05$ $x 10^{2} \mathrm{~N} . \mathrm{s} / \mathrm{m}^{2}$ ) reduziu a resistência tecidual após o desafio comparativamente aos animais do grupo OVA $(p<0,01)$. 
A elastância tecidual basal aumentou no grupo exposto à ovoalbumina (OVA: $1,70 \pm 0,06 \times 10^{4} \mathrm{~N} / \mathrm{m}^{2}$ ) comparativamente aos expostos a inalações com soro fisiológico (SF: $1,50 \pm 0,06$, SF-L: $1,47 \pm 0,06$ $x 10^{4} \mathrm{~N} / \mathrm{m}^{2} \mathrm{p}<0,001$ para todas as comparações). O tratamento com L-NAME em animais expostos a ovoalbumina. (OVA-L: $1,40 \pm 0,05 \times 10^{4} \mathrm{~N} / \mathrm{m}^{2}$ ) reduziu a elastância tecidual comparativamente aos animais do grupo OVA $(p<0,01)$.

A elastância tecidual aumentou nos grupos expostos a ovoalbumina (OVA: $1,99 \pm 0,06 \times 10^{4} \mathrm{~N} . \mathrm{s} / \mathrm{m}^{2}$ ) após o desafio antigênico comparativamente aos expostos a inalações com soro fisiológico (SF: 1,63 \pm 0,06, SF-L: 1,2 \pm $0,06 \times 10^{4} \mathrm{~N} / \mathrm{m}^{2}, \mathrm{p}<0,001$ para todas as comparações). O tratamento com LNAME em animais expostos a ovoalbumina (OVA-L: $1,59 \pm 0,6 \times 10^{4} \mathrm{~N} / \mathrm{m}^{2}$ ) reduziu todas as respostas quando comparados aos animais do grupo OVA $(p<0,01)$

Não houve diferenças entre os grupos em relação à avaliação da histerisividade tanto nos valores basais (SF: $0,04 \pm 0,00$; SF-L: $0,05 \pm 0,00$;

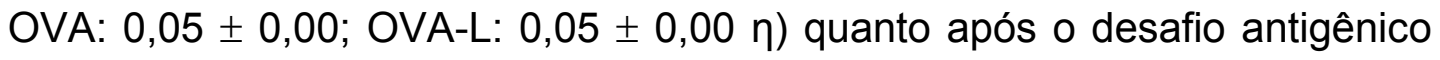
(SF: $0,04 \pm 0,00 ;$ SF-L: $0,05 \pm 0,00 ;$ OVA: $0,05 \pm 0,00 ;$ OVA-L: $0,05 \pm 0,00$ $\eta)$. 


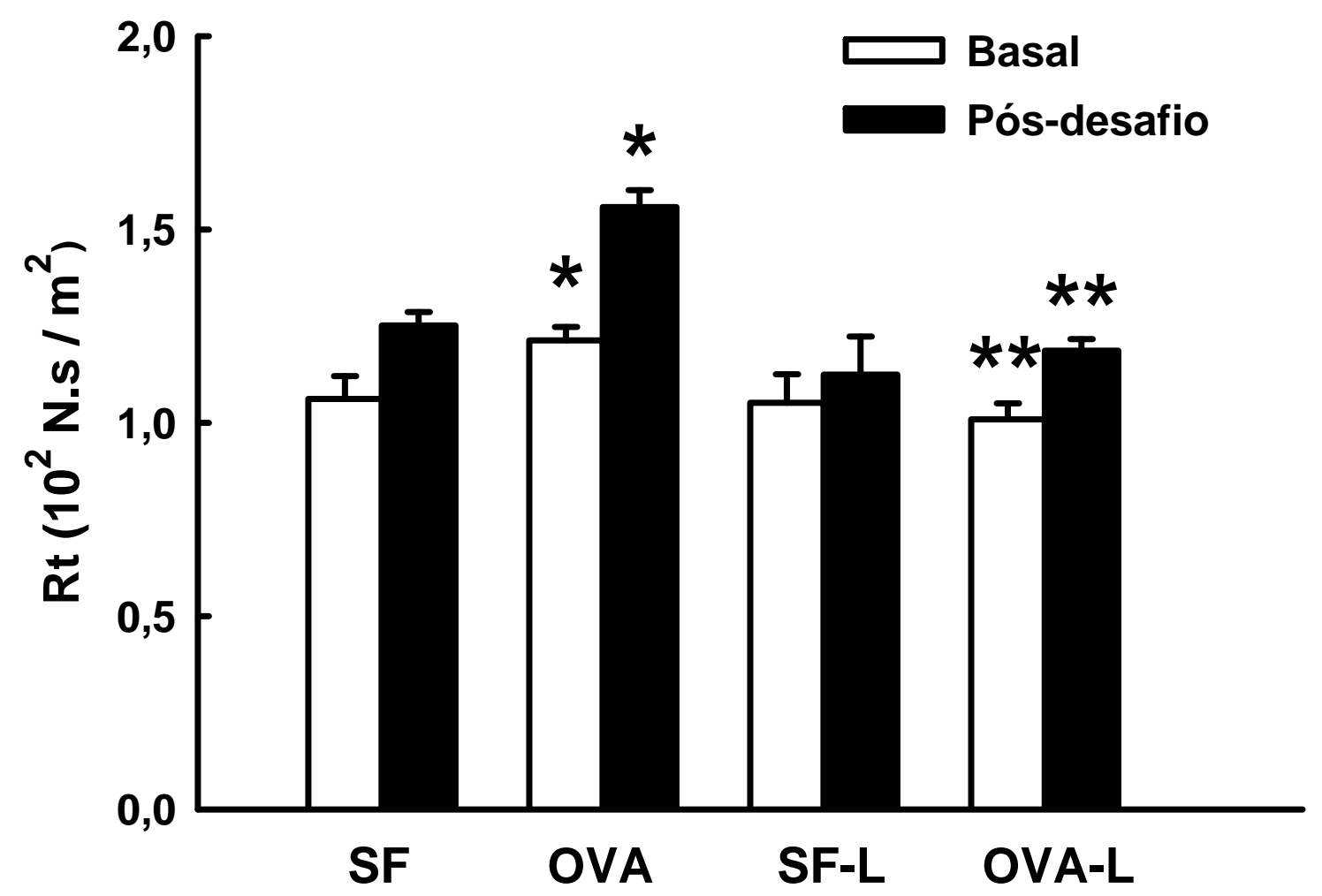

Figura 9. Valores de resistência basal e pós-desafio antigênico dos grupos que receberam sete inalações com ovoalbumina ou soro fisiológico e que foram tratados com L-NAME ou veículo. Valores estão expressos em média e erro padrão. * $\mathrm{p}<0,05$ comparado ao basal e pós-desafio do grupo $\mathrm{SF}$, respectivamente. ${ }^{* *} p<0,001$ comparado ao grupo OVA respectivamente. 


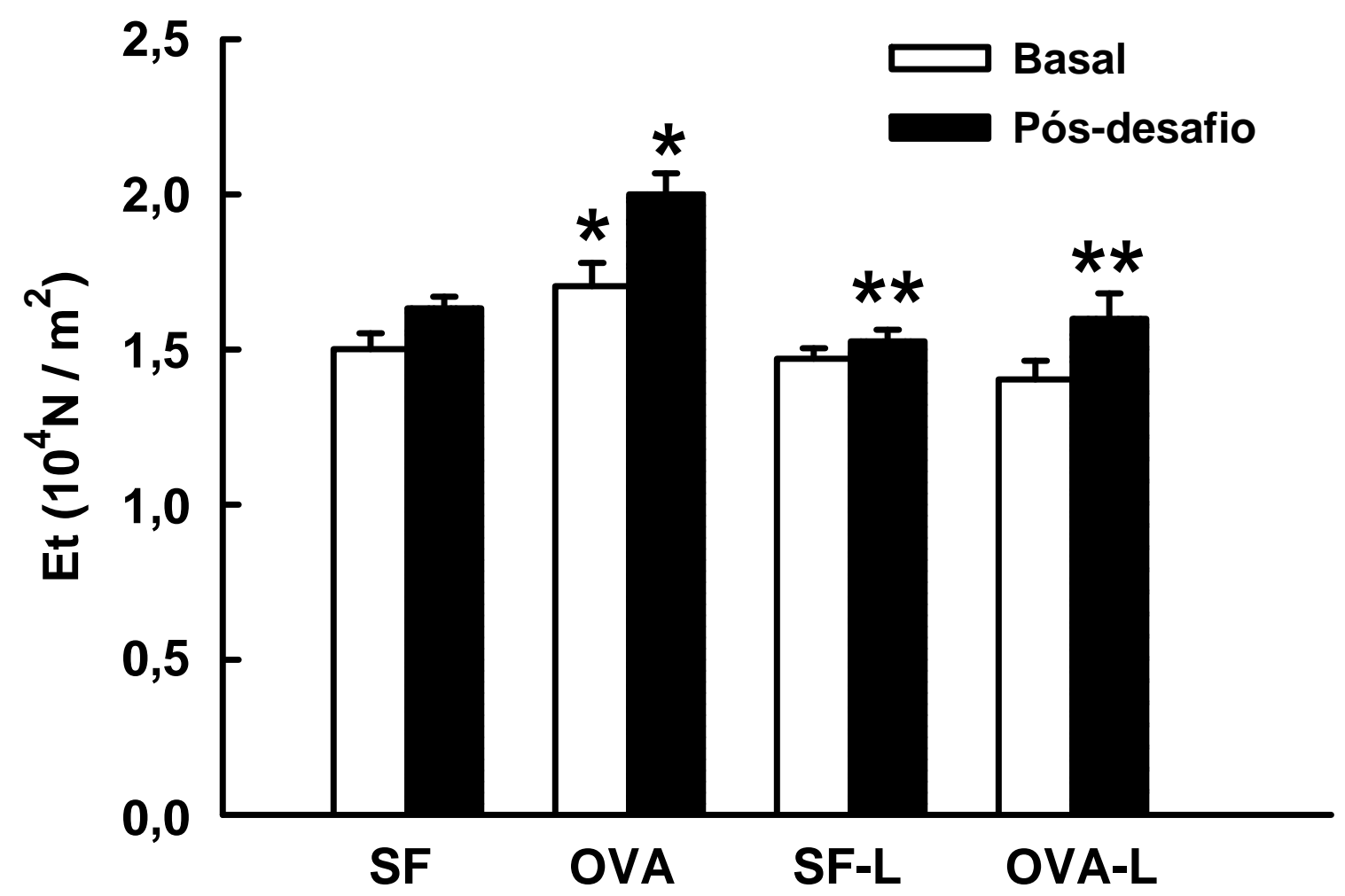

Figura 10. Valores de elastância basal e pós-desafio antigênico dos grupos que receberam sete inalações com ovoalbumina ou soro fisiológico e que foram tratados com L-NAME ou veículo. Valores são expressos em média e erro padrão. " $\mathrm{p}<0,05$ comparado ao basal e pós-desafio do grupo SF respectivamente. ${ }^{* *} p<0,001$ comparado ao grupo OVA respectivamente. 


\section{3. Análise Morfométrica}

Todos os grupos mostraram composição anatômica similar nas fatias de tecido pulmonar periférico com aproximadamente $60 \%$ de tecido alveolar. (Tabela 1).

Tabela 1. Proporção de estruturas de alvéolos, vasos e vias aéreas no fragmento de tecido pulmonar periférico. Os valores foram expressos em porcentagens (média \pm erro padrão).

\begin{tabular}{|c|c|c|c|}
\hline Grupos & Alvéolos (\%) & Vasos (\%) & Vias aéreas (\%) \\
\hline SF & $56,20 \pm 1,82$ & $1,61 \pm 0,5$ & $3,51 \pm 1,16$ \\
\hline OVA & $64,29 \pm 1,38$ & $1,44 \pm 0,38$ & $2,84 \pm 0,97$ \\
\hline SF-L & $61,8 \pm 1,49$ & $1,36 \pm 0,46$ & $2,16 \pm 0,97$ \\
\hline OVA-L & $57,95 \pm 1,59$ & $1,05 \pm 0,30$ & $2,56 \pm 0,84$ \\
\hline
\end{tabular}




\subsubsection{Densidade de Eosinófilos}

A densidade de eosinófilos no parênquima está representada na Figura 11. Observamos que houve um aumento na densidade de eosinófilos nos animais expostos à ovoalbumina (OVA: $6,23 \pm 0,8810^{4} \mu \mathrm{m}^{2}$; OVA-L: $8,52 \pm 1,1610^{4} \mu \mathrm{m}^{2}$ ) quando comparados aos controles (SF: $4,70 \pm 0,70$ $10^{4} \mu \mathrm{m}^{2}$, SF-L: $\left.4,36 \pm 1,0410^{4} \mu \mathrm{m}^{2}, \mathrm{p}<0,05\right)$. O tratamento com L-NAME não afetou estas respostas.

\subsubsection{Densidade de Células nNOS e iNOS Positivas}

Na Figura 12 observamos o número de células nNOS e iNOS positivas presentes no fatia de parênquima pulmonar periférico. Houve um aumento significativo no número de células nNOS positivas nos animais do grupo ovoalbumina (OVA: $3,56 \pm 0,4110^{4} \mu \mathrm{m}^{2}$ ) comparativamente aos controles (SF: $\left.2,41 \pm 0,3710^{4} \mu \mathrm{m}^{2}, \mathrm{SF}-\mathrm{L}: 1,76 \pm 0,04110^{4} \mu \mathrm{m}^{2} ; \mathrm{p}<0,05\right) . \mathrm{O}$ tratamento com L-NAME reduz o número das células nNOS positivas em animais expostos à ovoalbumina (OVA-L: $1,13 \pm 0,41 \quad 10^{4} \mu \mathrm{m}^{2}$ ) comparativamente aos animais dos grupos OVA $(p<0,001)$. Não houve diferença entre os grupos SF e SF-L. 
$\mathrm{Na}$ Figura 12 observamos também o número de células iNOS positivas presentes no fatia de parênquima pulmonar periférico. Houve um aumento significativo no número de células iNOS positivas nos animais do grupo ovoalbumina (OVA: 8,63 $\pm 0,6010^{4} \mu \mathrm{m}^{2}$ ) comparativamente aos controles (SF: $6,33 \pm 0,6410^{4} \mu \mathrm{m}^{2} ;$ SF-L: $\left.4,88 \pm 0,9410^{4} \mu \mathrm{m}^{2} ; \mathrm{p}<0,05\right) . \mathrm{O}$ tratamento com L-NAME reduz o número das células iNOS positivas em animais expostos à ovoalbumina (OVA-L: $1,44 \pm 1,01 \quad 10^{4} \mu \mathrm{m}^{2}$ ) comparativamente aos animais dos grupos OVA $(p<0,001)$. Não houve diferença entre os grupos SF e SF-L. 


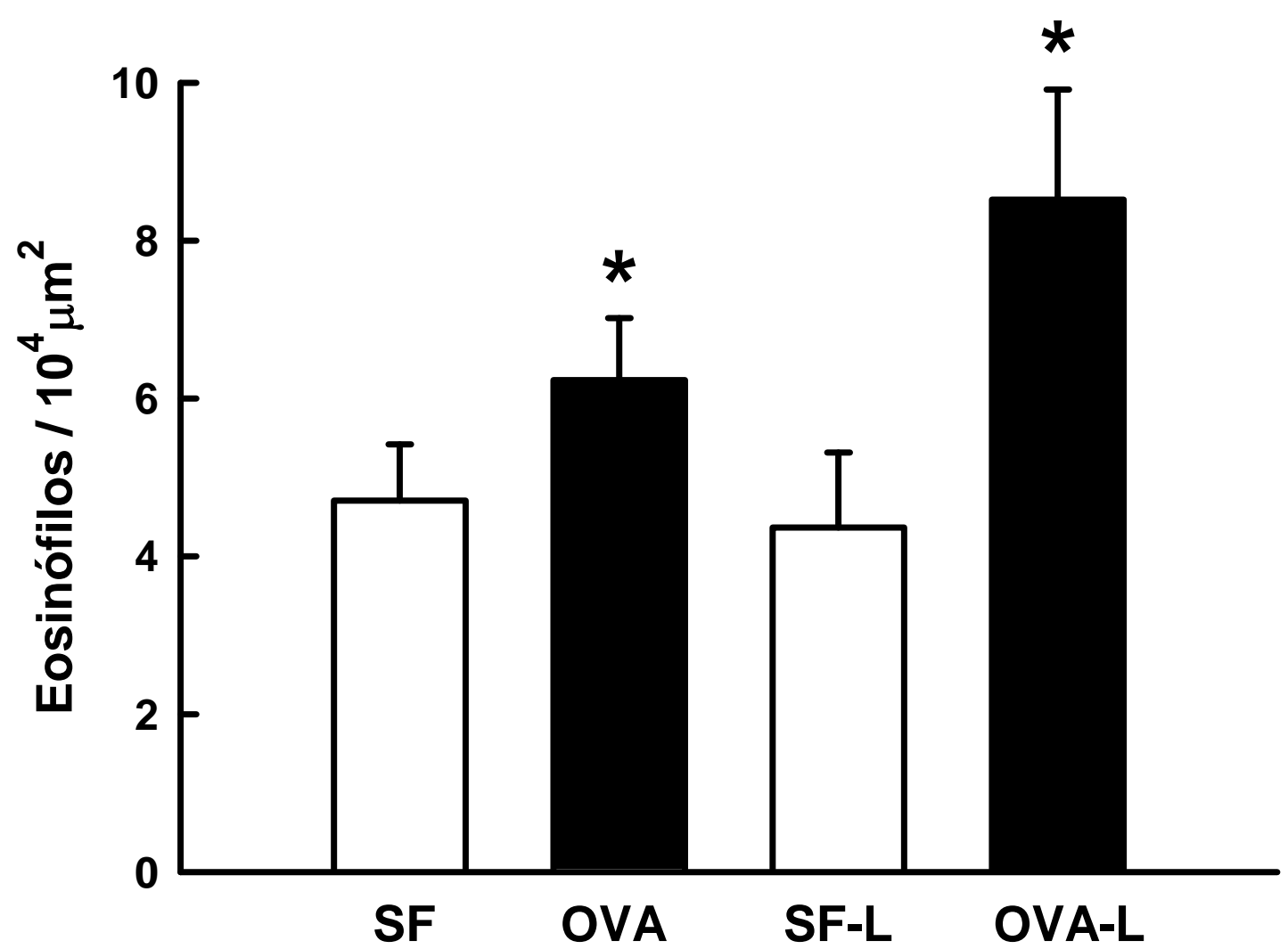

Figura 11. Densidade de eosinófilos no parênquima pulmonar em animais expostos a sete inalações com ovoalbumina ou soro fisiológico e tratados com L-NAME ou veículo. Os valores são expressos em média e erro padrão. ${ }^{*} p<0,001$ comparados com os grupos SF e SF-L. 


$$
\text { M. }
$$




\subsubsection{Análise do Remodelamento da Matriz Extracelular}

\section{Proporção de Volume de Fibras Elásticas e Colágenas}

A proporção de volume de fibras colágenas no septo alveolar está demonstrada na Figura 13. Houve um aumento na proporção de volume de fibras colágenas nos animais expostos à ovoalbumina (OVA: 18,31 $\pm \cdot 0,86$, OVA-L: $19,71 \pm 0,86 \%)$ comparativamente ao observado nos animais expostos à solução fisiológica (SF: $9,84 \pm$ 0,93, SF-L: $13,44 \pm 1,01 \%$, $p<0,001)$. Não houve diferenças na proporção de volume de fibras colágenas, nos animais do grupo OVA-L, comparativamente aos animais inalados com ovoalbumina e tratados com veículo de L-NAME.

A proporção de volume de fibras elásticas no septo alveolar está demonstrada na Figura 14. Houve um aumento na proporção de volume de fibras de fibras elásticas nos animais expostos à ovoalbumina (OVA: 16,19 \pm $0,61 \%$ ) comparativamente ao observado nos animais expostos à solução fisiológica (SF: $7,46 \pm 0,69$, SF-L: $11,46 \pm 0,75 \%, p<0,001$ ). Os animais expostos à ovoalbumina que receberam tratamento crônico com L-NAME (OVA-L: $13,05 \pm$ 0,65\%) apresentaram uma diminuição da proporção de volume de fibras elásticas no septo alveolar comparativamente aos animais do grupo OVA $(p<0,001)$. 


\subsubsection{Proporção de Volume de Actina}

Não houve diferenças na proporção de volume de actina no parênquima pulmonar periférico nos animais de todos os grupos experimentais (grupos OVA: 11,25 \pm 0,42, SF: 10,39 $\pm 0,48$, OVA-L: 9,96 \pm 0,48 SF-L: $11,47 \pm 0,48 \%)$. 


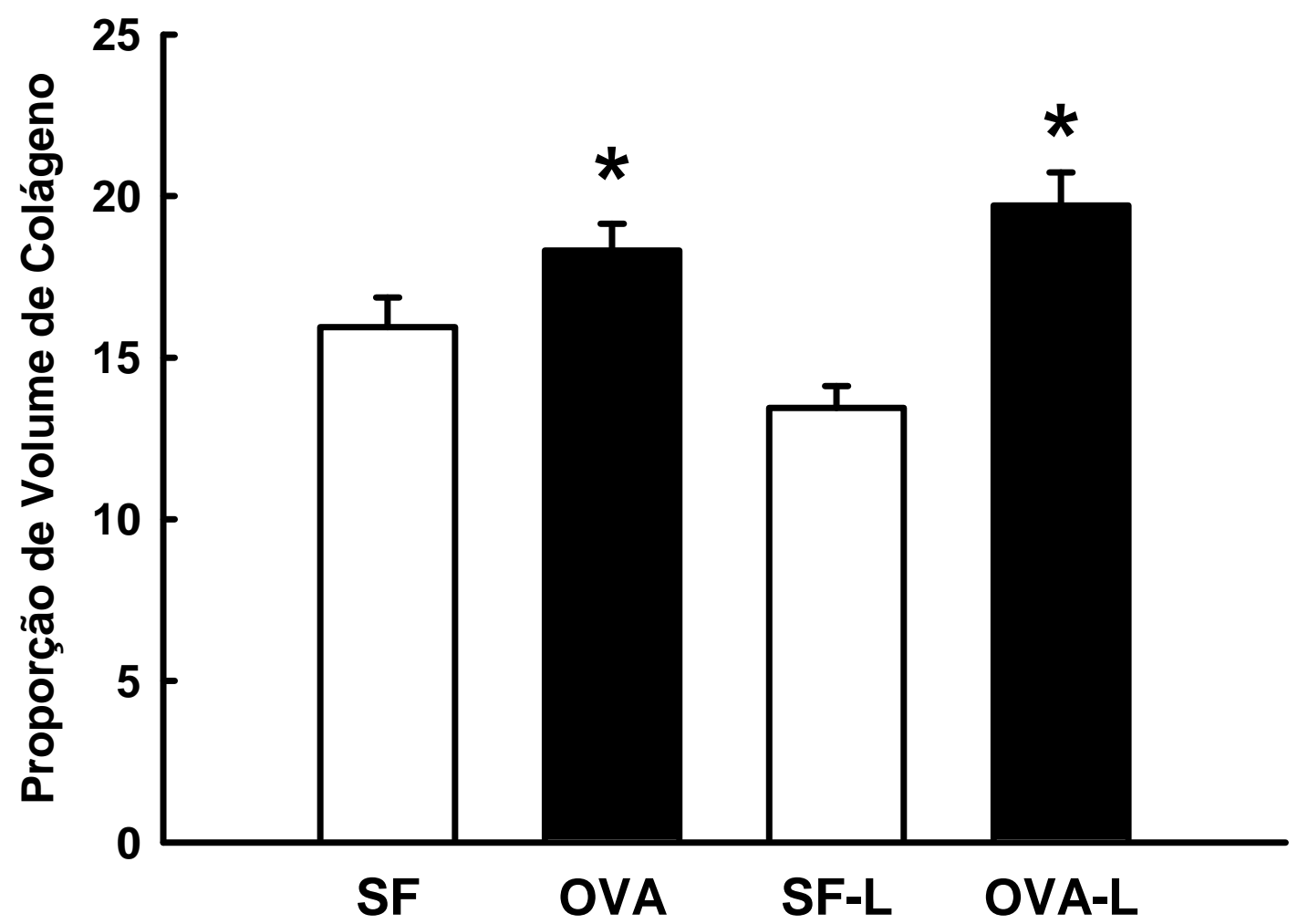

Figura 13. Proporção de volume de fibras colágenas no parênquima pulmonar de animais que receberam inalações com ovoalbumina e inalações com soro fisiológico e foram tratados cronicamente com L-NAME ou veículo. Valores são expressos em média e erro padrão. Resultados são expressos em porcentagem. ${ }^{*} p<0,001$ comparado ao grupo SF e SF-L. 


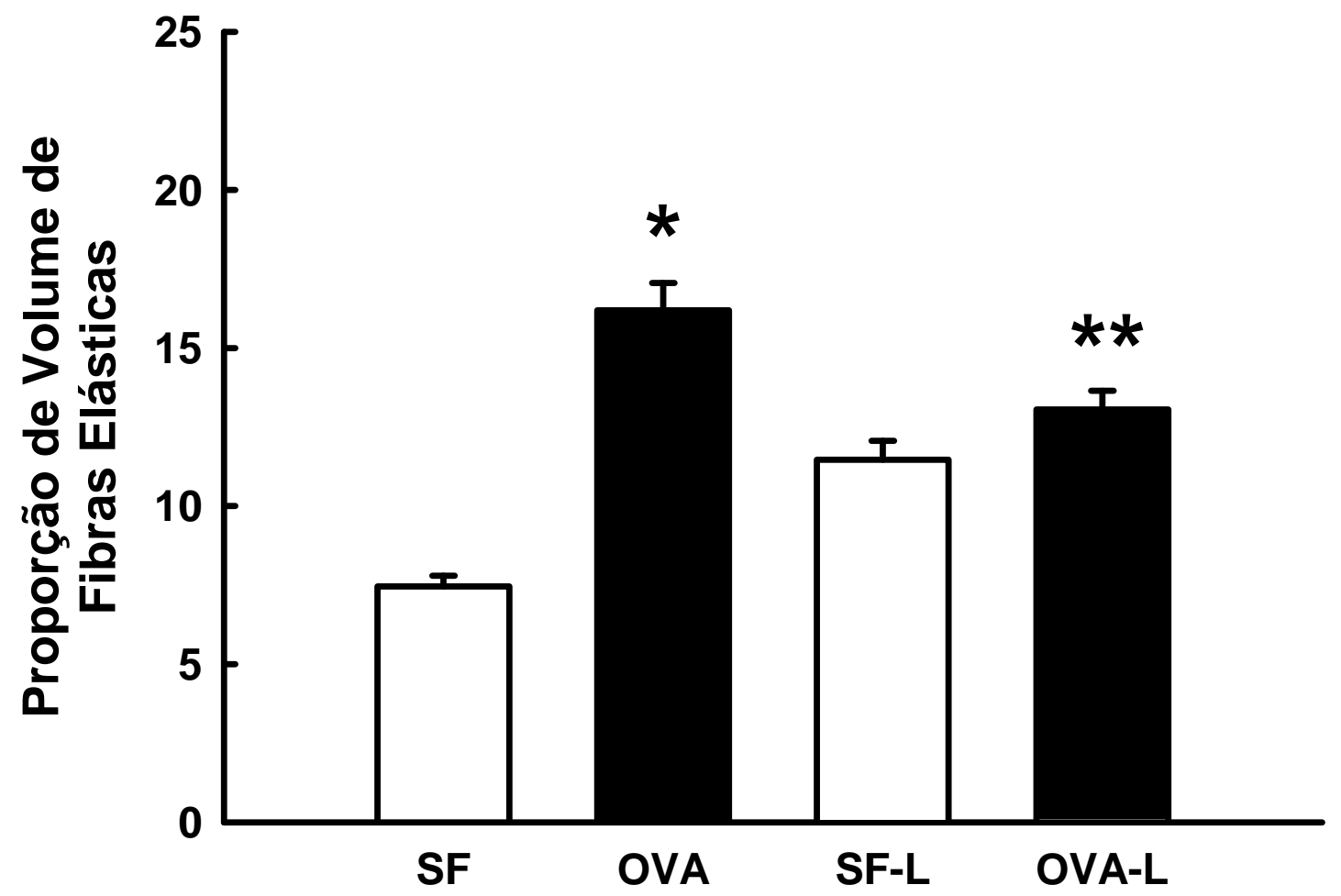

Figura 14. Proporção de volume de fibras elásticas no parênquima pulmonar de animais que receberam inalações com ovoalbumina e inalações com soro fisiológico e foram tratados cronicamente com L-NAME ou veículo. Valores são expressos em média e erro padrão. Resultados são expressos em porcentagem. ${ }^{*} p<0,001$ comparado aos grupos SF e SF-L. ${ }^{* *} p<0,001$ comparado ao grupo OVA. 


\subsubsection{Proporção de Volume de 8-iso-PGF2 $\alpha$}

A proporção de volume de 8-iso-PGF2 $\alpha$ no septo alveolar esta demonstrada na Figura 15. Os animais expostos à ovoalbumina (grupo OVA: $14,21 \pm 0,7 \%$ ) apresentaram um aumento na proporção de volume de 8-isoPGF2 $\alpha$ comparativamente ao observado nos animais controle (grupos SF: $5,42 \pm 0,9$ e SF-L: $3,29 \pm 0,89 \%, p<0,001)$. Os animais expostos à ovoalbumina que receberam tratamento crônico com L-NAME (OVA-L: 7,54 \pm 0,89\%) apresentaram diminuição na proporção de volume de 8-iso-PGF2 $\alpha$ comparativamente ao observado nos animais do grupo OVA $(p<0,001)$. Não houve diferença significativa entre os animais dos grupos controle. 


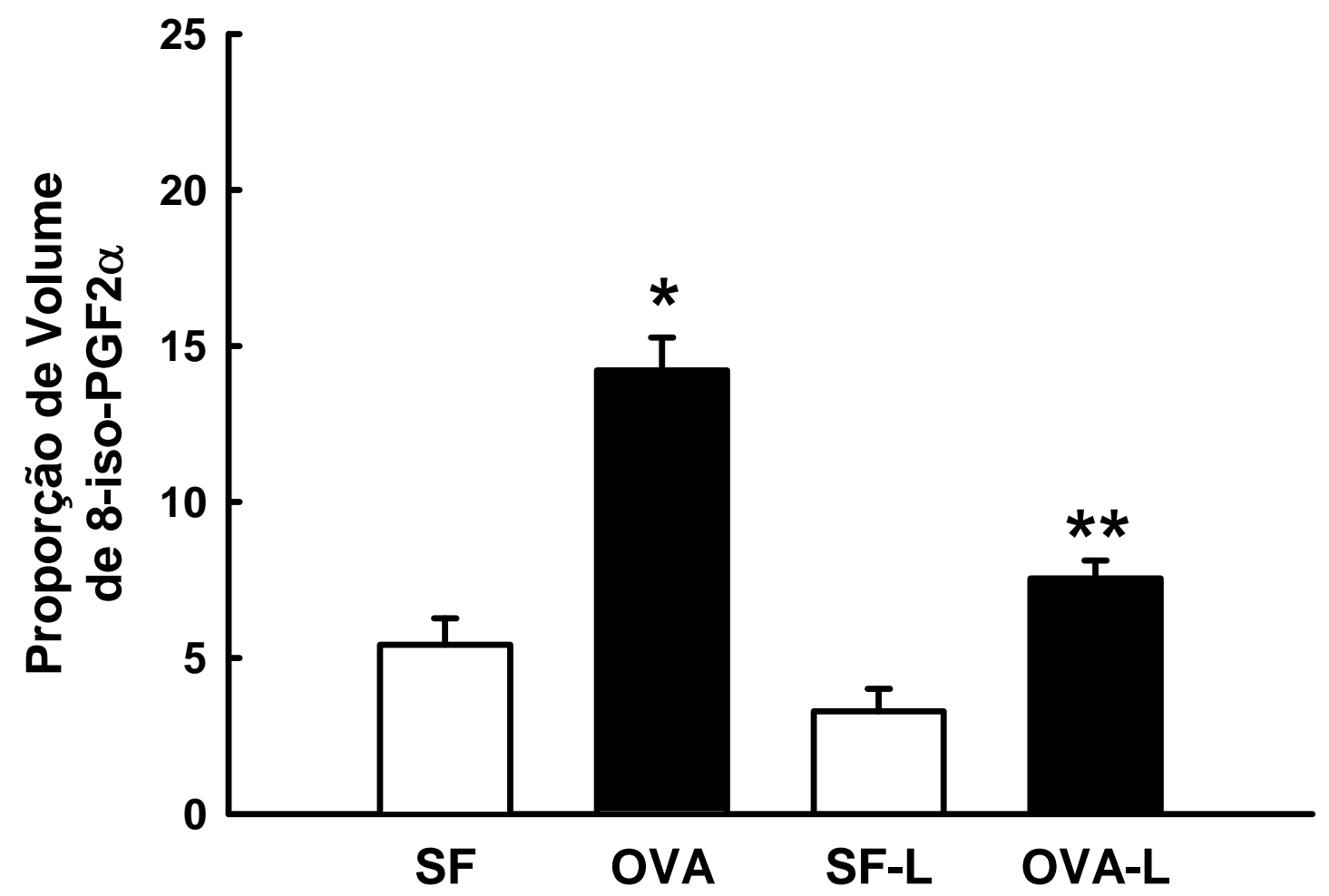

Figura 15. Proporção de volume do 8-iso-PGF2 $\alpha$ no septo alveolar de cobaias que receberam sete e inalações com ovoalbumina ou soro fisiológico e foram tratados cronicamente com L-NAME ou veículo. Valores são expressos em média e erro padrão. Resultados são expressos em porcentagem. ${ }^{*} p<0,001$ comparado ao grupo SF e SF-L. ${ }^{* *} p<0,001$ comparado ao grupo OVA. 

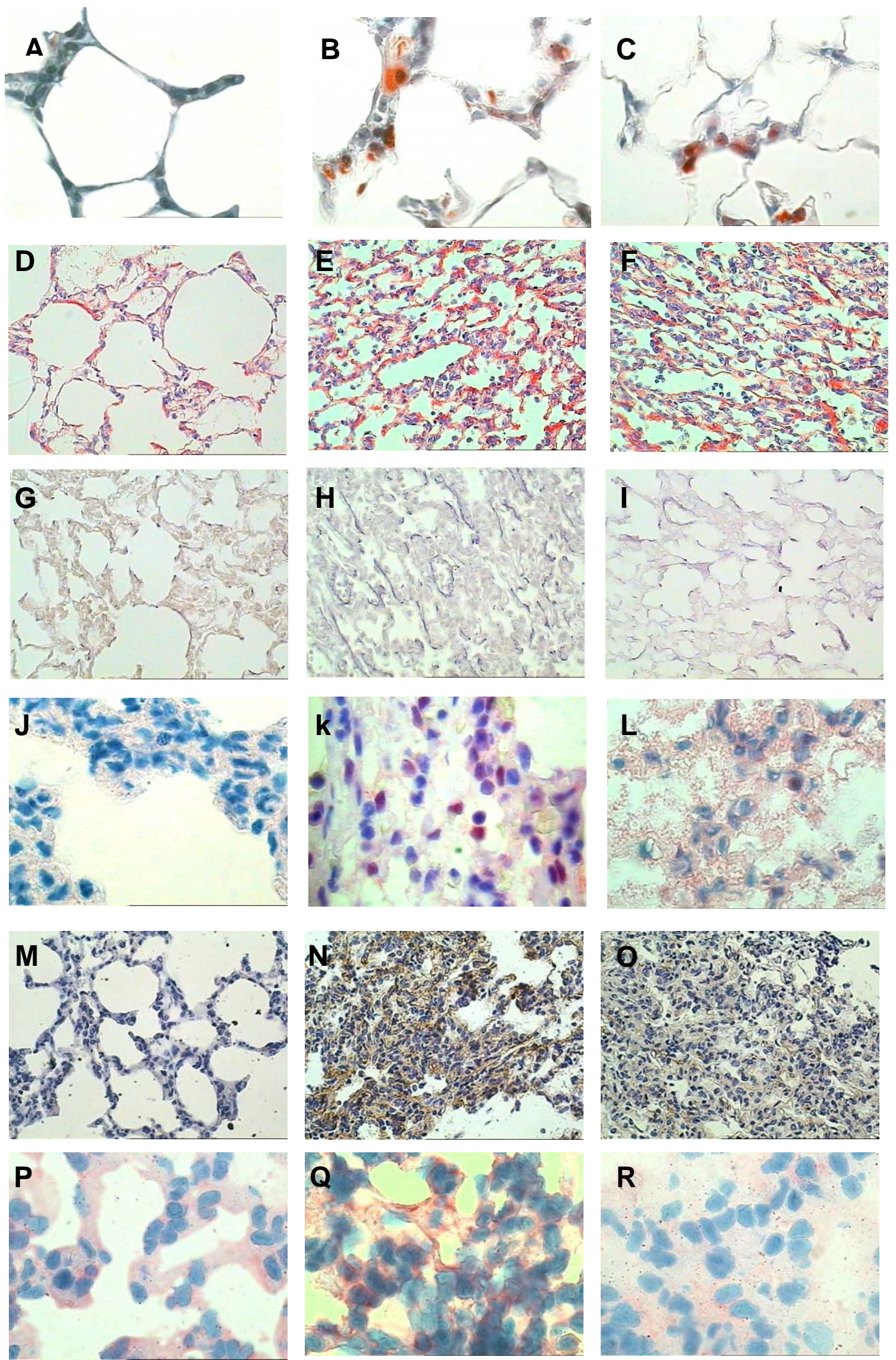
Figure 16. Fotomicrografias representativas do parênquima pulmonar distal coradas com LUNA (painéis A, B e C), Picro-Sírius (D, E e F), ResorcinaFucsina de Weigert (painéis $\mathrm{G}, \mathrm{H}$ e I), células nNOS positivas (painéis $\mathrm{J}, \mathrm{K}$ e L) e 8-iso- PGF2 $\alpha$ (painéis $M, N$ e O ), células iNOS positivas (painéis $P, Q$ e $R)$ em cobaias que receberam inalações com SF (A, D, G, J, M e P) ou aquelas que foram expostas cronicamente à ovoalbumina e tratadas com veículo $(B, E, H, K, N$ e $Q)$ ou tratadas cronicamente com L-NAME (C, F, I, $\mathrm{L}$, $\mathrm{O}$ e R). Nota-se que o tecido pulmonar de cobaias expostas à ovoalbumina apresenta infiltração eosinofílica,com deposição de colágeno e fibras elásticas no septo alveolar. O tratamento crônico com L-NAME diminui o conteúdo de fibras elásticas nos animais expostos à ovoalbumina, bem como o número de células nNOS e iNOS positivas, além da redução da expressão 8-iso-PGF2 $\alpha$ no tecido pulmonar periférico. 


\subsubsection{Correlação Histopatológica e Funcional}

Houve uma correlação positiva e significativa entre as respostas de resistência máxima após o desafio com ovoalbumina e a expressão de 8-isoPGF2 $\alpha(r=0,44, p<0,03)$. Além disto, também observamos uma correlação positiva e significativa entre a densidade de fibras elásticas e a expressão de 8-iso-PGF2 $\alpha(r=0,4, p<0,05)$. 
DISCUSSÃO 
No presente estudo demonstramos que a inibição das enzimas envolvidas na síntese do óxido nítrico atenua a constrição do tecido pulmonar periférico. Este resultado correlacionou-se a uma redução da produção de isoprostanos, particularmente o PGF2 $\alpha$ e do conteúdo de fibras elásticas presentes no septo alveolar. É importante ressaltar que a modulação da resposta observada de mecânica de tecido pulmonar periférico pela inibição das óxido nítrico sintases não foi modificada pela intensidade da resposta inflamatória eosinofílica como também pelo conteúdo de fibras colágenas presentes no septo alveolar.

A eficácia desta forma de tratamento com L-NAME neste modelo animal já havia sido previamente demonstrada (Prado et al., 2005b e 2006). O presente estudo confirmou estes resultados visto que houve uma redução significativa no número de células que expressavam nNOS e iNOS no parênquima pulmonar distal das cobaias com inflamação pulmonar alérgica crônica que receberam tratamento com L-NAME. Em estudo anteriormente desenvolvido, havíamos demonstrado que o tratamento com L-NAME, no mesmo tempo e dose utilizada no presente estudo, reduziu o óxido nítrico exalado em mais de $50 \%$ nas cobaias com inflamação alérgica crônica submetidas a esse tratamento quando comparadas aos grupos controles.

O tratamento com L-NAME foi iniciado vinte e quatro horas após a quarta inalação para que não ocorresse interferência com a sensibilização. Isto porque, a partir desse momento, os animais já estavam sensibilizados (título de $\lg _{1}$ 1:320) (Leick-Maldonado et al., 2004). Outro aspecto 
importante é que neste momento os animais já apresentavam infiltrado eosinofílico e linfocitário ao redor das vias aéreas e no parênquima distal (dados não mostrados). De fato, avaliamos previamente os efeitos do tratamento com L-NAME no processo de sensibilização e observamos que o mesmo não interfere com a produção de anticorpos (Prado et al., 2005a; 2005b e 2006).

Diversos estudos sugerem que os efeitos do óxido nítrico são mais evidentes em vias aéreas proximais (Belvisi et al., 1991; Dupuy et al., 1992; Prado et al., 2005a; Prado et al., 2006). No entanto, poucos autores avaliaram os efeitos da inibição das óxido nítrico sintases na modulação das respostas funcionais, inflamatórias e de remodelamento que ocorrem no parênquima pulmonar decorrentes do desencadeamento de uma resposta inflamatória crônica. Tal observação pode decorrer do fato de que há uma progressiva redução de fibras do sistema não adrenérgico não colinérgico ao longo das ramificações brônquicas (Ricciardollo et al., 2004). Dupuy et al. (1992) mostraram que o óxido nítrico inalado atua como um broncodilatador de vias aéreas distais somente quando altas doses foram administradas.

Analisando-se as respostas de mecânica oscilatória, observamos que o tratamento com L-NAME reduziu tanto a resistência quanto a elastância do tecido pulmonar periférico, tanto na avaliação basal quanto a resposta máxima após o desafio com ovoalbumina nos animais previamente sensibilizados a este antígeno. Estes resultados sugerem que o óxido nítrico contribui para a constrição do parênquima pulmonar neste modelo experimental. 
Neste estudo utilizamos o mesmo protocolo de sensibilização e a mesma abordagem de tratamento com L-NAME previamente (Prado et al., 2005a; 2006). Os autores demonstraram que o tratamento crônico com LNAME induziu o aumento da resistência do sistema respiratório (Rrs), o que sugere um efeito em vias aéreas proximais. Estes efeitos na avaliação da Rrs ocorreram tanto no basal quanto após o desafio antigênico. Os autores também observaram que o tratamento crônico com L-NAME reduziu a elastância do sistema respiratório (Ers) em situação basal, mas não afetou a resposta máxima após o desafio antigênico, sugerindo que os efeitos do oxido nítrico em vias aéreas distais e/ou parênquima pulmonar foram diferentes daqueles observados em vias aéreas proximais, o que provavelmente deve ser devido a um efeito no parênquima pulmonar.

Embora os mecanismos exatos envolvidos nos efeitos do tratamento com L-NAME na redução da constrição do parênquima pulmonar não estejam totalmente esclarecidos, algumas explicações podem ser sugeridas. Muitos autores têm discutido que a produção de óxido nítrico pode contribuir para a resposta de estresse oxidativo, ampliando os efeitos deletérios nos pulmões (Hickman-Davis et al.,1999).

O potente oxidante peroxinitrito é formado por meio da interação do óxido nítrico e superóxido por uma rápida reação iso-estequiométrica (Muijers et al., 1997; Pryor e Squadrito, 1995). A formação de peroxinitrito leva a peroxidação e a geração de isoprostanos e, dentre eles o PGF2 $\alpha$ (Wood et al., 2003). Embora estudos prévios avaliassem os efeitos do 
PGE2, outro representante da família dos isoprostanos, e demonstrassem um efeito mais potente como constritor do que um PGF2 $\alpha$. Este último isoprostano é considerado a forma predominantemente gerada durante a ativação da via do estresse oxidativo (Montuschi et al., 1999a). Jourdan et al., em 1997 mostraram que o tratamento com L-NAME é capaz de quase abolir a produção de PGF2 $\alpha$.

Recentemente, os isoprostanos, particularmente o PGF2 $\alpha$, têm sido considerados como marcadores viáveis da injúria oxidante in vivo (Mehrabi et al., 2001; Mallat et al., 1998) e a sua produção está associada à potencialização da obstrução brônquica e alteração de permeabilidade vascular e formação de edema em cobaias (Collins et al., 1999).

Os isoprostanos são produzidos pela ativação da via fosfolipase. Após liberação na membrana passam para a circulação e são rapidamente metabolizados e atuam como potentes constritores do músculo liso (Fukunaga et al., 1993; Kawikova et al., 1996; Wood et al., 2003). Um aumento dos níveis de 8 isoprostano tem sido demonstrado na urina de pacientes com DPOC (Praticò et al.,1998). Os isoprostanos são considerados constritores vasculares (Kromer e Tippins, 1996; Mobert et al., 1997), particularmente das artérias pulmonares. São responsáveis pelo aumento da hiperresponsividade das vias aéreas (Held e Ulhig, 2000) e na musculatura lisa das vias aéreas atuam como constritores (Okazawa et al., 1997). Além disto, aumentam a quantidade de exsudação plasmática (Held e Ulhig, 2000). 
A escolha dos isoprostanos como marcadores de estresse oxidativo decorre do fato de que estas substâncias são estáveis, podem ser medidas em concentrações mínimas, como nanomolares, em amostras de fluidos como, por exemplo, o lavado broncoalveolar. As medidas não apresentam modificações diurnas e têm sido utilizadas como marcadores de várias doenças como, por exemplo, Alzheimer, Diabetes Mellitus, Lupus Eritematoso Sistêmico e outras doenças hepáticas (Montuschi et al., 1999b). Em relação à asma, Wood et al. (2000) concluíram que o estresse oxidativo está aumentado, sinalizado pelo aumento dos níveis de PGF2 $\alpha$ plasmáticos, em pacientes com quadro leve.

O efeito constritor dos isoprostanos tanto em vias aéreas, quanto na regulação do tônus da musculatura lisa vascular, parece ser decorrente de efeitos na tirosina quinase, Rho e Rho quinase levando à diminuição da atividade da cadeia leve da fosfatase da miosina (Janssen et al., 2001). A resposta do sistema é associada com um aumento nos níveis da cadeia leve de miosina fosforilada, o que leva à contração muscular (Belvisi et al.,1991). Observamos, no presente estudo, que a atenuação das respostas de mecânica foi associada à significativa diminuição da densidade do PGF2a no parênquima pulmonar, sugerindo um efeito do óxido nítrico dependente da ativação da via do estresse oxidativo.

Considerando que o PGF2a é um mediador solúvel e de meia vida reduzida, optamos por realizar também o mesmo estudo imunohistoquímico nos fragmentos de pulmão contralateral, que não foram avaliados na 
mecânica oscilatória e, portanto não ficaram no banho de Krebs. Não houve diferença significativa quanto à expressão deste isoprostano no parênquima pulmonar entre os grupos submetidos ou não ao protocolo de avaliação de mecânica oscilatória.

Em relação à resposta inflamatória eosinofílica decorrente do estímulo inflamatório crônico cabe ressaltar que a inibição crônica das óxido nítrico sintases pelo tratamento com L-NAME não modificou este recrutamento celular no parênquima pulmonar. Os efeitos do óxido nítrico no recrutamento eosinófilico são ainda um assunto de controvérsia (Ferreira et al., 1998; Ricciardollo et al., 2004; Prado et al., 2005a; Prado et al., 2005b; Prado et al., 2006; Ricciardollo et al., 2006b).

Ferreira et al. (1998) estudaram a influência do oxido nítrico na infiltração eosinofílica das vias respiratórias de ratos sensibilizados com ovoalbumina. Os animais foram tratados com L-NAME durante quatro semanas. O lavado broncoalveolar foi realizado em intervalos de $6,24,48$ e 72 horas após a injeção intraperitoneal de ovoalbumina. O desafio peritoneal em ratos sensibilizados com ovoalbumina causou um aumento significativo no número total de leucócitos do lavado broncoalveolar em 24 e 48 horas após o desafio com ovoalbumina. Referente ao tempo de 24 horas após a injeção de ovoalbumina, o tratamento crônico dos animais não afetou nem o número total nem o diferencial dos leucócitos. Entretanto após 48 horas da aplicação da ovoalbumina, o total de células encontradas foi reduzido em aproximadamente em $48 \%$ nos animais tratados com L-NAME e isto foi associado com a inibição de infiltração eosinofilica. A avaliação histológica 
dos pulmões destes animais (48 horas após o desafio de ovoalbumina) também mostrou uma redução do infiltrado eosinofílico nos segmentos respiratórios.

Prado et al. (2005a) estudaram a expressão de iNOS em células inflamatórias em cobaias com inflamação alérgica crônica em vias aéreas e demonstraram que os animais sensibilizados e tratados com L-NAME agudo apresentaram uma diminuição dos eosinófilos, das células mononucleares e a da expressão de iNOS nestas células. Os mesmos autores também observaram que o recrutamento eosinofílico diminuiu somente quando os animais foram tratados com 1400W (inibidor específico da iNOS).

Ricciardollo et al. (2006a) demonstraram que a produção de óxido nítrico via ativação de iNOS é regulada por diferentes citocinas, dependentes da ativação de $\mathrm{NF}_{-\kappa} \beta$. A produção de óxido nítrico pode aumentar a resposta oxidativa e por meio de espécies reativas do nitrogênio, podem amplificar as respostas inflamatórias na asma e DPOC. Cabe lembrar que o óxido nítrico exalado está aumentado em pacientes com asma atópica estável e estes níveis estão ainda mais alterados durante as exacerbações de asmáticos (Kharitonov et al., 1994; Belvisi et al., 1995; Deykin et al., 1998) e de pacientes com DPOC (Ansarin et al., 2001; Ricciardollo et al., 2006a).

Riccciardolo et al. (2004) descreveram que o óxido nítrico, derivado de células epiteliais, macrófagos e células Th1, exerce um papel importante na amplificação e na perpetuação da resposta inflamatória Th2, tanto na asma alérgica quanto na asma não alérgica. A ativação de iNOS pode 
potencializar a resposta de células epiteliais, previamente expostas a citocinas pró-inflamatórias como TNF- $\alpha$ e IL-1 $\beta$ secretadas por macrófagos e IFN- $\gamma$ secretado por células Th1. É possível que infecções virais possam aumentar a expressão de células epiteliais de vias aéreas, aumentando a secreção de óxido nítrico durante as exacerbações asmáticas (Carraro et al., 2006).

O presente estudo demonstrou que animais expostos à ovoalbumina apresentaram um aumento no conteúdo de fibras elásticas no septo alveolar. Demonstramos também que o tratamento crônico com L-NAME em animais expostos à ovoalbumina previne o aumento da quantidade de fibras elásticas no septo alveolar. Ao avaliarmos as correlações morfo-funcionais observamos uma associação entre a redução do conteúdo destas fibras e a atenuação da resposta de mecânica de parênquima pulmonar observada nestes animais.

Embora não fôssemos capazes de esclarecer os mecanismos exatos que explicam a modulação do conteúdo de fibras elásticas do parênquima pulmonar pela inibição das óxido nítrico sintases, algumas hipóteses podem ser sugeridas. Pastor et al. (2006) estudaram um modelo experimental de enfisema pulmonar induzido por papaína e observaram que a substância amorfa eletrodensa foi rompida. Houve desaparecimento da mesma após 20 horas da instilação de papaína e, em dois meses, houve novo acúmulo de fibras elásticas. Este processo associou-se à deposição de colágeno, particularmente na parede do ducto alveolar. Cantor et al. (2006) avaliaram o 
efeito de oxidantes na atividade da elastase in vitro. Os autores sugeriram que o peróxido de hidrogênio e outros oxidantes derivados de células inflamatórias ou do meio ambiente atuam ativadores da elastase, levando a nova re-síntese de fibras elásticas. Este processo pode resultar em uma organização morfo-funcional anormal. Contudo, outros autores (Johanson et al., 1971) têm sugerido que as fibras elásticas podem estar normais depois da atuação de um processo de reparo.

Provavelmente, o aumento no conteúdo de fibras elásticas observadas em animais expostos à ovoalbumina seja devido ao processo de reparação. Considerando que o tratamento com L-NAME reduziu o estresse oxidativo, o processo de injúria/reparo foi atenuado, como observado no presente estudo.

Por fim, observamos que o tratamento crônico com L-NAME não modificou o conteúdo de fibras colágenas no parênquima pulmonar dos animais sensibilizados. No entanto, outros estudos anteriores sugerem um efeito pró-fibrótico modulado pelo óxido nítrico. No mesmo modelo animal, Prado et al. (2006) demonstraram que a inibição das óxido nítrico sintases pelo tratamento crônico com L-NAME aumenta o conteúdo de colágeno ao redor das vias aéreas. Considerando os resultados observados nas vias aéreas e no parênquima pulmonar neste modelo experimental podemos sugerir algumas hipóteses. Em primeiro lugar as diferenças na expressão da arginase I e II no tecido conectivo peribrônquico em relação ao observado no parênquima pulmonar como sugerido por Wood et al. (2000). Além disto, cabe ressaltar que, embora o parênquima distal também esteja alterado em 
asmáticos e neste modelo experimental de inflamação crônica pulmonar, a intensidade da resposta de recrutamento eosinofílico é muito maior na parede das vias aéreas do que no parênquima pulmonar (Tibério et al., 1997; Lanças et al., 2006) e estas células são capazes de ativar mecanismos que podem lesar o epitélio e estimular a produção de TGF- $\beta$ (Prado et al., 2006).

Kotaru et al. (2006), estudando biópsias de pacientes asmáticos, isolaram fibroblastos das vias aéreas e do parênquima distal e compararam a sua morfologia, proliferação, expressão de actina e a síntese de procolágeno tipo I e eotaxina 1 . Os resultados encontrados sugerem que os fibroblastos das vias aéreas são morfologicamente distintos dos fibroblastos do parênquima pulmonar. Os fibroblastos do parênquima distal são mais largos, com aparência estrelada e com mais projeções citoplasmáticas. Os fibroblastos das vias aéreas sintetizam mais pró-colágeno tipo I após estímulo com TGF- $\beta$. Estes estudos sugerem que existem dois tipos de fibroblastos no pulmão. Estas diferenças estruturais podem explicar, pelo menos parcialmente, de que modo frente ao mesmo estímulo de injúria, ocorre uma aparente diversidade da intensidade da resposta de reparação em vias aéreas proximais, distais e no parênquima pulmonar de pacientes asmáticos e com outras doenças respiratórias. 


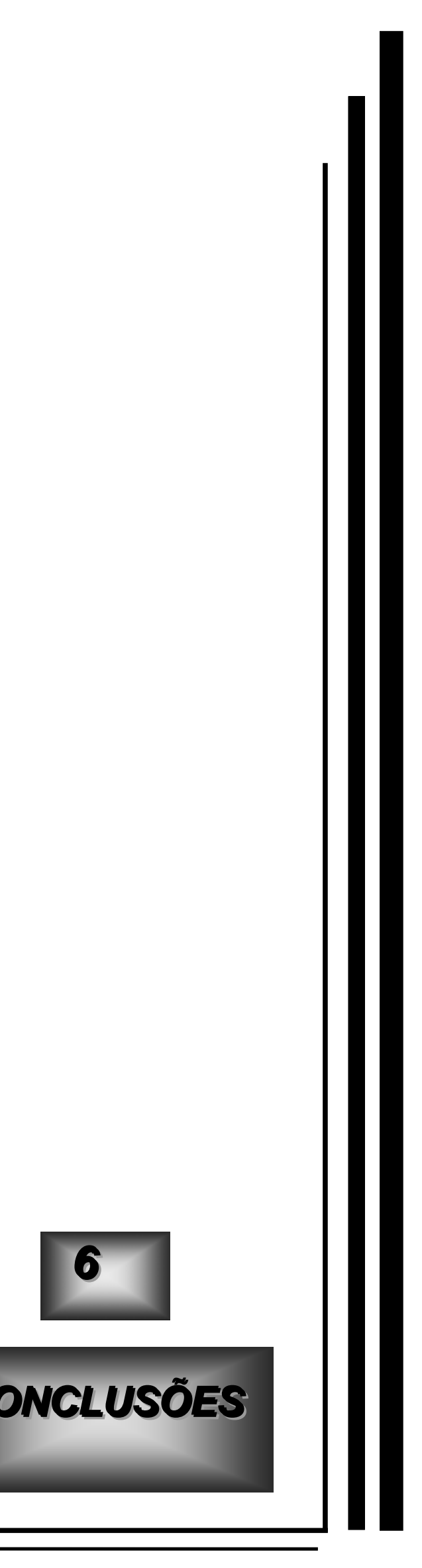


Deste modo, utilizando este modelo experimental de inflamação crônica pulmonar, pudemos concluir que:

1. O óxido nítrico apresenta papel constritor no parênquima pulmonar, dados confirmados pela melhora nas medidas de mecânica oscilatória de tecido pulmonar periférico, obtidas pela mensuração da resistência e elastância teciduais, tanto em situação basal como após o desafio antigênico quando as óxido nítrico sintases foram inibidas.

2. Em relação à modulação do remodelamento da matriz extracelular no parênquima pulmonar distal, o tratamento crônico com L-NAME não reduziu o conteúdo de fibras colágenas, mas reduziu a densidade de fibras elásticas.

3. Apesar da atenuação das respostas de mecânica oscilatória pulmonar com a inibição da produção de óxido nítrico, não houve redução da inflamação eosinofilica no parênquima pulmonar.

4. A inibição crônica da produção de óxido nítrico pelo L-NAME resultou em uma atenuação da ativação da via do estresse oxidativo no parênquima pulmonar distal, o que se associou à melhora da resposta máxima de resistência tecidual após o estímulo antigênico. 
5. Houve uma redução significativa no número de células que expressam nNOS e iNOS no parênquima pulmonar distal das cobaias com inflamação pulmonar alérgica crônica que receberam tratamento com L-NAME, o que confirma a eficácia do tratamento. 
Referências

Bibliográficas 
Alving K, Fornhem C, Wietzberg E, Lunderberg JM. Nitric oxide mediates cigarette- smoke-induced vasodilatadory responses in the lung. Acta Physiol Scand.1992; 146:407-08.

Alving K, Weitzberg E, Lundberg JM.Increased amounts of nitric oxide in exhaled air of asthmatics. Eur Resp J.1993; 6: 1368-1370.

Ansarin K, Chatkin JM, Ferreira IM, Gutierrez CA, Zamel N, Chapman KR. Exhaled nitric oxide in chronic obstrutive pulmonary disease: relationship to pulmonary function. Eur Respir J.2001; 5:934-8.

Bachofen $\mathrm{H}$. Lung tissue resistance and pulmonary hysteresis. J Appl Physiol.1968; 24:296-301.

Baddedge RC, Moore PK, Gathen Z, Hart SL. L-NG-nitroarginine pnitroanilide (L-NAPNA): a selective inhibitor of nitric oxide synthase in the brain [abstract]. Br J Pharmacol. 1993; 107:194P.

Barnes PJ. Reactive oxygen species and airway inflammation. Free Rad Biol Med .1990; 9:235-243.

Barnes PJ. NO or no NO in asthma? Thorax.1996; 51:218-20.

Barnes PJ, Belvisi MG. Nitric oxide and lung disease. Thorax.1993; 48:10341043.

Bell SG. The story of nitric oxide: from rascally radical to miracle molecule. Neonatal New. 2004; 23(4):47-51.

Belvisi MG, Stretton D, Barnes PJ. Nitric oxide as an endogenous modulator of colinergic neurotransmission in guinea-pig airways. Eur $\mathrm{J}$ Pharmacol. $1991 ; 198(2-3): 219-21$.

Belvisi M, Barnes PJ, Larkin S, Yacoub M, Tadjkarimi S, Williams TJ, Mitchell JA. Nitric oxide synthase activity is elevated in inflammatory lung disease in humans. Eur J Pharmacol. 1995; 283(1-3):255-8. 
Biaglioli MC, Kaul P, Singh I, Turner RB. The role of oxidative stress in rhinovirus induced elaboration of IL-8 by respiratory epithelial cells.Free Rad Biol Med.1999:26:454-462.

Böckmann S, Seep J, Jonas L. Delay of neutrophil apoptosis by the neuropeptide substance P: involvement of caspase cascade. Peptides. 2001; 22:661-70.

Bredt DS, Snyder SH. Nitric oxide mediates glutamate linked enhancement of cGMP levels in the cerebellum. Proc Natl Acad Sci USA. 1989; 86:9030-3.

Bredt DS, Hwang MP, Snyder SH. Localization of nitric oxide synthase indicating a neural role for nitric oxide. Nature. 1990; 347:768-70.

Bredt DS, Hwang PM, Glatt CE, Lowenstein C, Reed RR, Snyder SH.Cloned and expressed nitric synthase structurally resembles cytochrome P-450 reductase. Nature. 1991; 351:714-718.

Boulet LP. Airway remodeling in asthma. Clin Asthma Rev. 1997; 1: 55-62.

Bousquet J, Chanez P, Lacoste JY. Asthma: a disease remodeling the airways. Allergy.1992; 47:3-11.

Bousquet J, Jeffery PK, Busse WW, Johson M, Vignola AM. State of Art: Asthma from bronchoconstrition to airways inflammation and remodeling. Am J Respir Crit Care Med. 2000; 161: 1720-1745.

Burburan SM, Xisto DG, Rocco PR. Anaesthetic management in asthma. Minerva Anestesiol.2007; 73(6):357-65.

Calhoun WJ, Jarjour NN, Gleich GJ, Stevens CA, Busse WW.Increased airway inflammation with segmental versus aerosol antigen challenge. Am Rev Respir Dis.1993; 147:1465-1471. 
Cantor JO, Shteyngart B, Cerreta JM, Ma S, Turino GM. Synergistic effect of hydrogen peroxide and elastase on elastic fiber injury in vitro. Exp Biol Med. 2006; 231(1):107-11.

Carraro S, Doherty J, Zaman K, Gainov I, Turner R, Vaughan J, Hunt JF, MárquezJ, Gaston B.S-nitrosothiols regulate cell-surface $\mathrm{pH}$ buffering by airway epithelial cells during the human immune responses to rhinovirus. $A m$ J Physiol Lung Cell Mol Physiol.2006; 290(5):L827-32.

Chung K F, Barnes PJ. Cytokines in asthma. Thorax.1999; 54:825-57.

Coers W, Timens W, Kempinga C, Klok PA, Moshage H. Specificity of antibodies to nitric oxide synthase isoforms in human, guinea pig, rat, and mouse tissues. J Histochem Cytochem.1998; 46:1385-92.

Collins CE, Quaggitto P, Wood L, O'Loughlin EV, Henry RL, Garg ML. Elevated plasma levels of $F_{2 a}$ isoprostane in cystic fibrosis. Lipids. 1999; 34(6):551-556.

Cortijo J, Esplugues J, Morcillo EJ,Perpiña M. Pharmacological analysis of the responsiveness of guinea-pig lung parenchymal strip to dopamine. Br. J. Pharmac. 1984; 83: 161-167

Culotta E, Koshland DE. NO news is good news. Science.1992; 258:1862-3.

Cutz E, Levinson H, Cooper DM. Ultrastructure of airways in children with asthma. Histopathology .1978; 2:407-421.

DATASUS (Banco de Dados do Sistema Único de Saúde) http://www.datasus.gov.br

de Monchy JG, Kauffman HF, Venge P, Koeter GH,Jansen HM, Sluiter HJ, de Vries K.Bronchoalveolar eosinophilia during allergen-induced late asthmatic reactions.Am Rev Respir Dis.1985;131:373-376. 
del Maestro RF, Bjork J, Arfors K. Increase in microvascular permeability induced by enzymatically generated free radicals.I. In vivo study. Microvasc Res. 1981; 22:239-254.

Deykin A, Halpern O, Massaro AF, Drazen JM, Israel E. Expired nitric oxide after bronchoprovocation and repeated spirometry in patients with asthma. Am J Respir Crit Care Med.1998; 157(3 Pt 1):769-75.

Doelman CJA, Bast A. Oxygen radicals in lung pathology. Free Rad Biol Med 1990a; 9:381-400.

Doelman CJA, Leurs R, Oosterom WC, Bast A. Mineral dust exposure and free radical-mediated lung damage. Exp Lung Res .1990b; 16:41-55.

Dupuy PM, Shore SA, Drazen JM, Frostell C, Hill WA, Zapol WM. Bronchodilator action of inhaled nitric oxide in guinea pigs. J Clin Invest. 1992; 90:421-8.

Eiserich JP, Patel RP, O'Donnell VB. Pathophysiology of nitric oxide and related species: free radical reactions and modification of biomolecules. Mol Aspects Med. 1998; 19(4-5):221-357.

Erjefält JS, Erjefält I, SundlerF, Persson CG. Mucosal nitric oxide may tonically suppress airways plasma exudation. Am J Respir Crit Care Med. 1994; 150(1):227-32.

Faffe DS, Silva GH, Kurtz PM, Negri EM, Capelozzi VL, Rocco PR, Zin WA. Lung tissue mechanics and extracellular matrix composition in a murine model of silicosis. J Appl Physiol. 2001; 90 ( 4) : 1400-6.

Ferreira HH, Bevilacqua E, Gagioti SM, De Luca IM, Zanardo RC, Teixeira CE, Sannomiya P, Antunes E, De Nucci G. Nitric oxide modulates eosinophil infiltration in antigen-induced airway inflammation in rats. Eur J Pharmacol. 1998; 358:253-9. 
Foreman JC, Rising TJ, Webber SE. A study of the histamine H2-recpetor mediating relation of the parenchymal lung strip preparation of the guineapig. Br J Pharmac.1985; 86:465-473.

Fukunaga M, Takahashi K, Badr KF. Vascular smooth muscle actions and receptor interactions of 8-isoprostaglandin E2, an E2isoprostane. Biochem Biophys Res Comm .1993;195:507-515.

Fredberg JJ, Stamenovic D. On the imperfect elasticity of lung tissue. J Appl Physiol. 1989.67:2408-19.

Gaston B, Reilly J, Drazen JM, Fackler J, Ramdev P, Arnelle D, Mullins ME, Sugarbaker DJ, Chee C, Singel DJ. Endogenous nitrogen oxides and bronchodilator S-nitrosothiols in human airways. Proc Natl Acad Sci U S A. 1993; 90(23):10957-61.

Global Strategy for Asthma Management and Prevention, Global Initiative for Asthma (GINA) 2007. Available from: http://www.ginasthma.org.

Guo CB, Liu MC, Galli SJ, Bochner BS, Kagey-Sobotka A, Lichtenstein LM.Identification of IgE-bearing cells in the late phase response to antigen in the lung as basophils. Am J Respir Cell Mol Biol.1994; 10:384-390.

Hanazawa T, Kharitonov SA, Barnes PJ. Increased nitrotyrosine in exhaled breath condensate of patients with asthma. Am J Respir Crit Care Med 2000;162:1273-1276.

Held HD, Uhlig S. Mechanisms of endotoxin-induced airway and pulmonary vascular hyperrreactivity in mice. Am J Respir Crit Care Med 2000; 162:1547-1552.

Hickman-Davis J, Gibbs-Erwin J, Lindsey JR and Matalon S. Surfactant protein A mediates mycoplasmacidal activity of alveolar macrophages by production of peroxynitrite. Proc Natl Acad Sci USA. 1999; 96(9):4953-8. 
Högman M, Frostell C, Arnberg H, Hedenstierna G. Inhalation of nitric oxide modulates methacoline-induced bronchoconstriction in the rabbit. Eur Respir J. 1993; 6:177-80.

Holgate ST.Asthma genetics:waiting to exhale. Nat Genet. 1997; 15:227-229. Hunt JF, Fang K, Malik R, Snyder A, Malhotra N, Platts-Mills TA, Gaston B. Endogenous airway acidification. Implications for asthma pathophysiology. Am J Respir Crit Care Med. 2000; 161(3 Pt 1):694-9.

Ibiapina CC, Cruz AA, Camargos PAM. Hidrofluoralcano como propelente dos aerossóis pressurizados de dose medida: histórico, deposição pulmonar, farmacocinética, eficácia e segurança. J Pediatr (Rio J).2004;80:441-6.

International study of asthma and allergies in childhood Steering Committee Worldwide variations in the prevalence of asthma symptoms: the International Study of Asthma and Allergies in Childhood (ISSAC).Eur Respir J.1998; 12:315-35.

Janssen LJ, Premji M, Netherton S, Coruzzi J, Lu-Chao H, Cox PG. Vasoconstritor actions of isoprostanes via tyrosine kinase and rho kinase and canine pulmonary vascular smooth muscles. Bristish Journal of Phermacology.2001; 132:127-134.

Janssens SP, Shimouchi A, Quertermous T, Bloch DB, Bloch KDCloning and expression of a cDNA encoding human endothelium-derived relaxing factor/nitric oxide synthase. J Biol Chem. 1992; 267(31): 22694.

Jarjour NN, Calhoun WJ. Enhanced production of oxygen radicals in asthma. J Lab Clin Med .1994; 123:131-136.

Johanson WG, Pierce AK, Reynolds RC. The evolution of papain emphysema in the rat. J Lab Clin Med. 1971;78:599-607. 
Jourdan KB, Mitchell JA, Evans TW. Release of isoprostanes by human pulmonary artery in organ culture: a cyclo-oxygenase and nitric oxide dependent pathway. Biochem Biophys Res Commun.1997; 233(3):668-72.

Kaliner MA, Barnes PJ, Persson CGA. Asthma. Its Pathology and Treatment. New York: $2^{\text {nd }}$ ed. Marcel Decker Inc.; 1991.

Katsumata U, Miura M, Ichinose M, ET al. Oxygen radicals produce airway constriction and hyperreponsiveness in anesthetized cats. Am Rev Respir Dis. 1990; 141:1158-1161.

Kawikova I, Barnes PJ, Takahashi T, Tadjkarimi S, Yacoub MH, Belvisi MG.8-epi-PGF2alpha, a novel noncyclooxygenase-derived prostaglandin,constricts airways in vitro. Am J Respir Crit Care Med. 1996; 153:590-596.

Kharitonov SA, Yates D, Robbins RA, Logan-Sinclair R, Shinebourne EA, Barnes PJ. Increases nitric oxide in exhaled air of asthmatic patients.Lancet. 1994; 343:133-5.

Kotaru C, Schoonover KJ, Trudeau JB, Huynh ML, Zhou X, Hu H, Wenzel SE. Regional fibroblast heterogeneity in the lung: implications for remodeling. Am J Respir Crit Care Med.2006; 173(11):1208-15.

Kraft M. The distal airways: are they important in asthma? Eur Respir J. 1999; 14(6):1403-17.

Kraft M. Location of asthma inflammation and the distal airways: clinical implications.Curr Med Res Opin.2007; 23(3):S21-7.

Kromer BM, Tippins JR.Coronary artery constriction by the isoprostane *-epiprostaglandin F2alpha.Br J Pharmacol.1996; 119:1276-1280.

Kuo HP, Liu S, Barnes PJ. The effects of endogenous nitric oxide on neurogenic plasma exudation in guinea-pig airways. Eur $\mathrm{J}$ Pharmacol. 1992;221:385-8. 
Lai J, Rogers RA, Ekstein BA, Fredberg JJ. Dynamic changes in alveolar duct geometric in response to 10-3 histamine. Am J Respir Crit Care Med. 1994; 149:A538.

Lamas S, Marsden PA, Li GK, Tempst P, Michel T. Endothelial nitric oxide synthase: molecular cloning and characterization of a distinct constitutive enzyme isoform. Proc Natl Acad Sci USA. 1992; 89:6348-52.

Lanças T, Kasahara DI, Prado CM, Tibério F.L.C.I, Martins MA and Dolhnikoff M. Comparison of early and late responses to antigen of sensitized guinea pig parenchymal lung strips. J Appl Physiol. 2006; 100(5):1610-6.

Leick-Maldonado EA, Kay FU, Leonhardt MC, Kasahara DI, Prado CM, Fernandes FT, Martins MA, Tibério IFLC. Comparison of glucocorticoid and cysteinyl leukotriene receptor antagonist treatments in an experimental model of chronic airway inflammation in guiena-pigs. Clin Exp Allergy. 2004; $34: 145-52$.

Leite-Jr JH, Rocco PR, Faffe DS, Romero PV, Zin WA. On the preparation of lung strip for tissue mechanics measurement. Respir Physiol Neurobiol. 2003; 134( 3): 255-62.

Levine SJ. Bronchial epithelial cell-cytokine interactions in airway inflammation. J Invest Med.1995; 43:241-249.

Lí CG, Rand MJ. Evidence that part of NANC relaxant response of guineapig trachea to electrical field stimulation is mediated by nitric oxide. $\mathrm{Br} \mathrm{J}$ Pharmacol. 1991; 102:919-4.

Ludwig MS, Dreshaj I, Sollway J, Munoz A, Ingram Jr. R.H. Partitioning of pulmonary resistance during constriction in the dog: effects of volume history. J. Appl. Physiol. 1987; 62: 807-815. 
Ludwig MS and Dallaire MJ. Structural composition of lung parenchymal strip and mechanical behavior during sinusoidal oscillation. J Appl Physiol.1994 77:2029-35.

Lopez-Aguilar J, Romero PV. Effect of elastase pretreatment on rat lung strip induced constriction. Respir Physiol. 1998; 113(3): 239-46.

Mahapatra P. Social, economic and cultural aspects of asthma:na exploratory study in Andra Pradesh, Índia. Hyderbasd, India:Institute of Heatalth Systems;1993.

Mallat Z, Plhilip I, Lebret M, Chatel D, Maclouf J, Tedgui A. Elevated levels of 8-isoprostagladin F2alpha in pericardial fluid of pavients with heart failure:a potencial role for in vivo oxidant stress in ventricular dilatation and progression to heart failure. Circulation.1998; 97:1536-9.

Marion RJ, Creer TL, Reynolds RV.Direct and indirest costs associated with the management of childhood asthma. Ann Allergy .1985; 54(1):31-4.

Mauad, Thais, Souza, Sandrini Lopes De, Saldiva, Paulo Hilário Nascimento et al. Remodelamento brônquico na asma. J. Pneumologia. 2000; 26(2)9198.

Mauad T, Silva LF, Santos MA, Grinberg L, Bernard FD, Martins MA, Saldiva $\mathrm{PH}$ and Dolhnikoff $\mathrm{M}$. Abnormal attachments with decreased elastic fiber content in distal lung in fatal asthma. Am J Respir Crit Care Med. 2004; 170(8): 857-62.

Mehrabi MR, Serbecic N, Ekmekcioglu C, Tamaddon F, Ullrich R, Sinzinger $\mathrm{H}$, Glogar HD. The isoprostane 8-epi-PGF (2alpha) is a valuable indicator of oxidative injury in human heart valves. Cardiovasc Pathol.2001; 10:241-245.

Milne GL, Yin H, Brooks JD, Sanchez S, Jackson Roberts L, Morrow JD. Quantification of f2-isoprostanes in biological fluids and tissues as a measure of oxidant stress. Methods Enzymol.2007; 433:113-26. 
Moncada S, Palmer RMJ, Higgs EA. Biosynthesis of nitric oxide from Larginina: a pathway for the regulation of cell function and communication. Biochem Pharmacol.1989; 38:1709-15.

Moncada S, Palmer RMJ, Higgs EA. Nitric Oxide: physiology, pathophysiology and pharmacology. Pharmacol Rev. 1991; 43:109-42.

Moncada S, Higgs A. The L-arginine-nitric oxide pathway. $N$ Engl J Med. 1993; 329:2002-12.

Mobert J, Becker BF, Zahler S, Gerlach E. Hemodynamic effects of isoprostanes (8-isoprostaglandin F2alpha and E2) in isolated guinea pig hearts. J Cardiovasc Pharmacol 1997; 29:789-794.

Montefort S, Gratziou C, Gounding D, Polosa R, Haskard DO, Howarth PH, Holgate St. Bronchial biopsies evidence for leucocyte infiltration and upregulation of leucocyte-endoethlial cell adhesion molecules 6 hours after local allergen challenge of sensitized asthmatic airways. J Clin Invest.1994; 93:1411-21.

Montuschi P, Corradi M, Ciabattoni G, Nightingale J, Kharitonov SA, Barnes PJ. Increased 8-isoprostane, a marker of oxidative stress, in exhaled condensation in asthma patients. Am J Respir Crit Care Med. 1999a; 160:216-220.

Montuschi P, Curro D, Ragazzoni E, Preziosi P and Ciabattoni G. Anaphylasis increases 8-iso-prostaglandin F2alpha release from guinea-pig lung in vitro. Eur J Pharmacol. 1999b;365(1):59-64.

Muijers RBR, Folkerts G, Henricks PAJ, Sadeghi-Hashjin G and NijKamp FP. Peroxynitrite: a two faced metabolite of nitric oxide.Life Sci. 1997; 60:183345.

Nakashima AS, Prado CM, Lanças T, Ruiz VC, Kasahara DI, LeickMaldonado EA, Dolhnikoff M, Martins MA, Tibério IF.Oral tolerance attenuates changes in in vitro lung tissue mechanics and extracellular matrix 
remodeling induced by chronic allergic inflammation in guinea pigs.J Appl Physiol. 2008; 104(6):1778-85.

National Institute of Health/World Health Organization. National Asthma Education and prevention program. Expert panel Report 2. Guidelines for the diagnosis and management of asthma. Washington, U.S. Department of Health, Education, and Welfare, 1997.

Neffen H, Fristscher C, Schacht FC, Levy G, Chiarella P, Soriano JB.Asthma control in Latin America:the asthma insights and reality in latin America (AIRLA)survey.Rev Panam Salud Publica.2005;17(3):191-7.

Norman V, Keith CM. Nitrogen oxides in tobacco smoke. Nature. 1965; 205:915-6.

Okazama A, Kawikova I, Cui Z, Skoogh B, Lotvall J.8-epi-PGF2alpha induces airflow obstruction and airway plasma exudation in vivo. Am J Respir Crit Care Med.1997; 155:436-441.

Palmer RMJ, Ashton DS, Moncada S.Vascular endothelial cells synthesize nitric oxide from L-arginine.Nature.1998; 33: 664-666.

Paré PD, Michoud MC, Boucher RC, Hogg JC. Pulmonary effects of acute and chronic antigen exposure of immunized guinea pigs. J Appl Physiol. 1979; 46:346-53.

Platts-Mills T, Wheatley L. The role of allergy and atopy in asthma. Curr Opin Pulmon Med.1996; 2:29-34.

Prado CM, Leick-Maldonado EA, Arata V, Kasahara ID, Martins MA and Tibério F.L.C.I . Neurokinins and inflammatory cell iNOS expression in guinea pigs with chronic allergic airway inflammation.Am J Physiol Lung Cell Mol Physiol.2005a; 288(4): L741-8. 
Prado CM, Leick-Maldonado EA, Kasahara DI, Capelozzi VL, Martins MA and Tibério F.L.C.I . Effects of acute and chronic nitric oxide inhibition in an experimental model of chronic pulmonary allergic inflammation in guinea pigs. Am J Physiol Lung Cell Mol Physiol. 2005b; 289(4):L677-83.

Prado CM, Leick-Maldonado EA, Yano L, Leme AS, Capelozzi VL, Martins MA and Tibério F.L.C.I. Effects of nitric oxide synthases in chronic allergic airway inflammation and remodeling. Am J Physiol Lung Cell Mol Biol. 2006; 35(4):457-65.

Prado CM, Leick-Maldonado EA, Miyamoto L, Yano LM, Kasahara DI, Martins MA, Tibério IF. Capsaicin-sensitive nerves and neurokinins modulate non-neuronal nNOS expression in lung. Respir Physiol Neurobiol.2008; 160(1): 37-44.

Praticò D, Basili S, Vieri M, Cordova C, Violi F, Fitzgerald GA.Chronic obstructive pulmonary disease is associated an increase in urinary levels of isoprostane F2a III, an index of oxidant stress.Am J Respir Crit Care Med.1998;158:1709-1714.

Pryor WA, Squadrito G. The chemistry of peroxynitrite: a product from the reaction of nitric superoxide. Am J Physiol. 1995; 268:L699-722.

Radi R, Beckman J, Bush K, Freeman B. Peroxynitriteinduced membrane lipid peroxidation: The cytotoxic potential of superoxide and nitric oxide. Arch Biochem Biophys .1991; 288:481-487.

Reiter CD, Teng RJ, Beckman JS. Superoxide reacts with nitric oxide to nitrate tyrosine at physiological pH via peroxynitrite.J Biol Chem. 2000; 275(42):32460-6.

Rennard SI, Floreani AA. Nonstandard and potential future therapies for asthma. Clin Chest Med. 1995; 16(4):735-44. 
Ress DD, Palmer RMJ, Schulz R, Hodson HF, Moncada S.Characterisation of three inhibitors of endothelial nitric oxide synthase in vitro and vivo. $\mathrm{Br} \mathrm{J}$ Pharmacol.1990;101,746.

Ribeiro MO, Antunes E, De Nucci G, Lovisolo SM, Zatz R. Chronic inhibition of nitric oxide synthesis. A new model of artery hypertension. Hypertesion. 1992; 20(3):298-303.

Ricciardollo FL, Sterk PJ, Gaston B, Folkerts G. Nitric oxide in heath and disease of respiratory system. Physiol Rev. 2004; 84:731-765.

Ricciardollo FL, Nijkamp FP and Folkers G. Nitric oxide synthase (NOS) as therapeutic target for asthma and chronic obstructive pulmonary disease. Currr Drug Targets. 2006a; 7(6):721-35.

Ricciardollo FL, Di Stefano A, Sabatini F and Folkerts G. Reactive nitrogen species in the respiratory tract. Eur J Pharmacol. 2006b; 533:240-52.

Robinson D, Hamid Q; Bentley A, Ying S;Kay AB;Durham,SR. Activation of CD4+ T cells, increased TH2-type cytokine mRNA expression, and eosinophil recruitment in bronchoalveolar lavage after allergen inhalation challenge in patients with atopic asthma. J Allergy Clin Immunol.1993; 92):313-324.

Rocco PR, Negri EM, Kurtz PM, Vasconcellos FP, Silva GH, Capelozzi VL, Romero PV and Zin WA. Lung tissue mechanics and extracellular matrix remodeling in acute lung injury. Am J Respir Crit Care Med.2001; 164(6): 1067-71.

Romero PV, Zin WA and Lopez-Aguilar J. Frequency characteristics of lung tissue strip during passive stretch and induced pneumoconstriction.J Appl Physiol. 2001; 91: 882-890. 
Rhoden KJ, Barnes PJ. Effect of hydrogen peroxide on guineapig tracheal muscle in vitro: role of cyclooxygenase and airway epithelium. $\mathrm{Br} \mathrm{J}$ Pharmacol .1989; 98:325-330.

Salerno FG, Dallaire M, Ludwig MS. Does the anatomic makeup of parenchymal lung strips affect oscillatory mechanics during induced constriction? J. Apply. Physiol. 1995; 79 (1): 66-72.

Salerno FG, Ludwig MS. Dissociation between hysteresivity and tension in constricted tracheal and parenchymal strips. J Appl Physiol.1998; 85(1):91-7.

Santoni G, Amantini C, Lucciarini R, Perfumi M, Pompei P, and Piccoli M. Neonatal capsaicin treatment affects rat thymocyte proliferation and cell death by modulating substance $P$ and neurokinin-1 receptor expression. Neuroimmunomodulation. 2004, 11(3):160-72.

Scherle W. A simple method for volumetry of organs in quantitative stereology. Mikroskopie. 1970; 26(1):57-60.

Sedgwick JB, Holt PG. Down-regulation of immune responses to inhaled antigen: studies on the mechanism of induced supression.Immunology.1985; 56:635-42.

Solé D, Yamada E, Vana AT, Werneck G, Freitas LS, Sologuren MJ. Internacional Study of Asthma and Allergies in Childhood (ISAAC): Prevalence of asthma and asthma -related symptoms among Brazilian schoolchildren. J Invest Clin Immunol.2001; 11:123-8.

Solé D, Cassol VE, Silva AR, Teche SP, Rizzato TM, Bandim LC, Sarinho ES, Camelo-Nunes IC.Prevalence of symptoms of asthma, rhinitis, and atopic eczema among adolescents living in urban and rural areas in different regions of Brazil. Allergol Immunopathol (Madr). 2007; 35(6): 248-53. 
Takahashi K, Nammour TM, Fukunaga M, Ebert JD, Morrow JD, Roberts LJ. Glomerular actions of a free radical generated novel prostaglandin, 8-epiPGF2 $\alpha$, in the rat. Evidence for interactions with thromboxane A2 receptors. J Clin Invest.1992; 90:136-141.

Tanaka R, Ludwig MS. Changes in viscoelastic properties of rat lung parenchymal strips with maturation. J Appl Physiol. 1999; 87(6):2081-9.

Tate RM, van Benthuysen KM, Shasby DM, McMurtry IF, Repine JE. Oxygen-radical-mediated permeability edema and vasoconstriction in isolated perfused rabbit lungs. Am rev Respir Dis.1982; 126:802-806.

Tayeh MA, Marletta M.A. Macrophage oxidation of L-arginine to nitric oxide, nitrite and nitrate: Tetrahydrobiopterin is required as a cofactor. $\mathrm{J}$ Biol Chem. 1989;264:654-8.

Tibério IFLC, Turco, GMG, Leick-Maldonado EA, Sakae RS, Paiva PSO, Warth MPTN, Lapa e Silva JR, Saldiva PHN, Martins MA. Effects of neurokinin depletion on airway inflammation induced by chronic antigen exposure. Am J Respir Crit Care Med. 1997; 155:1739-47.

Toyoshima MT, Ito GM, Gouveia N. Trends in morbidity for respiratory diseases among hospitalized patients in the city of São Paulo. Rev Assoc Med Bras. 2005;51(4):209-13.

Tulic MK, Hamid Q. New insights into the pathophysiology of the small airways in asthma. Clin Chest Med.2006; 27(1):41-52.

Vallyathan V, Shi X. The role of oxygen free radicals in occupational and environmental lung diseases. Environ Health Perspect. 1997; 105(1):165-77.

Van Parijs L, Abbas AK. Homeostasis and self-tolerance in the immune system:turning lymphocytes off. Science.1998; 280:243-8.

Xie Q-W, Cho HJ, Calaycay J, Mumford RA, Swiderek KM, Lee TD, Ding A, Troso T, Nathan C. Cloning and characterization of inducible nitric oxide synthase from mouse macrophages. Science. 1992; 256:225-8. 
Xisto DG, Farias LL, Ferreira HC, Pincanço MR, Amitrano D, Lapa e Silva JR, Negri EM, Carnielli D, F. Silva, LF, Capelozzi VL, Faffe DS, Zin WA and Rocco PM. Lung parenchyma remodeling in a murine model of chronic allergic inflammation. Am J Respir Crit Care Med.2005; 171(8):829-37.

Watanabe T, Okano M and Hattori H, Yoshino T, Ohno N, Ohta N Sugata, Zar JH. Biostatistical Analysis. 2. ed. 1984.Englewood Cliffs: Prentice-Hall Inc: 206-235.

Weibel ER. Principles and methods for the morphometric study of the lung and other organ. Lab Invest.1963; 12:31-55.

Weiss KB, Sullivan SD. The health economics of asthma and rhinitis.Assessing the economic impact. J Allergy Clin Immunol.2001; 107:38.

Weiss EB, Bellino JR. Leukotriene-associated toxic oxygen metabolites induces airway hyperreactivity.Chest.1986; 89:709-716.

Wood LG, Gibson PG, Garg ML. Biomarkers of lipid peroxidation, airway inflammation and asthma. Eur Respir J. 2003; 21: 177-186.

Wood LG, Fitzgerald DA, Gibson PG, cooper DM, Garg ML. Lipid peroxidation as determined by plasma isoprostanes is related to disease severity in mild asthma. Lipids. 2000; 35:967-974.

Wu W, Chen Y, Hazen SL. Eosinophil peroxidase nitrates protein tyrosyl residues.Implications for oxidative damage by nitrating intermediates in eosinophilic inflammatory disorders. J Biol Chem. 1999; 274(36): 25933-44. 
Patrícia Angeli, Carla M. Prado, Débora G. Xisto, Pedro L. Silva, Caroline P.

Pássaro, Hugo D. Nakazato, Edna A. Leick-Maldonado, Milton A. Martins,

Patricia R. M. Rocco and Iolanda F. L. C. Tibério

Am J Physiol Lung Cell Mol Physiol 294:1197-1205, 2008. First published Mar 21, 2008;

doi:10.1152/ajplung.00199.2007

You might find this additional information useful...

This article cites 44 articles, 25 of which you can access free at:

http://ajplung.physiology.org/cgi/content/full/294/6/L1197\#BIBL

Updated information and services including high-resolution figures, can be found at:

http://ajplung.physiology.org/cgi/content/full/294/6/L1197

Additional material and information about AJP - Lung Cellular and Molecular Physiology can be found at:

http://www.the-aps.org/publications/ajplung

This information is current as of June 9, 2008 .

AJP - Lung Cellular and Molecular Physiology publishes original research covering the broad scope of molecular, cellular, and integrative aspects of normal and abnormal function of cells and components of the respiratory system. It is published 12 times a year (monthly) by the American Physiological Society, 9650 Rockville Pike, Bethesda MD 20814-3991. Copyright @ 2005 by the American Physiological Society. ISSN: 1040-0605, ESSN: 1522-1504. Visit our website at http://www.the-aps.org/. 


\title{
Effects of chronic L-NAME treatment lung tissue mechanics, eosinophilic and extracellular matrix responses induced by chronic pulmonary inflammation
}

\author{
Patrícia Angeli, ${ }^{1}$ Carla M. Prado, ${ }^{1}$ Débora G. Xisto, ${ }^{2}$ Pedro L. Silva, ${ }^{2}$ Caroline P. Pássaro, ${ }^{2}$ \\ Hugo D. Nakazato, ${ }^{1}$ Edna A. Leick-Maldonado, ${ }^{1}$ Milton A. Martins, ${ }^{1}$ Patricia R. M. Rocco, ${ }^{2}$ \\ and Iolanda F. L. C. Tibério ${ }^{1}$ \\ ${ }^{1}$ Department of Medicine, School of Medicine, University of Sao Paulo, São Paulo; and ${ }^{2}$ Laboratory of Pulmonary \\ Investigation, Carlos Chagas Filho Institute of Biophysics, Ilha do Fundão, Centro de Ciências da Saúde, Federal University \\ of Rio de Janeiro, Rio de Janeiro, Brazil
}

Submitted 17 May 2007; accepted in final form 20 March 2008

Angeli P, Prado CM, Xisto DG, Silva PL, Pássaro CP, Nakazato HD, Leick-Maldonado EA, Martins MA, Rocco PR, Tibério IF. Effects of chronic L-NAME treatment lung tissue mechanics, eosinophilic and extracellular matrix responses induced by chronic pulmonary inflammation. Am J Physiol Lung Cell Mol Physiol 294: L1197-L1205, 2008. First published March 21, 2008; doi:10.1152/ajplung.00199.2007.-The importance of lung tissue in asthma pathophysiology has been recently recognized. Although nitric oxide mediates smooth muscle tonus control in airways, its effects on lung tissue responsiveness have not been investigated previously. We hypothesized that chronic nitric oxide synthase (NOS) inhibition by $N^{\omega}$-nitro-L-arginine methyl ester (L-NAME) may modulate lung tissue mechanics and eosinophil and extracellular matrix remodeling in guinea pigs with chronic pulmonary inflammation. Animals were submitted to seven saline or ovalbumin exposures with increasing doses $(1 \sim 5 \mathrm{mg} / \mathrm{ml}$ for 4 wk) and treated or not with L-NAME in drinking water. After the seventh inhalation $(72 \mathrm{~h})$, animals were anesthetized and exsanguinated, and oscillatory mechanics of lung tissue strips were performed in baseline condition and after ovalbumin challenge $(0.1 \%)$. Using morphometry, we assessed the density of eosinophils, neuronal NOS (nNOS)- and inducible NOS (iNOS)-positive distal lung cells, smooth muscle cells, as well as collagen and elastic fibers in lung tissue. Ovalbumin-exposed animals had an increase in baseline and maximal tissue resistance and elastance, eosinophil density, nNOS- and iNOS-positive cells, the amount of collagen and elastic fibers, and isoprostane-8- $\mathrm{PGF}_{2 \alpha}$ expression in the alveolar septa compared with controls $(P<0.05)$. L-NAME treatment in ovalbumin-exposed animals attenuated lung tissue mechanical responses $(P<0.01)$, nNOS- and iNOS-positive cells, elastic fiber content $(P<0.001)$, and isoprostane-8-PGF $2 \alpha$ in the alveolar septa $(P<0.001)$. However, this treatment did not affect the total number of eosinophils and collagen deposition. These data suggest that NO contributes to distal lung parenchyma constriction and to elastic fiber deposition in this model. One possibility may be related to the effects of $\mathrm{NO}$ activating the oxidative stress pathway.

experimental models of asthma; lung parenchyma constriction; elastic fibers; oxidative stress; $N^{\omega}$-nitro-L-arginine methyl ester

ALTHOUGH ASTHMA IS DEFINED as a chronic airway inflammatory disease, recent investigations have emphasized the importance of lung tissue alterations in the pathophysiology of this syndrome. In recent years, the significance of lung parenchyma mechanical properties has been characterized as one of the major determinants

Address for reprint requests and other correspondence: I. de Fátima Lopes Calvo Tibério, Departamento de Clínica Médica, Faculdade de Medicina da Universidade de São Paulo, Av. Dr. Arnaldo, 455-Sala 1210, 01246-903, São Paulo, SP, Brazil (e-mail: iocalvo@uol.com.br). of physiological function $(36,40)$. Additionally, current investigations have shown that patients who died of asthma presented important alterations in lung parenchyma $(14,20)$ that could also be reproduced in animal models of experimental asthma $(15,46)$. Considering that lung parenchymal strips have long been used to study the behavior of the peripheral lung, they are commonly used to evaluate the mechanical and pharmacological properties of lung periphery (39).

Nitric oxide (NO) is an important modulator of inflammatory diseases such as asthma $(22,26,28,33)$. In the respiratory tract, NO can be produced by residential and also by inflammatory cells and is generated via oxidation of L-arginine, which is catalyzed by the enzyme NO synthase (NOS). NO derived from the constitutive isoforms of NOS [neuronal NOS (nNOS) and endothelial NOS] and other NO-adduct molecules (nitrosothiols) are able to modulate bronchomotor tone. On the other hand, NO derived from inducible NOS (iNOS) seems to be a molecule with immunomodulatory effects $(32,34)$.

Several lines of evidence suggest a role of NO in the bronchodilator response, particularly in larger airways, since the nitrergic innervation decreases throughout the bronchial tree (5). Prado et al. (27) demonstrated that the inhibition of NO by chronic $N^{\omega}$-nitro-L-arginine methyl ester (L-NAME) treatment amplified both respiratory system resistance and elastance responses and that it also interfered with the extracellular matrix airway remodeling in an experimental model of chronic lung inflammation. Considering that the respiratory system elastance responses are related to alterations in distal airways and lung tissue, the authors suggested that NO could also be involved in the modulation of lung tissue constriction. In addition, Dupuy et al. (5) proposed that inhaled NO only affects distal airways at high doses, suggesting that, although less intensive, NO can also modulate distal airways and/or lung tissue responses.

Therefore, we hypothesized that NOS inhibition modulates lung parenchyma responses in a guinea pig model of chronic pulmonary inflammation. We evaluated the effects of chronic L-NAME administration, an unspecific inhibitor of NO production, on the modulation of lung tissue mechanics, eosinophilic inflammation, and extracellular matrix tissue remodeling in this experimental model.

\footnotetext{
The costs of publication of this article were defrayed in part by the payment of page charges. The article must therefore be hereby marked "advertisement" in accordance with 18 U.S.C. Section 1734 solely to indicate this fact.
} 


\section{MATERIALS AND METHODS}

Animals received humane care in compliance with the Guide for Care and Use of Laboratory Animals (National Institutes of Health publication 85-23, revised 1985), and the Local Ethical Committee approved the study.

Experimental model of pulmonary allergic inflammation. Chronic airway inflammation was induced as previously described $(10,17)$. Male Hartley guinea pigs $(300-400 \mathrm{~g})$ were placed in a box coupled to an ultrasonic nebulizer (US-1000; ICEL), and an aerosol of ovalbumin (grade V, Sigma-Aldrich Chemical) diluted in $0.9 \% \mathrm{NaCl}$ (normal saline) was generated for $15 \mathrm{~min}$ or until respiratory distress occurred. Respiratory distress was defined as the onset of sneezing, coryza, cough, and/or in drawing of the thoracic wall, and the observer who made the decision to withdraw the animals from the inhalation box was blinded to the treatment status of the animal. The animals received seven inhalations during $4 \mathrm{wk}$, with increasing ovalbumin concentrations (1 5 mg/ml) to counteract tolerance (Fig. 1). Control animals received aerosolized normal saline $(0.9 \% \mathrm{NaCl})$.

Chronic L-NAME treatment. Chronic L-NAME treatment (60 $\mathrm{mg} \cdot \mathrm{kg}^{-1} \cdot$ guinea $\mathrm{pig}^{-1} \cdot \mathrm{day}^{-1}$ ) was carried out as previously described $(27,28)$. Briefly, guinea pigs received L-NAME dissolved in the drinking water ad libitum (OVA-L or NS-L groups, see below), beginning $24 \mathrm{~h}$ after the fourth inhalation of either ovalbumin or normal saline to avoid interference with the sensitization (Fig. 1). Control animals received sterile drinking water.

Experimental groups. Four groups of guinea pigs were used in the experimental protocol: 1) the first group received inhalations with normal saline and sterile drinking water (NS group, $n=8$ ); 2) the second group received ovalbumin aerosols and sterile drinking water (OVA group, $n=10$ ); 3 ) the third group received inhalation with normal saline and L-NAME diluted in the drinking water (NS-L group, $n=7)$; 4) the fourth group received ovalbumin aerosols and L-NAME diluted in the drinking water (OVA-L group, $n=8$ ).

Mechanics of lung parenchymal strips. After the last inhalation (72 h), animals were sedated with diazepam (1 mg ip), anaesthetized with pentobarbital sodium $(50 \mathrm{mg} / \mathrm{kg})$, and tracheostomized. After that, the thorax was opened, and the animals were exsanguinated. The lungs were removed en bloc and placed in a modified Krebs-Henseleit $\left(\mathrm{K}-\mathrm{H}\right.$ ) solution (in $\mathrm{mM}$ : $118.4 \mathrm{NaCl}, 4.7 \mathrm{KCl}, 1.2 \mathrm{~K}_{3} \mathrm{PO}_{4}, 25$ $\mathrm{NaHCO}_{3}, 2.5 \mathrm{CaCl}_{2} \cdot \mathrm{H}_{2} \mathrm{O}, 0.6 \mathrm{MgSO}_{4} \cdot \mathrm{H}_{2} \mathrm{O}$, and 11.1 glucose) at $\mathrm{pH}=7.40$ and $6^{\circ} \mathrm{C}(36)$. Strips $(3 \times 3 \times 10 \mathrm{~mm})$ were cut from the periphery of the left lung and suspended vertically in a K-H organ bath maintained at $37^{\circ} \mathrm{C}$, continuously bubbled with a mixture of $95 \%$

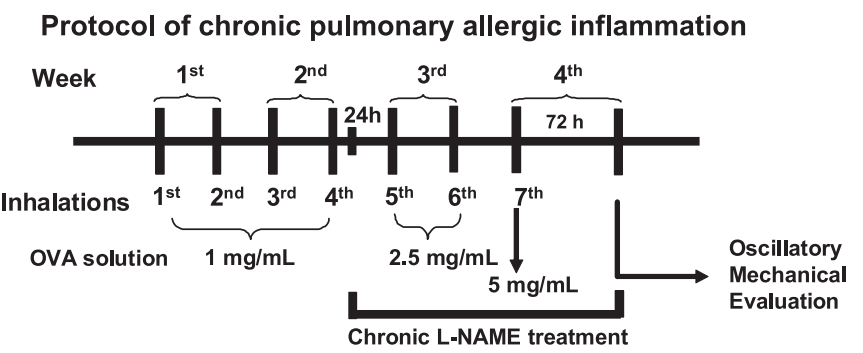

Fig. 1. Time line of the experimental protocol. The guinea pigs were submitted to 7 inhalations ( $2 \mathrm{x} / \mathrm{wk}$ during $4 \mathrm{wk})$ with aerosols of normal saline or ovalbumin solution with increasing doses of antigen. For the 1st to the 4th inhalations, the dose used was $1 \mathrm{mg} / \mathrm{ml}$ of ovalbumin ( $2 \mathrm{wk})$. In the 5 th and 6th inhalations ( $3 \mathrm{rd} \mathrm{wk}$ ), animals inhaled $2.5 \mathrm{mg} / \mathrm{ml}$ of ovalbumin and in the 7 th inhalation (beginning of the 4th wk) a $5 \mathrm{mg} / \mathrm{ml}$ dose of antigen was used. The solution of ovalbumin or normal saline was continuously aerosolized for $15 \mathrm{~min}$ or until respiratory distress occurred (sneezing, coryza, cough, or retraction of the thoracic wall). After the 7 th inhalation $(72 \mathrm{~h})$, all guinea pigs were anesthetized and exsanguinated, and lungs were removed and submitted to the experimental protocol of oscillatory mechanics. We analyzed the lung tissue elastance and resistance in baseline and after a challenge with $0.1 \%$ of ovalbumin in the bath.
$\mathrm{O}_{2}-5 \% \mathrm{CO}_{2}$. Lung strips were weighed, and their unloaded resting lengths $\left(L_{0}\right)$ were determined with a caliper. Lung strip volume was measured by simple densitometry, as: volume $=\Delta \mathrm{F} / \delta$, where $\Delta \mathrm{F}$ is the total change in force before and after strip immersion in $\mathrm{K}-\mathrm{H}$ solution and $\delta$ is the mass density of $\mathrm{K}-\mathrm{H}$ solution $(17,18,35-39)$. Parenchyma strips were suspended vertically in a K-H organ bath (30 $\mathrm{ml}$ internal volume) maintained at $37^{\circ} \mathrm{C}$ and continuously bubbled with $95 \% \mathrm{O}_{2}-5 \% \mathrm{CO}_{2}$ as previously described (39). Briefly, one end of the strip was attached to a force transducer (LETICA TRI-110; Scientific Instruments, Barcelona, Spain), whereas the other one was fastened to a lever arm actuated by means of a modified woofer driven by the signal generated by a computer and analog-to-digital converted (AT-MIO-16-E-10, National Instruments, Austin, TX). A sidearm of this rod was linked to a second force transducer (LETICA TRI-110; Scientific Instruments) by means of a silver spring of a known Young's modulus, thus allowing the measurement of displacement (Fig. 2). Neither amplitude dependence $(<0.1 \%$ change in stiffness) nor phase changes with frequency were detected in the 0.01 - to $14-\mathrm{Hz}$ range. The hysteresivity of the system $(<0.003)$ was frequency independent

Cross-sectional, unstressed area $\left(A_{0}\right)$ of the strip was determined from volume and unstressed length, according to $A_{0}=\mathrm{vol} / L_{0}$. Basal force $\left(F_{B}\right)$ for a stress of $0.1 \mathrm{~N} / \mathrm{cm}^{2}$ was calculated as $F_{B}(N)=10$ $\left(\mathrm{N} / \mathrm{cm}^{2}\right) \times A_{\mathrm{O}}\left(\mathrm{cm}^{2}\right)$ and adjusted by vertical displacement of the force transducer, as previously described (8). The displacement signal was then set to zero. Once basal force and displacement signals were adjusted, the length between bindings $\left(L_{\mathrm{B}}\right)$ was measured by means of a precision caliper. Instantaneous length during oscillation around $L_{\mathrm{B}}$ was determined by adding the value of $L_{\mathrm{B}}$ to the measured value of displacement at any time. Instantaneous average cross-section area $\left(A_{\mathrm{i}}\right)$ was determined as $A_{\mathrm{i}}=\mathrm{vol} / L_{\mathrm{i}}\left(\mathrm{cm}^{2}\right)$, where $L_{\mathrm{i}}$ is instantaneous length.

Instantaneous stress $\left(\sigma_{\mathrm{i}}\right)$ was calculated by dividing force $(\mathrm{F}$; in $\mathrm{g})$ by $A_{\mathrm{i}}\left(\mathrm{cm}^{2}\right)$, i.e., $\sigma_{\mathrm{i}}=\mathrm{F} / A_{\mathrm{i}}$. Strain was calculated as $\Delta \varepsilon=(L-$ $\left.L_{\mathrm{B}}\right) / L_{\mathrm{B}}$. After the basal force was adjusted to $0.5 \times 10^{-2} \mathrm{~N}$, each parenchyma strip was preconditioned by sinusoidal oscillation of the tissue during $30 \mathrm{~min}$ (frequency $=1 \mathrm{~Hz}$, which is a large enough amplitude to reach a final force of $1 \times 10^{-2} \mathrm{~N}$ ). Thereafter, the amplitude was adjusted to $5 \% L_{0}$, and the oscillation was maintained for another $30 \mathrm{~min}$, or until a stable length-force loop was reached. The isometric stress adaptation period resulted in a final force of $0.5 \times$ $10^{-2} \mathrm{~N}$. After preconditioning, the strips were oscillated at a frequency $(f)$ of $1 \mathrm{~Hz}(36,46)$ and with a constant force of $0.5 \times 10^{-2}$ $\mathrm{N}$. The bath solution was renewed regularly (every $20 \mathrm{~min}$ ) with $37^{\circ} \mathrm{C}$ $\mathrm{K}-\mathrm{H}$ solution.

All mechanical parameters were measured cycle by cycle. Tissue resistance $(\mathrm{R})$ was determined from the enclosed area of force length loops: $\mathrm{R}=(4 \times H) /\left[\pi \times \omega \times(\Delta \varepsilon)^{2}\right]$, where $H$ is the stress-strain hysteresis area, $\omega$ is the angular frequency $[\omega=2 \pi f(\mathrm{rad} / \mathrm{s})$, where $f$ is frequency], and $\Delta \varepsilon$ is the normalized strain or peak-to-peak change in length divided by $L_{\mathrm{B}}$. Tissue dynamic $\mathrm{E}$ was determined as: $\mathrm{E}=$ $(\Delta \sigma \iota / \Delta \varepsilon) \cos \theta$, where $\Delta \sigma \iota$ is the peak-to-peak change in force, and $\theta$ is the phase lag between force and displacement $\left(\theta=\sin ^{-1}\{4 \times\right.$ $H /[\pi(\Delta \sigma \iota \times \Delta \varepsilon)]\})$. The $\eta$, which is an empirically determined variable that quantifies the dependence of dissipative processes on elastic processes (7), was calculated as $\eta=\tan \theta$.

Tissue resistance $(R)$, elastance $(E)$, and hysteresivity $(\eta)$ were calculated at baseline condition and after ovalbumin challenge (dose of $0.1 \%$ of ovalbumin) $(7,40)$.

Morphometric analysis. Lung tissue strips were fixed at $-70^{\circ} \mathrm{C}$ by immersion in Carnoy's fixative [solution of ethanol-chloroform-acetic acid (60:30:10)]. After $24 \mathrm{~h}$, the lungs were kept at $-20^{\circ} \mathrm{C}$, and the concentration of ethanol was progressively increased to reach that of absolute ethanol (41). To assure the homogeneity of the strip samples used, slices were cut ( $5 \mu \mathrm{m}$ thick), stained with hematoxylin-eosin, and analyzed through an integrating eyepiece with a coherent system made of a 100-point grid consisting of 50 lines of known length 


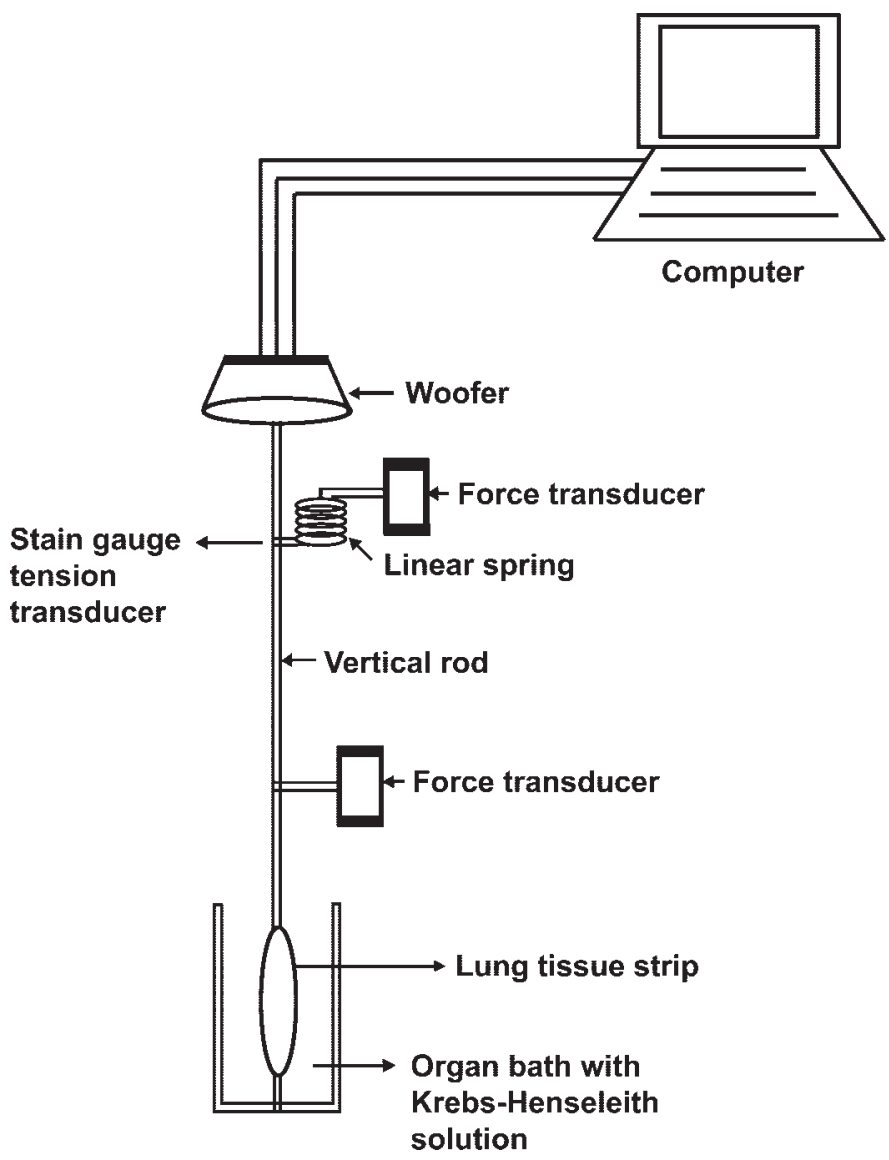

Fig. 2. Schematic setup used for tissue mechanics measurements.

coupled to a light microscope. Sections were examined at $\times 400$ magnification, and the fractional areas of alveolar wall (AW), blood vessel wall (BVW), and bronchial wall (BW) were determined by the point-counting technique (43). All points falling on these components were counted and divided by the total number of points. This analysis was performed in 10 random, nonoverlapping fields in each strip. BVW and BW were counted when a point fell on the endothelial layer, the epithelial layer, the smooth muscle, or associated connective tissue. Points falling on alveolar air spaces, blood vessel lumen, and bronchial lumen were excluded.

Quantification of eosinophil density. Slices (5 $\mu \mathrm{m}$ thick) of lung strips were stained with Luna's eosinophil granule stain for the detection of eosinophils $(19,42)$. By conventional morphometry, we analyzed the density of eosinophils within the alveolar septa of lung strips. Using a 100-point grid with a known area $\left(10^{4} \mu \mathrm{m}^{2}\right.$ $\times 1,000$ magnification) attached to the microscope ocular, we counted the number of points hitting alveolar tissue in each field and the number of eosinophils within the alveolar septa. Eosinophil density was determined as the number of eosinophils in each field divided by tissue area. Measurements are expressed as cells per $10^{4}$ $\mu \mathrm{m}^{2}$. Counting was performed in 10 fields of lung strip in each animal.

Immunohistochemistry for nNOS detection. Histological sections of $5 \mu \mathrm{m}$ were stained with specific monoclonal $\operatorname{IgG}_{2 \mathrm{a}}$ antibody to nNOS (nNOS/NOS type I-N31020; BD Transduction Laboratories, San Diego, CA) to detect nNOS expression. Immunohistochemistry was performed as previously described (28). Briefly, sections were initially incubated in a humid chamber $(30 \mathrm{~min}$ at room temperature) with a blocking solution containing normal mouse serum followed by the primary monoclonal antibody anti-nNOS from mouse (overnight at room temperature). After three washes in
TBS for $5 \mathrm{~min}$, sections were incubated with a streptavidinalkaline phosphatase conjugate (LSAB + AP-streptavidin AP; Dako, Carpinteria, CA) for $30 \mathrm{~min}$ at $37^{\circ} \mathrm{C}$, followed by incubation with Fast Red TR substrate for $6 \mathrm{~min}$ and light hematoxylin counterstaining (Merck) for $1 \mathrm{~min}$. We counted eosinophils, epithelial cells, and macrophages that were positive for nNOS. These cells were determined as the number of positive cells in each field divided by tissue area, at a magnification of $\times 1,000$, and were expressed as distal lung cells positive for nNOS expression $\left(10^{4} \mu \mathrm{m}^{2}\right)$.

Immunohistochemistry for iNOS detection. For iNOS detection, we used the same sections employed at the morphometric evaluation of nNOS expression. Immunohistochemistry was performed as previously described (3). Subsequently, the sections were incubated seven times for $5 \mathrm{~min}$ at room temperature with a blocking solution containing 3\% hydrogen peroxide. Polyclonal antisera raised in rabbit against iNOS (cod. RB-9242-P; LabVision, NeoMarkers, Fremont, CA) (26) were used as primary antisera [incubation overnight in a humid chamber (refrigerator) at $4-8^{\circ} \mathrm{C}$, $1: 400$ dilution in BSA]. After three 5-min washes in PBS, sections were incubated with a secondary antibody [Vector ABCElite, horseradish peroxidase (HRP), cod. PK-6101; Vector Laboratories, Burlingame, CA] at $37^{\circ} \mathrm{C}$ in a humidity chamber. Slides were given three more 5-min washes in PBS and revealed with 3,3'-diaminobenzidine (DAB) (cod. K3468; DakoCitomation). Slides were given abundant washes in tap water. This was followed by Harry's hematoxylin counterstaining for $1 \mathrm{~min}$. A total of 10 fields was analyzed per lung as described above. We counted eosinophils, epithelial cells, and macrophages that were positive for iNOS. These cells were determined as the number of positive cells in each field divided by tissue area, at a magnification of $\times 1,000$, and were expressed as distal lung cells positive for iNOS expression in cells per unit area $\left(10^{4} \mu \mathrm{m}^{2}\right)$ (27).

Quantification of collagen and elastic fiber density. Lung strips were also stained with Picrosirius, a specific method for collagen detection and Weigert's Resorcin-Fuchsin method for elastic fibers (4). From each strip, 20 different microscopic fields were randomly selected to quantify collagen and elastic fibers. Quantification $(\times 400$ magnification) was carried out by the same method described above. The volume proportion of collagen and elastic fibers in the alveolar tissue of lung strips was determined by dividing the number of points hitting collagen or elastin by the total number of points hitting the alveolar septa. Results were expressed as percentage of area.

Immunohistochemistry for actin. Immunohistochemical staining was performed using monoclonal antibody to $\alpha$-smooth muscle actin (Dako) at a 1:500 dilution. Sections were deparaffinized, and $0.5 \%$ peroxidase in methanol solution was applied for $10 \mathrm{~min}$ to inhibit endogenous peroxidase activity. Antigen retrieval was performed with a citrate solution for $30 \mathrm{~min}$. Sections were incubated with anti-human smooth muscle actin (1A 4; Dako) overnight at $4{ }^{\circ} \mathrm{C}$. LSAB Plus-HRP kit (K-0690; DAKO) was used as secondary antibody, and DAB (Sigma Chemical, St. Louis, MO) was used as chromogen. The sections were counterstained with Harris hematoxylin (Merck, Darmstadt, Germany). The analysis was performed in the slides stained for actin by applying the same point-counting technique described above. We determined the volume proportion of smooth muscle-specific actin in the alveolar septa as the relation between the number of points falling on actin-stained and non-actin-stained tissue (5). Measurements were carried out at $\times 400$ in each slide.

Immunohistochemistry for 8-iso- $P G F_{2 \alpha}$ detection. Immunohistochemical staining was performed using antibody to anti-8-epi-PGF ${ }_{2 \alpha}$ (Oxford Biomedical Research, Rochester Hills, MI) at a 1:500 dilution (23). Sections were deparaffinized and washed seven times for 5 min with $3 \% \mathrm{H}_{2} \mathrm{O}_{2} 10 \mathrm{~V}$ to inhibit endogenous peroxidase activity. After washes in PBS and water, the antigen retrieval was performed with tripsine for $20 \mathrm{~min}$. Afterward, three washes in PBS were performed for $3 \mathrm{~min}$ each. Sections were incubated with anti-8-epi$\mathrm{PGF}_{2}$ diluted in BSA overnight. After washes in PBS, ABCKit 
Vectastain (Vector Elite PK-6105) was used as secondary antibody, and DAB (Sigma Chemical) was used as chromogen. The sections were counterstained with Harris hematoxylin (Merck). The analysis was performed in the slides stained for 8 -isoprostane-PGF $2 \alpha$ by applying the same point-counting technique described above. We determined the volume proportion of 8 -iso- $\mathrm{PGF}_{2 \alpha}$ in the alveolar septa as the relation between the number of points falling on 8iso- $\mathrm{PGF}_{2 \alpha}$-stained and nonstained tissue. Measurements were carried out at $\times 400$ in each slide (23). All morphometric analyses described in this section were performed by individuals blinded to the protocol design.

Statistical analysis. Values are expressed as means \pm SE. Statistical analysis was performed using the SigmaStat 2.0 statistical software package (Jandel, San Raphael, CA). Data were evaluated by two-way analysis of variance, and multiple comparisons were made using the Holm-Sidak method. A $P$ value of $<0.05$ was considered significant (47).

\section{RESULTS}

Mechanics of lung parenchymal strips. Values of oscillatory pulmonary mechanics in baseline condition and after antigen challenge are shown in Fig. 3. Tissue resistance and elastance were higher in ovalbumin-exposed animals compared with saline-exposed ones in baseline condition $(P<0.05$ for all
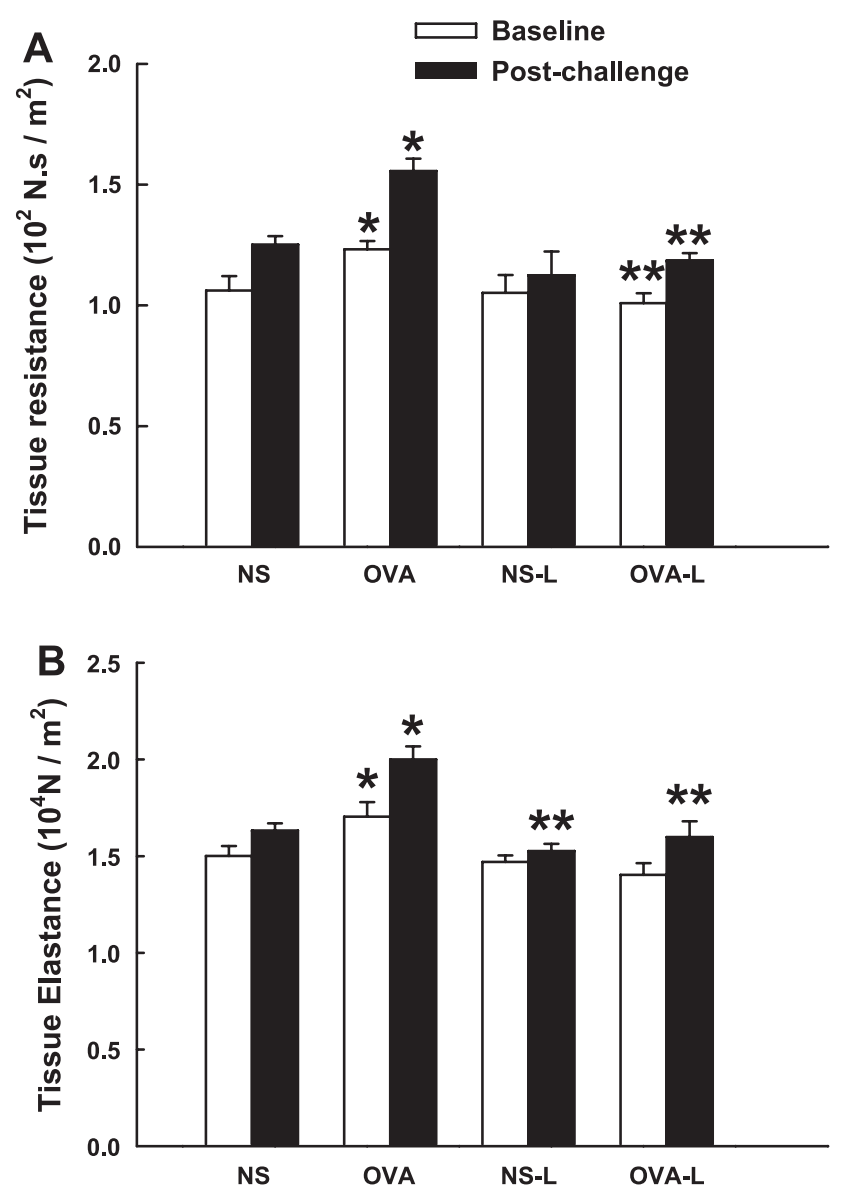

Fig. 3. Baseline and postovalbumin challenge $(0.1 \%)$ values of tissue resistance $(A)$ and elastance $(B)$ in guinea pigs exposed to 7 inhalations with ovalbumin or normal saline and chronically treated with $N^{\omega}$-nitro-L-arginine methyl ester (L-NAME) or vehicle. Values are expressed as means $\pm \mathrm{SE}$. $* P<$ 0.05 compared with baseline and postchallenge values of the normal saline (NS) group; $* * P \leq 0.01$ compared with the ovalbumin (OVA) group. comparisons). Tissue resistance and elastance were higher in ovalbumin-exposed animals compared with saline-exposed ones after challenge ( $P<0.05$ for all comparisons). L-NAME treatment in ovalbumin-exposed animals (OVA-L group) reduced all these responses compared with ovalbumin-exposed and vehicle-treated animals $(P<0.01)$. Hysteresivity was similar in all groups in baseline [NS: $0.04 \pm 0.00$; NS-L: $0.05 \pm 0.00$; OVA: $0.05 \pm 0.00$; OVA-L: $0.05 \pm 0.00 \eta]$ and after OVA challenge [NS: $0.04 \pm 0.00$; NS-L: $0.05 \pm 0.00$; OVA: $0.05 \pm 0.00$; OVA-L: $0.05 \pm 0.00 \eta]$.

Morphometric analysis. All groups showed similar anatomical composition of lung strips with $\sim 60-70 \%$ of AW.

Eosinophil density in lung tissue is shown in Fig. 4. We observed that there was an increase in the eosinophil density in ovalbumin-exposed animals compared with saline-exposed ones $(P<0.05)$. L-NAME treatment did not affect this response. Figure 5 shows the number of nNOS- and iNOSpositive distal lung cells in alveolar tissue. There was a significant increase in both nNOS- and iNOS-positive cells in the OVA group compared with controls $(P<0.05)$. L-NAME treatment reduced the number of both nNOS- and iNOSpositive cells in ovalbumin-exposed animals $(P<0.001)$. There was no difference between NS and NS-L groups.

The amount of collagen (Fig. 6A) and elastic fibers (Fig. 6B) in the alveolar septa is shown in Fig. 6. Both collagen and elastic fiber contents were higher in ovalbumin-exposed animals compared with the saline-exposed ones $(P<0.001)$. Ovalbumin-exposed animals that received chronic L-NAME treatment presented lower elastic fiber content in the alveolar septa compared with those that received vehicle $(P<0.001)$. The L-NAME treatment did not modify collagen fiber deposition in lung tissue.

Volume proportion of smooth muscle-specific actin was similar in all groups (OVA group: $11.25 \pm 042$; NS group: $10.39 \pm 0.48$; OVA-L group: $9.96 \pm 0.48$; NS-L group: $11.47 \pm 0.48 \%)$.

Volume proportion of 8 -iso-PGF $2 \alpha$ in alveolar septa is shown in Fig. 7. Ovalbumin-exposed animals showed higher values of 8-isoprostane-PGF ${ }_{2 \alpha}$ density compared with salineexposed ones $(P<0.001)$. Ovalbumin-exposed animals that received chronic L-NAME treatment (OVA-L group) presented lower content of 8 -iso- $\mathrm{PGF}_{2 \alpha}$ positive tissue compared with those that received vehicle (OVA group, $P<0.001$ ). There was no significant difference between saline-exposed animals.

To evaluate if the strip procedures in the bath interfere with immunohistochemistry evaluation, we also performed the immunohistochemistry to detect the 8 -iso-PGF $2 \alpha$ in the lung that was not submitted to the strip evaluation. We observed that the ovalbumin group (OVA group: $25.24 \pm 1.90$ ) presented a higher volume proportion of 8-isoprostane- $\mathrm{PGF}_{2 \alpha}$ positive tissue compared with saline-exposed ones [(NS group: $4.81 \pm$ 2.55; NS-L group: $7.83 \pm 1.61), P<0.001]$. Ovalbuminexposed animals that received chronic L-NAME treatment (OVA-L group: $3.81 \pm 1.61$ ) presented a lower volume proportion of 8 -iso- $\mathrm{PGF}_{2 \alpha}$ positive tissue compared with those exposed to ovalbumin that received only vehicle $(P<0.001)$. There was no significant difference between saline-exposed animals.

Figure 8 shows representative photomicrographs of lung parenchyma stained with Luna $(A-C)$, Picrosirius $(D-F)$, Weigert's Resorcin-Fuchsin $(G-I)$, nNOS-stained eosinophils 


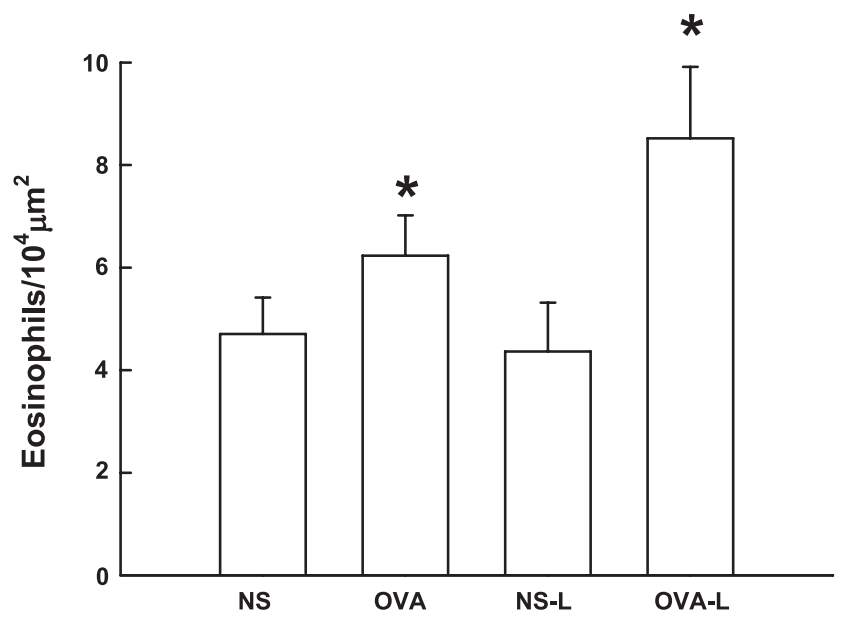

Fig. 4. Eosinophil density in lung tissue of guinea pigs exposed to 7 inhalations with ovalbumin or normal saline and treated with L-NAME or vehicle. Values are expressed as means \pm SE. $* P<0.05$ compared with NS and NS + L-NAME (NS-L) groups.

$(J-L)$, and 8 -iso- $\mathrm{PGF}_{2 \alpha}(M-O)$ in guinea pigs that received saline inhalation $(A, D, G, J$, and $M)$ or those chronically exposed to ovalbumin with vehicle $(B, E, H, K$, and $N)$ or chronic treatment with L-NAME $(C, F, I, L$, and $O)$. Lung tissue of ovalbumin-exposed animals presented eosinophil infiltration with collagen and elastic fiber deposition within the alveolar septa. Chronic L-NAME treatment reduced the amount of elastic fibers in ovalbumin-exposed animals as well as the number of nNOS-positive eosinophils and 8-iso- $\mathrm{PGF}_{2 \alpha}$ positive tissue.

\section{DISCUSSION}

In the present study, we have data suggesting that NO is involved in the mechanical responses of distal lung parenchyma. Using an animal model of chronic lung inflammation in guinea pigs, we showed that NOS inhibition attenuated lung tissue constriction, which was associated with a reduction in isoprostanes $\left(8\right.$-iso- $\left.\mathrm{PGF}_{2 \alpha}\right)$ generation and elastic fiber depo-

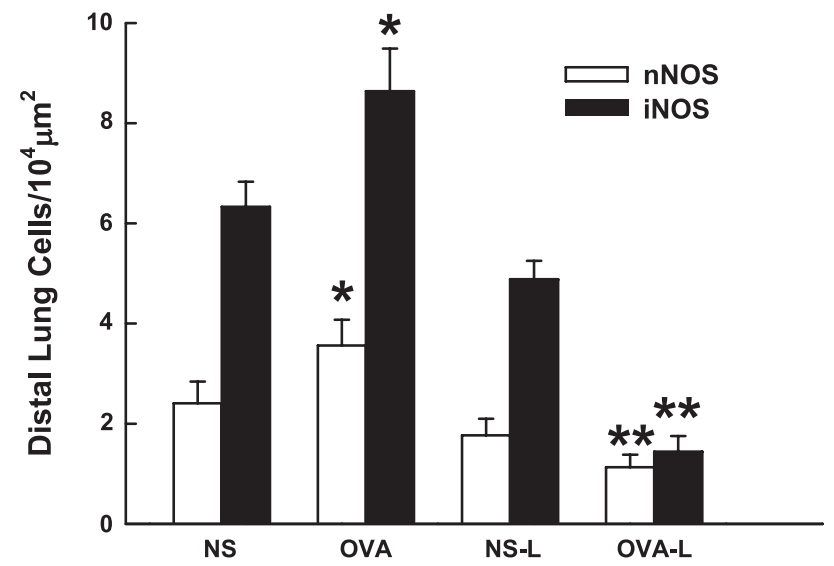

Fig. 5. Neuronal (nNOS) and inducible (iNOS) nitric oxide synthase-positive distal lung cells (eosinophils, macrophages, and epithelial cells in alveolar septa) of guinea pigs previously exposed to 7 inhalations with ovalbumin or normal saline and treated with L-NAME or vehicle. Values are expressed as means \pm SE. $* P<0.05$ compared with NS and NS-L groups; $* * P<0.001$ compared with OVA group.
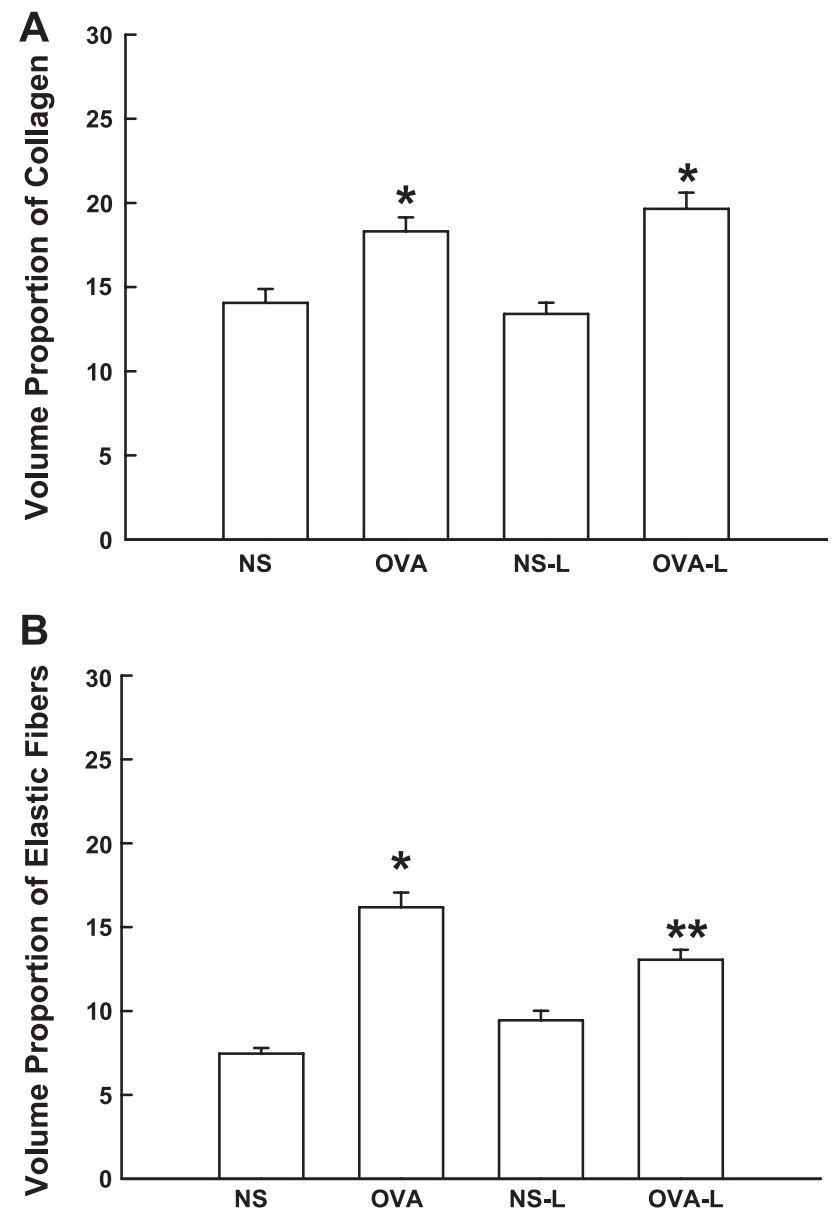

Fig. 6. Collagen $(A)$ and elastic fiber $(B)$ content in guinea pigs exposed to 7 inhalations with ovalbumin or normal saline and chronically L-NAME or vehicle treated. Values are expressed as means \pm SE. Results are expressed as percentage. $* P<0.001$ compared with NS and NS-L groups; $* * P<0.001$ compared with OVA group.

sition in alveolar septa. Notwithstanding a significant lung tissue mechanical attenuation, eosinophilic infiltration and collagen fiber deposition in alveolar septa were not modified by NOS inhibition.

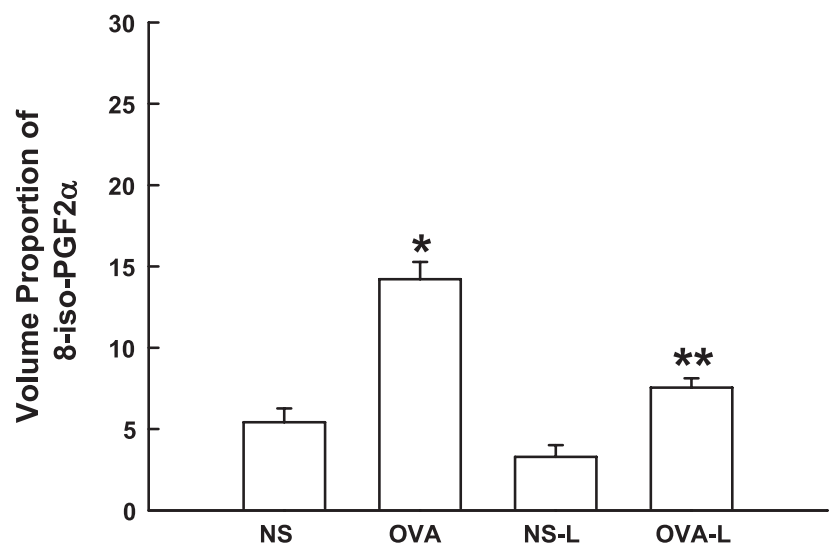

Fig. 7. Volume proportion of 8-isoprostane-PGF ${ }_{2 \alpha}$ in alveolar septa of guinea pigs exposed to 7 inhalations with ovalbumin or normal saline and chronically L-NAME or vehicle treated. Values are expressed as means \pm SE. Results are expressed as percentage. $* P<0.001$ compared with NS and NS-L groups; $* * P<0.001$ compared with OVA group. 
Fig. 8. Guinea pig lung tissue samples obtained from controls, OVA-exposed vehicle, and OVA-exposed LNAME treated, stained with Luna $(A-C$, magnification $\times 1,000)$, Picrosirius $(D-F, \times 400)$, Weighert ResorcinFuchsin $(G-I, \times 400)$, immunohistochemistry to nNOS $(J-L, \times 1,000)$ and 8-isoprostane $\mathrm{PGF}_{2 \alpha}$ detection $(M-O, \times 400)$. Control groups show scanty amounts of collagen fibers in alveolar tissue sections, coincident with the maintenance of the histoarchitecture of the alveolar septa, and a scarce number of eosinophils $(A)$ and those positive to nNOS $(J)$. In contrast, distal lung parenchyma of OVA-exposed vehicle-treated animals show intense eosinophilic infiltration $(B)$ within the alveolar septa, including those positive to nNOS expression $(K)$, an increase in the amount of collagen $(E)$ and elastic fibers $(H)$, and in the content of 8-isoprostane-PGF ${ }_{2 \alpha}$-positive tissue $(N)$. Chronic L-NAME treatment in ovalbumin-exposed animals did not interfere with the number of eosinophils $(C)$ and the collagen content present in the alveolar septa. However, this treatment reduced elastic fiber content $(I)$, the number of eosinophils positive to nNOS in alveolar septa $(L)$, and the amount of lung tissue positive to 8 -iso- $\operatorname{PGF}_{2 \alpha}(O)$.
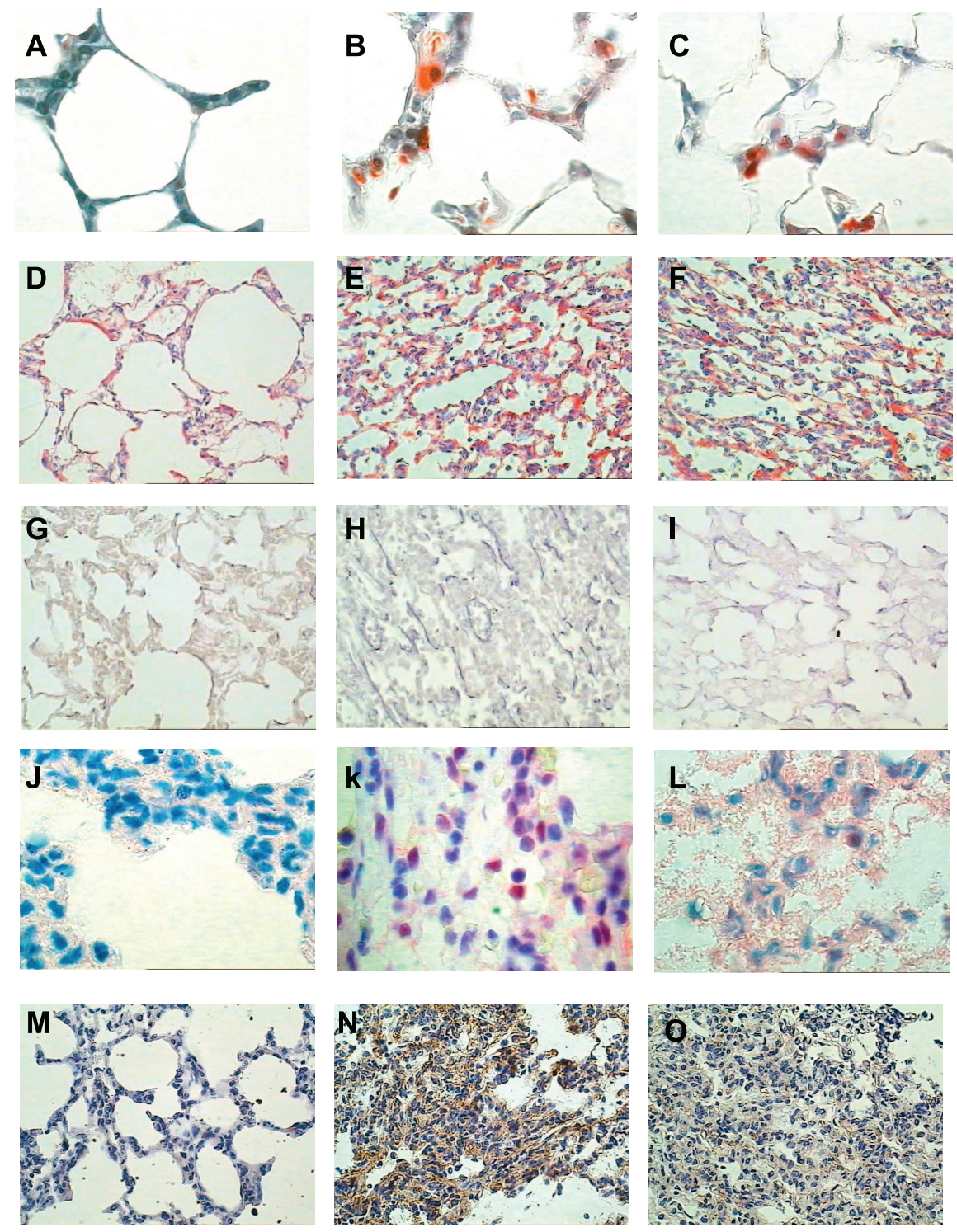

The effectiveness of L-NAME treatment in this animal model has been demonstrated previously $(27,28)$, and it was confirmed in the present study, since there was a significant reduction in both nNOS- and iNOS-positive distal lung cells of guinea pigs with chronic pulmonary inflammation that received treatment with L-NAME. In addition, we have previously shown (28) that chronic L-NAME treatment in this animal model reduced the exhaled NO by $\sim 50 \%$ compared with controls. The L-NAME treatment began $24 \mathrm{~h}$ after the forth inhalation to avoid interference with the sensitization since in this period animals have already been sensitized $\left(\operatorname{IgG}_{1}\right.$ title 1:320) (16). In fact we had previously evaluated the effects of this approach of L-NAME treatment in the sensitization process, and we observed that this treatment did not interfere with the sensitization $(26,27,28)$.

Several studies demonstrated that the effects of $\mathrm{NO}$ are more pronounced in proximal airways $(1,5,27,28)$. All of these studies showed that $\mathrm{NO}$ has an important role in the control of smooth muscle acting as a bronchodilator in proximal airways. However, few authors have previously evaluated NO-related effects on lung parenchyma. This may be due to the fact that there is a progressive reduction of nitrergic nerves toward the bronchial tree (34). Dupuy et al. (5) showed that inhaled NO acted as a bronchodilator of distal airways only when high doses were administrated.

By analyzing the oscillatory mechanical responses, we observed that L-NAME treatment reduced both baseline and postchallenge tissue resistance and elastance in ovalbuminexposed animals, suggesting that NO contributes to pulmonary parenchyma constriction in this experimental model.

In fact, in the present study, we used the same protocol of sensitization and the same approach of L-NAME treatment used in the study performed by Prado et al. $(27,28)$. Previously we noted that chronic L-NAME treatment induced a bronchoconstriction only in proximal airways, represented by resistance of respiratory system, both in physiological and after antigen challenge. The authors also observed that chronic L-NAME treatment reduced the baseline respiratory system elastance (Ers) and did not affect the Ers postantigen challenge, suggesting that the effects of NO in distal airways and/or lung 
parenchyma were different from those observed in proximal airways, and it could be due to a particular effect in lung parenchyma. In this regard, our findings are in accordance of those obtained by Prado et al. (28). Using a model of lung strip oscillatory mechanics that evaluate only the lung parenchyma, we also observed a reduction in lung tissue resistance and elastance after L-NAME treatment, suggesting that NO is involved in lung tissue constrictor effects induced by repeated ovalbumin exposures.

At least in our knowledge, there were no other studies that have evaluated the effects of $\mathrm{NO}$ in lung parenchyma. Although the exact mechanism involved in the effect of L-NAME treatment on reducing lung parenchyma constriction is unclear, some explanations can be suggested. Several authors have discussed that NO release by NOS activation also contributes to the oxidative stress, amplifying the deleterious and harmful effects on lungs (32). The potent oxidant peroxynitrite is formed by $\mathrm{NO}$ and superoxide interaction by a rapid isostoichiometric reaction $(24,29)$.

Peroxynitrite formation leads to lipid peroxidation and generation of isoprostanes ( 8 -iso- $\mathrm{PGF}_{2 \alpha}$ ). Although previous studies have evaluated the effects of $\mathrm{PGE}_{2}$, which was more potent as a constrictor than $\mathrm{PGF}_{2 \alpha}$, the latter isoprostane is considered the predominant form generated during free radical attack of cell membranes (23). Jourdan et al. (13) showed that L-NAME treatment greatly inhibits 8 -iso- $\mathrm{PGF}_{2 \alpha}$. Therefore, isoprostanes appear to induce airway and vascular smooth muscle contractions acting through tyrosine kinase, Rho, and Rho kinase, leading to decreased activity of myosin light chain phosphatase. The net response is associated with an increased level of phosphorylated myosin light chain and contraction (11). We observed in the present study that the attenuation of mechanical responses was associated with a significant decrease in 8-iso$\mathrm{PGF}_{2 \alpha}$ density in lung tissue, which corroborates the idea that NO-derived effects in distal parenchyma were more dependent on the oxidative stress pathway than on the eosinophilic recruitment.

In fact, chronic NOS inhibition by L-NAME treatment did not modify eosinophilic lung tissue infiltration induced by chronic lung inflammation. NO effects in eosinophil recruitment are still a matter of controversy $(26,27,28,33,34,6)$. Corroborating our findings, we previously showed that, in guinea pigs with chronic lung inflammation, eosinophilic airway recruitment was also not reduced by chronic L-NAME treatment (28). Although we have observed no effects on eosinophils, it is important to note that L-NAME could interfere with other cells $(3,32,34)$ such as macrophages, mast cells, lymphocytes, neutrophils, and also pneumocytes that can be presented in lung parenchyma, which was not evaluated in this model since there are no specific antibodies commercially available to detect these cells in guinea pigs.

The present study showed that ovalbumin-exposed animals presented an increase in elastic fiber content in the alveolar septa. We also demonstrated that chronic L-NAME treatment in ovalbumin-exposed animals prevented the increment in the amount of elastic fibers in the alveolar septa. It was remarkable that these findings were associated with the attenuation of lung tissue mechanics observed in these animals. In addition, we did not observe any difference in the elastic fiber content in ovalbumin-exposed animals, animals treated with L-NAME, and the saline-exposed animals.
One crucial question was related to the mechanisms that linked NO to elastogenesis and/or elastolysis, which were, until now, poorly understood. Although we were not able to clarify the exact mechanism linking $\mathrm{NO}$ and elastic fibers in the present study, some hypothesis could be suggested. Pastor et al. (25) studying an experimental model of papain-induced lung emphysema, observed that an electrodense amorphous substance was ruptured and tended to disappear $24 \mathrm{~h}$ after papain instillation, and after 2 mo there was an accumulation of elastic fibers associated with collagen deposition, particularly in the wall alveolar duct. Cantor et al. (2), evaluating the effects of oxidants on elastase activity in vitro, suggested that hydrogen peroxide and other oxidants derived from inflammatory cells or from the environment act as the priming agent for elastase-mediated breakdown of elastic fibers with de novo resynthesis, which may sometimes occur in an abnormal morphological organization with abnormal functional properties (25). However, other authors (12) have suggested that the elastic fibers might be normal after the repair process.

The induction of chronic lung inflammation in guinea pigs resulted in an increase of oxidative stress. We evaluated the oxidative stress in this study by 8 -iso- $\mathrm{PGF}_{2 \alpha}$ staining (23). The 8 -iso- $\mathrm{PGF}_{2 \alpha}$ is the most well-characterized isoprostane that may act through a novel receptor closely related to, but distinct from, the tromboxane $\mathrm{A}_{2} / \mathrm{PGH}_{2}$ receptor, with a high specificity for 8 -iso- $\mathrm{PGF}_{2 \alpha}$ (45). Considering the physiological effects of isoprostanes, Quaggiotto and Garg (30) demonstrated that 8-iso-PGE 2 produces physiological effects similar to 8-iso$\mathrm{PGF}_{2 \alpha}$, but at a reduced potency. In addition, Wood et al. (44) showed that 8 -iso- $\mathrm{PGF}_{2 \alpha}$ is increased in persistent asthmatic patients three to four times more compared with the normal group. For these reasons, the evaluation of 8-iso- $\mathrm{PGF}_{2 \alpha}$ represents a valuable indicator of the oxidative stress pathway (21, 23). Another important point is that 8 -iso- $\mathrm{PGF}_{2 \alpha}$ is a soluble and short-lived mediator. We also performed the evaluation of oxidative stress by immunohistochemistry in the lung that was not submitted to oscillatory mechanical evaluation. The findings were similar to those obtained in the lung strips.

Probably, the increase in elastic fiber content observed in ovalbumin-exposed animals can due to a repair process. Considering that L-NAME treatment reduced the oxidative stress, the elastic fiber injury/repair process was attenuated, as observed in the present study.

We observed that L-NAME treatment did not modify collagen fiber content in lung tissue of sensitized animals. Although previous study showed a profibrotic effect of $\mathrm{NO}(9,10)$, the mechanisms involved in these responses have to be further investigated. In the same animal model, Prado et al. (28) have previously demonstrated that the inhibition of NO by chronic L-NAME treatment amplified the extracellular collagen airway remodeling. The variability in the response observed concerning collagen deposition in airways and lung tissue of this animal model may be related to the higher activity of arginase I and II in the peribronchial connective tissue (31), as well as the intensity of the inflammatory response that was greater in airways compared with that in the lung tissue $(28,41)$.

In conclusion, our results suggest that NO plays an important role in lung tissue constriction and elastic fiber deposition within the alveolar septa in this animal model of chronic pulmonary inflammation. The activation of the pulmonary 
oxidative stress pathway, mainly 8 -iso- $\mathrm{PGF}_{2 \alpha}$, may contribute to these responses.

\section{ACKNOWLEDGMENTS}

We are grateful to the Brazilian Scientific Agencies, Conselho Nacional de Desenvolvimento Científico e Tecnológico, Fundação de Amparo à Pesquisa do Estado de São Paulo e do Rio de Janeiro, Programa de Núcleos de Excelência, and Laboratório de Investigação Médica do Hospital das Clínicas da Faculdade de Medicina da Universidade de São Paulo (LIM 20). We express our gratitude to Thais Mauad for help in isoprostane evaluation and to André Benedito da Silva and Jaqueline Lima do Nascimento for skilful technical assistance.

This study was presented in part at the International Meeting of the European Respiratory Society in Munich-2006.

\section{REFERENCES}

1. Belvisi MG, Stretton D, Barnes PJ. Nitric oxide as an endogenous modulator of cholinergic neuriotransmission in guinea-pig airways. Eur J Pharmacol 198: 219-221, 1991.

2. Cantor JO, Shteyngart B, Cerreta JM, Ma S, Turino GM. Synergistic effect of hydrogen peroxide and elastase on elastic fiber injury in vitro. Exp Biol Med 231: 107-111, 2006.

3. Coers W, Timens W, Kempinga C, Klok PA, Moshage H. Specificity of antibodies to nitric oxide synthase isoforms in human, guinea pig, rat, and mouse tissues. J Histochem Cytochem 46: 1385-1392, 1998.

4. Dolhnikoff M, Mauad T, Ludwig MS. Extracellular matrix and oscillatory mechanics of rat lung parenchyma in bleomycin- induced fibrosis. Am J Resp Crit Care Med 160: 1750-1757, 1999.

5. Dupuy PM, Shore SA, Drazen JM, Frostell C, Hill Zapol WM WA. Bronchodilator action of inhaled nitric oxide in guinea pigs. J Clin Invest 90: 421-442, 1992.

6. Ferreira HH, Bevilacqua E, Gagioti SM, De Luca IM, Zanardo RC, Teixeira CE, Sannomiya P, Antunes E, De Nucci G. Nitric oxide modulates eosinophil infiltration in antigen-induced airway inflammation in rats. Eur J Pharmacol 358: 253-259, 1998.

7. Fredberg JJ, Stamenovic D. On the imperfect elasticity of lung tissue. J Appl Physiol 67: 2408-2419, 1989.

8. Hickman-Davis J, Gibbs-Erwin J, Lindsey JR, Matalon S. Surfactant protein A mediates mycoplasmacidal activity of alveolar macrophages by production of peroxynitrite. Proc Natl Acad Sci USA 96: 4953-4958, 1999.

9. Hogaboam CM, Gallinat CS, Bone-Larson C, Chensue SW, Lukacs NW, Strieter RM, Kunkel SL. Collagen deposition in a non-fibrotic lung granuloma model after nitric oxide inhibition. Am J Pathol 153: 1861$1872,1998$.

10. Hsu YC, Wang LF, Chien YW. Nitric oxide in the pathogenesis of diffuse pulmonary fibrosis. Free Radic Biol Med 42: 599-607, 2007.

11. Janssen LJ. Isoprostanes: an overview and putative roles in pulmonary pathophysiology. Am J Physiol Lung Cell Mol Physiol 280: L1067L1082, 2001.

12. Johanson WG, Pierce AK, Reynolds RC. The evolution of papain emphysema in the rat. J Lab Clin Med 78: 599-607, 1971.

13. Jourdan KB, Mitchell JA, Evans TW. Release of isoprostanes by human pulmonary artery in organ culture: a cyclo-oxygenase and nitric oxide dependent pathway. Biochem Biophys Res Commun 233: 668-672, 1997.

14. Kraft M. The distal airways: are they important in asthma? Eur Respir J 14: 1403-1417, 1999.

15. Lanças T, Kasahara DI, Prado CM, Tibério FLCI, Martins MA, Dolhnikoff M. Comparison of early and late responses to antigen of sensitized guinea pig parenchymal lung strips. J Appl Physiol 100: 16101616, 2006.

16. Leick-Maldonado EA, Kay FU, Leonhardt MC, Kasahara DI, Prado CM, Fernandes FT, Martins MA, Tibério IF. Comparison of glucocorticoid and cysteinyl leukotriene receptor antagonist treatments in an experimental model of chronic airway inflammation in guinea-pigs. Clin Exp Allergy 34: 145-152, 2004.

17. López-Aguilar J, Romero PV. Effect of elastase pretreatment on rat lung strip induced constriction. Respir Physiol 113: 239-246, 1998.

18. Ludwig MS, Dallaire MJ. Structural composition of lung parenchymal strip and mechanical behavior during sinusoidal oscillation. J Appl Physiol 77: 2029-2035, 1994.

19. Luna LG. AFIP Manual of Histologic Staining Methods. New York: Mc Graw Hill, 1986.
20. Mauad T, Silva LF, Santos MA, Grinberg L, Bernard FD, Martins MA, Saldiva PH, Dolhnikoff M. Abnormal attachments with decreased elastic fiber content in distal lung in fatal asthma. Am J Respir Crit Care Med 170: 857-862, 2004.

21. Mehrabi MR, Serbecic N, Ekmekcioglu C, Tamaddon F, Ullrich R, Sinzinger H, Glogar HD. The isoprostane 8-epi-PGF(2alpha) is a valuable indicator of oxidative injury in human heart valves. Cardiovasc Pathol 10: 241-245, 2001.

22. Meurs H, McKay S, Maarsingh H, Hamer MA, Macic L, Molendijk N, Zaagsma J. Increased arginase activity underlies allergen-induced deficiency of c-NOS- derived nitric oxide and airway hyperresponsivess. $\mathrm{Br} \mathrm{J}$ Pharmacol 136: 391-398, 2002.

23. Montuschi P, Curro D, Ragazzoni E, Preziosi P, Ciabattoni G. Anaphylasis increases 8-iso-prostaglandin F2alpha release from guinea-pig lung in vitro. Eur J Pharmacol 365: 59-64, 1999.

24. Muijers RBR, Folkerts G, Henricks PAJ, Sadeghi-Hashjin G, NijKamp FP. Peroxynitrite: a two faced metabolite of nitric oxide. Life Sci 60: 1833-1845, 1997.

25. Pastor LM, Sanchez-Gascon F, Girona JC, Bernal-Manas CM, Morales E, Beltran-Frutos E, Canteras M. Morphogenesis of rat experimental pulmonary emphysema induced by intratracheally administered papain: changes in elastic fibers. Histol Histopathol 21: 13091319, 2006

26. Prado CM, Leick-Maldonado EA, Arata V, Kasahara ID, Martins MA, Tibério FLCI. Neurokinins and inflammatory cell iNOS expression in guinea pigs with chronic allergic airway inflammation. Am J Physiol Lung Cell Mol Physiol 288: L741-L748, 2005.

27. Prado CM, Leick-Maldonado EA, Kasahara DI, Capelozzi VL, Martins MA, Tibério FLCI. Effects of acute and chronic nitric oxide inhibition in an experimental model of chronic pulmonary allergic inflammation in guinea pigs. Am J Physiol Lung Cell Mol Physiol 289: L677L683, 2005.

28. Prado CM, Leick-Maldonado EA, Yano L, Leme AS, Capelozzi VL, Martins MA, Tibério FLCI. Effects of nitric oxide synthases in chronic allergic airway inflammation and remodeling. Am J Physiol Lung Cell Mol Physiol 290: L457-L465, 2006.

29. Pryor WA, Squadrito G. The chemistry of peroxynitrite: a product from the reaction of nitric superoxide. Am J Physiol Lung Cell Mol Physiol 268: L699-L722, 1995.

30. Quaggiotto P, Garg ML. Isoprostanes: indicators of oxidative stress in vivo and their biological activity. In: Antioxidant in Human Health and Diseases, edited by Basu TK, Norman T, and Garg MD. Oxford, UK: CAB, 1999, p. 393-410.

31. Que LG, Kantrow SP, Jenkinson CP, Piantadosi CA, Huang YCT. Induction of arginase isoforms in the lung during hyperoxia. Am J Physiol Lung Cell Mol Physiol 275: L96-L102, 1998.

32. Ricciardollo FL, Di Stefano A, Sabatini F, Folkerts G. Reactive nitrogen species in the respiratory tract. Eur J Pharmacol 533: 240-252, 2006.

33. Ricciardollo FL, Nijkamp FP, Folkers G. Nitric oxide synthase (NOS) as therapeutic target for asthma and chronic obstructive pulmonary disease. Currr Drug Targets 7: 721-735, 2006.

34. Ricciardollo FL, Sterk PJ, Gaston B, Folkers G. Nitric oxide in health and disease of the respiratory system Physiol Rev 84: 731-765, 2004.

35. Rocco PR, Facchinetti LD, Ferreira HC, Negri EM, Capelozzi VL, Faffe DS, Zin WA. Time course of respiratory mechanics and pulmonary structural remodelling in acute lung injury. Respir Physiol Neurobiol 143: 49-61, 2004.

36. Rocco PR, Negri EM, Kurtz PM, Vasconcellos FP, Silva GH, Capelozzi VL, Romero PV, Zin WA. Lung tissue mechanics and extracellular matrix remodeling in acute lung injury. Am J Respir Crit Care Med 164: 1067-1071, 2001.

37. Rocco PR, Souza AB, Faffe DS, Pássaro CP, Santos FB, Negri EM, Lima JG, Contador RS, Capelozzi VL, Zin WA. Effect of corticosteroid on lung parenchyma remodeling at an early phase of acute lung injury. Am J Respir Crit Care Med 168: 677-684, 2003.

38. Romero PV, Rodriguez B, Lopez-Aguilar J, Manresa F. Parallel airways inhomogeneity and lung tissue mechanics in transition to constricted state in rabbits. J Appl Physiol 84: 1040-1047, 1998.

39. Romero PV, Zin WA, Lopez-Aguilar J. Frequency characteristics of lung tissue strip during passive stretch and induced pneumoconstriction. J Appl Physiol 91: 882-890, 2001. 
40. Stamenovic D, Barnas G. Effect of surface forces on oscillatory behavior of lung. J Appl Physiol 79: 1578-1785, 1995.

41. Tibério IFLC, Turco GMG, Leick-Maldonado EA, Sakae RS, Paiva SO, do Patrocínio M, Warth TN, Lapa e Silva JR, Saldiva PH, Martins MA. Effects of neurokinin depletion on airway inflammation induced by chronic antigen exposure. Am J Respir Crit Care Med 155: 1739-1747, 1997.

42. Watanabe T, Okano M, Hattori H, Yoshino T, Ohno N, Ohta Sugata N, Takai Nishizaki KT. Roles of FcgammaRIIB in nasal eosinoplhilia and IgE production in murine allergic rhinitis. Am J Resp Crit Care Med 169: 105-112, 2004.

43. Weibel ER. Principles and methods for the morphometric study of the lung and other organ. Lab Invest 12: 31-55, 1963.
44. Wood LG, Fitzgerald DA, Gibson PG, Cooper DM, Garg ML. Lipid peroxidation as determined by plasma isoprostanes is related to disease severity in mild asthma. Lipids 35: 967-974, 2000.

45. Wood LG, Gibson PG, Garg ML. Biomarkers of lipid peroxidation, airway inflammation and asthma. Eur Respir J 21: 177-186, 2003.

46. Xisto DG, Farias LL, Ferreira HC, Pincanço MR, Amitrano D, Lapa e Silva JR, Negri EM, Carnielli D, F Silva LF, Capelozzi VL, Faffe DS, Zin WA, Rocco PM. Lung parenchyma remodeling in a murine model of chronic allergic inflammation. Am J Respir Crit Care Med 171: 829-837, 2005.

47. Zar JH. Biostatistical Analysis (2nd ed.) Englewood Cliffs, NJ: Prentice-Hall, 1984, p. 206-235.

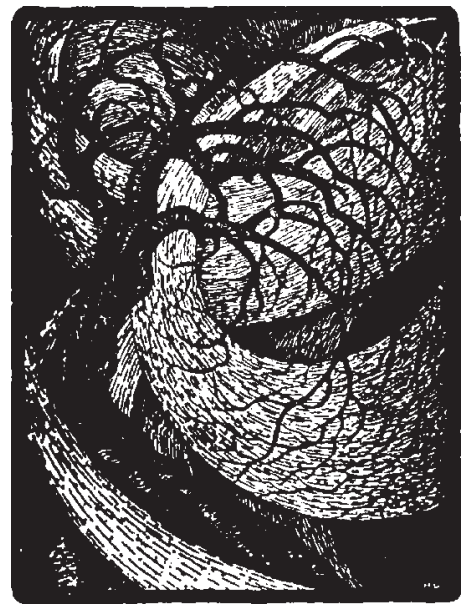

